\title{
UNQUEERING TRANSGENDER? A QUEER GEOGRAPHY OF TRANSNORMATIVITY IN TWO ONLINE COMMUNITIES
}

\author{
by \\ Fred Joseph LeBlanc

\begin{abstract}
A thesis
submitted to the Victoria University of Wellington in fulfilment of the requirements for the degree of Master of Arts

in Gender \& Women's Studies
\end{abstract}

Victoria University of Wellington 
ABSTRACT

This research implicates gender in the study of sexuality and suggests a genealogy of transgender that consists of both the medicalisation of transsexuality and the articulation of gender performances in gay liberation's politics of difference. While the transgender subject is often idealised in queer discourses, this research positions the transsexual (one articulation of transgender) as normative: conservative gender politics, the ontological separation of gender and sexuality that echoes assimilationist gay and lesbian politics, an identity based on essentialist biology and psychiatric "wrong body" discourses, and the privileging of passing technologies such as hormone replacement therapies and sex reassignment surgery (themselves justified though the elaboration of wrong body discourses).

Further to this, the public rendering of some transgender bodies as nonconformist results in violence and the need to explore alternate spaces of being, namely the internet which has the potential to build community, raise consciousness of gender and transgender oppression, but can also be used to legitimate transnormative (re)productions of the self.

The analysis of two online communities of transgender individuals shows the most frequent users tended to be transsexual and privileging conservative gender politics and an essentialist medical etiology of transsexuality. Users were 
also typically more knowledgeable in passing biotechnologies than some medical professionals. In one community that are tailored to transgender individuals, subjects felt at ease to discuss a variety of topics and explore the complications of transgender. In the second community, tailored towards feminists in general, transgender issues were addressed in a more confrontational manner, often exposing the transphobic nature of some feminisms. 
ACKNOWLEDGEMENTS

First and foremost, I wish to thank Nathan and my New Zealand family, as well as my parents and sisters, for experiencing my own narrative along with me (for better or worse). Thank you all for putting up with the opinions. Appreciation always goes to Amanda, Stefanie, Sunday, and Jasmine, who I look forward to seeing and philosophising with when I visit the United States. Much appreciation also goes to the nonhuman children, Otis and Totoro.

Thanks to my advisor, Dr Alison Laurie, for the amazing insight, guidance, and fleshing out this project, and to Dr Michelle Lunn for early discussions on what this project might have been. Great appreciation to undergraduate and postgraduate instructors, including Drs Elizabeth Grosz and Louisa Schein.

And, of course, thanks to all queer people who make the world interesting. 


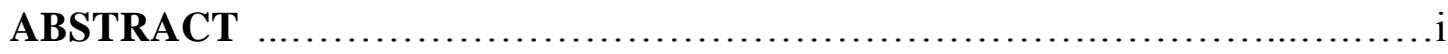

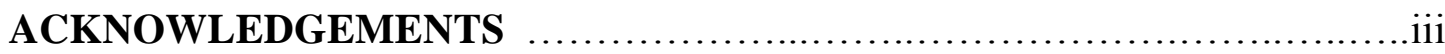

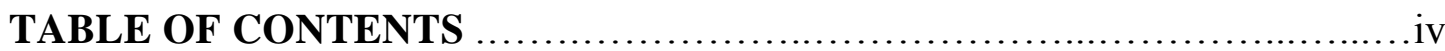

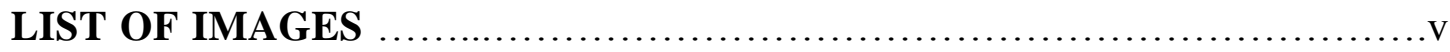

CHAPTER ONE: AN INTRODUCTION ................................ 01

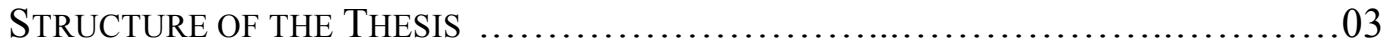

GENDER NONCONFORMITY AND THE CULTURAL MAINSTREAM ....................06

THE DEATH (AND REINCARNATION) OF QUEER? ................................................11

CHAPTER TWO: A REVIEW OF THE LITERATURE ................... 14

BECOMING TRANSGENDER .................................................. 19

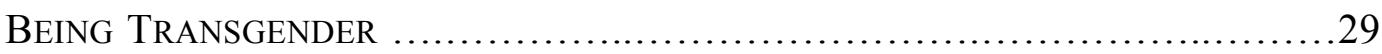

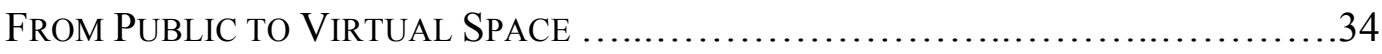

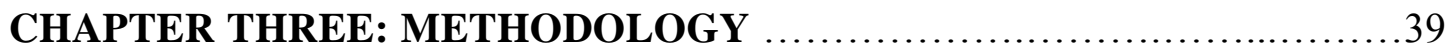

INTERTEXT: THE LIFE OF AN AMERICAN GAY ................................44

In/OUtSIDER AND For WHOM THE RESEARCH IS DESIGNED ...................49

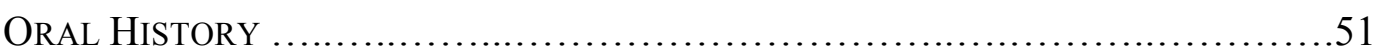

RESEARCH RESOURCES ................................................ 54

CHAPTER FOUR: MAKING A SPACE ON THE TRANSWEB ...............56

"We CAN Always Use More Trannies!"” ...................................58

A Space for Critical QueEr Ontology? Discourse as Violence ............66

THE TRANSSEXUAL PATIENT ................................................. 73

DON'T BE A HOT MESS ................................................... 79

VIOLENCE AS CONSCIOUSNESS-RAISING................................... 83

THINKING TRANSNORMATIVITY ........................................... 88

CHAPTER FIVE: BORROWED SPACE \& TRANSPHOBIC FEMINISM

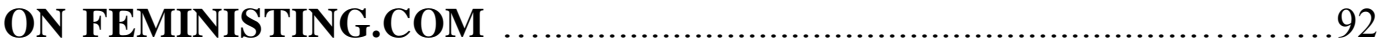

TRANSPHOBIA AND FEMINISM ............................................. 95

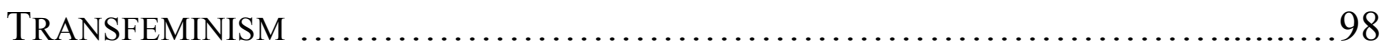

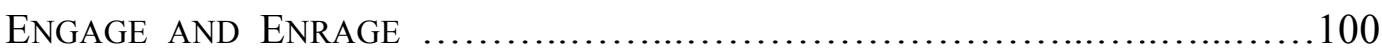

EDUCATING FEMINISTS? ..................................................... 106

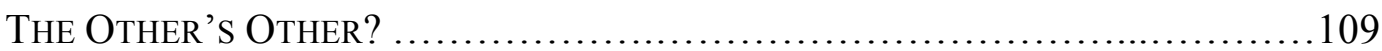

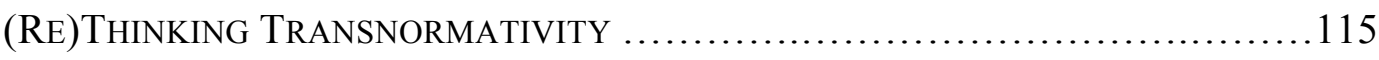

CHAPTER SIX: CONCLUSION .......................................... 122

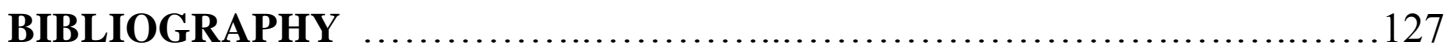


LIST OF IMAGES

IMAGE 1: INTERIOR OF CUBA'S PRESIDIO MODELO PRISON .......................27

IMAGE 2: FEMINISTING.COM'S MUDFLAP GIRL LOGO ......................... 96 


\section{AN INTRODUCTION}

For heterosexuals allowed homosexuals enormous social leeway for their excesses, so long as they agreed not to disturb the general peace of society at large.

-Andrew Sullivan, Virtually Normal: An Argument about Homosexuality (1995)

This thesis is a visible, psychical, and academic sign of my own sexuality and degrees of gender play. Not only have I had to come to terms with my sexuality for my own sense of self, I have also had to come to terms with how my masculinity is perceived because of it as well as having my sexuality presumed by my gender performance(s). Queer politics have provided me with an insistence that I can (re)invent my sexuality and gender on my terms. I include gender within my ontology of sexuality because gender nonconformity is often inferred as homosexuality and sexuality variances can have quite colourful and playful performances of gender without typically being termed "transgender," complicating the very notion of transgender and its relation to the gay and lesbian communities.

Transgender is an umbrella term to describe a variety of gender subversions, including, but not limited to, transvestism, transsexuality, drag, androgyny, and even intersexuality. Types of transgender subjectivities and performances are often delineated by their nature: transvestism is typically associated with fetishism, drag with the playful exaggeration of gender roles, and transsexuality with being "in the wrong body" and a desire to live long term as the gender that is not congruent to their sexed body. To complicate matters even more, 
for example, most transsexuals may choose genital reassignment surgery, whilst others may prefer to keep the genitals with which they were born. I use transgender in its broadest form, to incorporate any form(s) of gender subversion, as I believe the word's socio-political potential is to act to delimit any categorisation.

An online transgender community may help to frame debates and discourses to help challenge cultural assumptions about gender and gender variance, especially as they relate to and intersect with sexualities. As a means of promoting a dialogue with the public, the internet is one of the cheapest and far-reaching ways ideas can reach the public (Grauerholz and Baker-Sperry, 2007). Since there are virtually no controls over what can be published on the internet, it can be a place where marginalised voices and personal narratives can be heard. Once online and available globally, websites in the public domain have the potential to engage or enrage the public. And if feminist and queer projects are intertwined with a sense of social movement activity, they are already public. Transwebs, what I term websites designed by and targeted to transgender people, including informational resources, message boards, social interactions, etc, can be an effective medium to challenge cultural (mis)conceptions about gender, by providing critical and ontological alternatives to gender.

Employing poststructuralist perspectives, and in particular the analytical instruments of social constructionism, this research seeks to explore the following questions:

1. How did the category transgender come into meaning and how does it act to name and (re)produce its own subjects? 
2. Are certain transgender subjectivities and ontologies privileged and does that produce a sort of transnormativity?

3. How might an online resource be constituted by and constitutive of that which is transgender?

Further to this, this project will

1. document recurring themes in the communities and analyse the constructive discourses of community members and their dissemination of advice, information, and self-exploration/subjectivity formation;

2. explore the problematics in the diversity of the umbrella term "transgender";

3 . assess the theoretical "queerness" of transgender subjects varying from more normative (and unqueer?) transsexual subjectivities that are arguably framed by medical and "wrong body" discourses, and;

4. assess the ways in which the use of virtual space can have real effects in material space through consciousness-raising and cyberactivism.

\section{Structure of the Thesis}

The remainder of Chapter One will discuss introduce main themes upon which this thesis is based, including gender transgression in the cultural mainstream, from television to the internet, noting the public discomfort caused by gender variance. It also positions gender as both implicated in the genealogy of contemporary homosexuality and rights claims and within the proliferation of queer theories. It also provides a rationale for the use of an online internet community for the purposes of this project.

My own feminism is defined by my queerness as much as my queerness is defined by my feminism. As a queer man, I feel a sort of kinship with feminism. I will often discuss both feminist and queer theory in tandem; feminists and queers make not-so-strange bedfellows. Quoting comedian Margaret Cho, cultural theorist Deborah Thompson describes this relationship in her text on fag hags:

The marriage of two derogatory terms, fag and hag, symbolising the union of the world's most popular objects of scorn, homosexual and woman, 
creates a moniker that most of those who wear it find inoffensive, possibly because it smacks of solidarity. (2004: 42)

For me, homophobia and transphobia are misogyny by another name. To a man we might say, "You should be ashamed of being like a woman," because there is something troubling or offensive about being a woman. It is in this way Cho recognises the (male) homosexual and woman as objects of scorn and as joint potential for coalition. This is but an aspect of my feminism, of my queerness. (However, the relationship between gay men and women itself may not be as comfortable as it seems. My own experience is one of finding most gay men are repulsed by the mention of the female body, especially female genitals. Feminist Sheila Jeffreys (2005) refers to this as the "ick factor.")

To say that I identify with women is not, of course, to say I identify as a woman, which decades ago probably might have been my psychiatric diagnosis. Chapter Two deals with the history of medical discourse as it pertains to gender deviance, transsexualism, and gender performances' punitive consequences. It is no surprise, then, that "straight-acting" (masculine) gay men are less likely to be victims of abuse as effeminate men - gay or straight. It is in this way that gender transgression is (often violently) policed, both externally (by others) or internally (by oneself). This chapter also locates this research within wider epistemological debates about the status of knowledge(s) produced by feminist poststructuralist research. Because gender performances and the corporeality of the body are publicly read, individuals who disturb gender-normative expectations are often denied access to public space or excluded from public discourse through their visual transgression of gender, something that will be elaborated on. Gender pioneers, I will argue, can seek out new spaces in the form of the internet. 
However, can virtual spaces and transgender "virtual communities/citizens" subvert and overturn their marginality from both the (hetero)normative and queer communities and how might this be accomplished? Is virtual space a way to do this?

Chapter Three positions this research in queer geographical frameworks and the critique of the knowledge factory of positivist social sciences. It provides a detailed description of the design and process of this research project. Within this chapter, I articulate my own positionality within this research and how I have come to position my research within a queer epistemology, first considered by geographer Jon Binnie (1997), as well as discussing some works in oral history and biography as knowledge claim-making.

Chapter Four discusses some trends in one online transgender community as articulated through personal transgender narratives, including linguistic resignification, the polarisation of the radical queer academy, medical practices and essentialising constructions of transsexuality, and passing. It also notes that the dissemination of mainstream news is a possibility for consciousness-raising. Another, distinctly different online community is discussed in Chapter 5 and describes the difficulties in creating a transgender community on a feminist site.

Chapter Six concludes the thesis with a discussion of trends discovered within the online community. While the limits of this research are described, suggestions for elaboration and future researches are discussed. 


\section{Gender Nonconformity and the Cultural Mainstream}

But why the internet? Online communication allows for a global network of interaction and the distribution of knowledge claims. Digg.com is a social news website designed to allow people from all around the globe to discover and submit content from anywhere on the Internet. One submission was the news story "Matrix director Larry Wachowski now walks as a woman in LA," which received 1243 diggs, making it one of the most popular stories of the day it was released and allowed a link to it to remain on the homepage throughout the day (Digg, 2009). The story about the action film (read: expectedly hypermasculine) director beginning to live his life as a woman also received 246 comments, which ranged from offensive ("gay man is gay") to supportive ("Good for her. If that's who Larry really is, who is anyone to judge? And if you judge him, WHY?") to downright sophomoric (“are we sure that's a guy? because i'd hit it!”).

I find it difficult to completely detach sexuality and gender, as they are often conflated in the public imaginary and queering gender is often interpreted as homosexuality, as the above example indicates - the comment "gay man is gay" suggests the male-bodied Larry Wachowski is merely deluded and is just a gay man masquerading as a (presumed heterosexual) woman. Indeed, it is the effeminate fag and masculine dyke that make legible the confluence of gender "disturbance" and sexuality. But it is this very excess of gender that exposes gender's own constructedness. It is difficult to discuss transgender bodies without historically placing them within the queer community, as transgender is often conflated with homosexuality and a history of gay politics that has at times celebrated (and at times reviled) the ambiguous, gender-transgressive body. For this reason we have 
the notion of the LGBT community, a (rather loose) coalition combining gay, lesbian, bisexual, and transgender subjects.

Poststructuralist perspectives and the analytical tools of social constructionism provide an opportunity for feminists and queers to challenge contemporary certainties that define and shape bodies and practices. Individuals are understood as constituted from the meanings produced by discourse; individuals may be so-called agents making their own seemingly autonomous choices regarding the expression(s) of their gender and the negotiation of their gender identity, but they do so within a complex matrix of socially constructed meanings that may constrain - or make impossible - some choices. Geographer Gillian Rose (1993: 13) states, "If masculinity is itself fluid and diverse, and intersects with class, race and sexuality in complex and unstable ways, one form of feminism cannot be adequate to the task of resistance." This is, I believe, an avenue wherein queer theories might aid feminism. For queer theorist Judith Halberstam (2005: 5), "in queer renderings of postmodern geography, the notion of a body-centred identity gives way to a model that locates sexual subjectivities within and between embodiment, place, and practice." Judith Butler (1990) herself warns that feminism should be mindful of not idealising or privileging certain bodies or expressions of gender, for example essentialist notions of women as woman-born and subsequently erasing other identities of "woman." Queer theories are critical sites where contemporary contemplations and contestations of gender and sexuality exist. 
Of course, I have my reservations around the theorising of the political versus establishing a queer politics. While postmodernism is "simultaneously a crisis and an opportunity" (Halberstam 2005: 6), postmodernism has often been criticised for creating an apolitical politics. While the relationship between theory and praxis is already troubled, English scholar Frederick Roden (2001) suggests it is especially strained in liberation politics; that essentialism debates and postmodern theoretical arguments on fluidity may not - and often cannot translate into real political action. The academy, as well as my many years of education that has culminated in this thesis, is privileged and I could not write about gender performance and social construction without being in a certain position in terms of education and learning, despite the fact that many political actors may not have the same access to education and theory that I may have had. The goal, then, is to try to exist within the academy and make the apolitical political once again, to write to satisfy the academy as well as activists, to link theory and praxis. For example, transphobia cannot be ignored by the academy so subjects' transgressive bodies can be theorised and discussed, used and discarded, dissected and analysed in absence of the very real conditions faced by gender variant individuals that constitute their very subjectivity and experiences, whether negative or positive.

Personal gender performance inevitably leads to public gender assessment and transgendered individuals are often invisible in Western cultures because of a presumed binary classification of gender - or, more accurately, assignment to one of only two existing categories. Sociologist Emily W. Kane (2006) found that heterosexual fathers engage in more differential treatment of sons and daughters 
and enforce gender boundaries more than mothers, who appear to maintain gender boundaries more towards sons than daughters, both parents conflating male gender variance and homosexuality. She suggests that the subordination of nonhegemonic masculinities occurs from birth. Not surprisingly, hegemonic masculinity is heterosexual, with contempt for homosexuality, gender variance, and other suggestions of "failed masculinity." Again, we see the conflation and fear of gender deviation as an indicator of sexual deviation. Because transgendered individuals violate conventional notions of gender they become targeted for discrimination and abuse, with transwomen, individuals born male but identify and express as female, at particular risk of violence. Indeed, psychologists Arnold Grossman and Anthony D'Augelli (2006) found that the most important concern of transgendered youths was personal safety and the fear of violence.

Gay liberation played an enormous role in effectively immobilising gays and lesbians following the police raid on the Stonewall Inn in 1969, which defined the starting point of the gay rights movements and confronted the early homophile philosophy of assimilation. The Stonewall Inn catered to some of the most marginalised of gay men: transvestites, drag queens, the effeminate, and hustlers. In the early hours of 28 June 1969 New York City the police raided the institution with the intention to arrest any men dressed as women. The raid did not go as planned and ultimately sparked the modern gay liberation movement. Simple assimilation was no longer the goal as gay liberationists focused on gay pride, the rejection of homosexuality as a psychiatric condition, and the hetero/homo dichotomy. However, it was more than a movement to liberate sexuality. Gay liberation demonstrated that the hetero/homo dichotomy implicates the 
masculine/feminine binary of sex roles that views masculine and feminine as mutually exclusive.

The gay liberation and lesbian feminist movements placed a particular emphasis on community and a unified gay/lesbian identity-based politics. Gay liberation and lesbian feminism saw their projects as a release from hetero/homo and masculine/feminine roles. By the mid-1970s, however, people of colour particularly lesbians of colour - began to recognise their interests were not always adequately represented and their experiences often overlooked and began to critique the movements' bias towards the white and middle-class, questioning whether gay liberation is a project of identity-based exploitation. Constructionist scholars and the immergence of poststructuralism provided a way to deconstruct the category of the gay/lesbian subject and recognise a dissenting voice and as such poststructuralism inspired a revolt by the gay/lesbian periphery against the gay/lesbian centre. The notion of a unified gay/lesbian identity-based politics was now in dispute: individuals no longer have a core gay/lesbian essence that race and class only subtly affect. Individuals are simultaneously gay/lesbian, white/black/Hispanic/indigenous, and middle/working class, each shaped by and shaping the others. For example, Butler (1990) argues that feminism represents the limits of identity politics and the category of women by failing to recognise its own constitutive power of claims to identity. The feminist articulation of a stable, gendered subject is thus problematised as the foundational premise of a feminism that relies on a binary gender/sex discourse. Indeed, for Butler the category of women is "normative and exclusionary and is invoked with the unmarked dimensions of class and racial privilege intact" (ibid.: 19). 
By the 1980s, marginalised sexual and gender minorities, such as bisexuals and S/M practitioners, stood out against the dominant couple-dominated intimate norm. $\mathrm{S} / \mathrm{M}$ in particular was a threat to the socially conservative gay mainstream since it challenged the privileging of gender preference in defining sexual identity, as men who may have sex with men exclusively defined their sexual identity in relation to their S/M practices instead (Seidman, 1993). Embarrassed by certain members, the mainstream gay community became more conservative and moved back toward a politics of assimilation and normalcy.

I suggest that today queer culture is centred on social difference and the multiplicity of identities. In poststructuralist terms, appealing to one's sexual, gender, or ethnic identity as the grounds for community-building is particularly problematic because of those categories' instabilities and exclusions. While gay liberation framed homosexuality as an issue of sexual politics, poststructuralists frame the hetero/homo dichotomy in Western culture as political itself. Sociologist Steven Seidman (ibid.) argues that the notion of queer unites the heterogenous interests and desires marginalised by gay liberation. For him "queers are not united by any unitary identity but only by their opposition to disciplining, normalising social forces," maintained by the gay/lesbian centre (ibid.: 133).

\section{The Death (and Reincarnation) of Queer?}

With the defining queer texts Epistemology of the Closet and Gender Trouble now two decades old, some argue that which is known as Queer Theory has exhausted itself. Has the flirtation with queer become a bored marriage, 
staying together for the sake of the children (i.e., young scholars)? A recent issue of South Atlantic Quarterly was devoted to the question "What's so queer about queer studies now?" In it, Law and English scholars Janet Halley and Andrew Parker reflect on the fact that

[T]he authors around whom queer theory crystallized seem to have spent the past decade distancing themselves from their previous work: in recent years, for example, Judith Butler has been writing about justice and human rights, Michael Warner about sermons and secularism, and Eve Kosofsky Sedgwick about Melanie Klein and Buddhism. (Halley and Parker, 2007: 421-422).

The journal notes, however, its own scarcity of work in non-Anglophone literatures, which may be a reflection of queer studies, itself. While it problematised certainties of identity and state sanctioned monogamous heterosexuality with its persistence of critique, critics of queer theories have noted that Western queer subjectivities - particularly American queer subjectivities assume innocence of their own "colonising fantasies" (Hoad, 2007: 516).

English scholar Neville Hoad suggests the era of Queer Theory is on the wane. When anyone - even heterosexuals - can be queered, has the queer theoretical project imploded upon itself and been exhausted to a sort of postqueerness? Or perhaps "queer theory" did not even exist. Feminism itself may have been a sort of queer knowledge project. After all, feminism has long been concerned with the (dis)articulation of gender and sexuality. Perhaps Queer Theory was an en vogue feminism, a brand new feminism marketed to sexual dissidents and gender outlaws.

Another critique of Queer Theory is that since its inquiry originated from sexuality, it must deal exclusively with sexuality. However, there is research that 
is broadening the scope of queerness, such as feminist geographer Robyn Longhurst's (2008) discussion of adult nursing, interspecies breastfeeding, and men who breastfeed, all phenomena she refers to as queer breastfeeding, not to mention research conducted on gender, class, religion, and race, all of which potentially intersect with sexuality.

While some research on online communication technologies has been focused on gender differences, media scholar Irmi Karl (2007: 48) challenges queer theories to pay attention to "what kinds of gender identities are being forged in the process and how... sexual identities intersect with gender identities through an engagement with the technological." Cyberqueer subjects are produced through a historical production of utopias, with the intersection of cyber and queer as the "intersection of two promissory discourses, which unfold through utopian thinking about technological futures" (O'Riordan, 2007: 17). However, there is also evidence to suggest that online queer communities have fixed identity hierarchies (ibid.: 26). Given that transgender has emerged as a collective term for all gender variance - arguably heteronormative transsexuals, radical genderfuckers, sexualised transvestites, etc - can online communities (re)produce a hierarchy within this category of being, failing the idealism of the cyberqueer project? 


\section{A REVIEW OF THE LITERATURE}

Within the boundaries of our present scientific knowledge, the gender disordered patient presents to the physician as a physically, endocrinologically and genetically normal individual.

-Herbert Bower, MD (2001)

Poststructuralism is a set of theories regarding the relationship between language, subjectivity, social organisation, and power, as well as an analysis of the mechanism by which people adopt particular discursive positions (Weedon, 1987). Poststructuralism does not have one fixed meaning, but refers to the works of many thinkers, including Jacques Derrida and Michel Foucault. While early, prominent poststructuralists tended to be (heterosexual and cisgender ${ }^{1}$ ) men, the theorists who have produced much of the early poststructuralist texts had an unsympathetic attitude towards feminism and gay politics; however this has not kept feminists and queer theorists from engaging these texts. For example, Foucault's theory of discourse and power was appropriated by poststructuralist feminists analysing patriarchal power relations.

Poststructuralism developed out of the limits of humanist approaches to the social sciences. The humanist self is an autonomous agent and this notion of the self presumes a continuous, coherent identity; people make autonomous, rational decisions and exist separate from the external world. Poststructuralism rejected this notion of an all knowing rational self that had varying degrees of power to control

\footnotetext{
${ }^{1}$ Cisgender is identifying one's social gender as congruent to one's biological gender assignment, i.e., not trans. From the Latin prefix meaning on the same side as.
} 
its own life trajectory. For poststructuralists, the construction of the self is a kind of activity and the discursive $I$ is produced through language. Language no longer describes a person's life, but produces it and locates it in a framework of social and historical discourses. Subjectivity is socially produced in a wide range of discursive practices, including economic, racial, social, political, and sexual influences. It is a geography of embodiment wherein the body is a site of knowledge production and an effect of discursive practices, as "the individual is always the site of conflicting forms of subjectivity" (Weedon, 1987: 33). Most importantly, poststructuralism calls into question such analytical categories such as gender and sexuality.

Poststructuralism allows for the understanding of existing power relations and to identify methods of resistance and strategies for change. Discourses can be thought of as patterns of speech, concepts, values, and statements from ontological ways of giving meaning to both the physical and social worlds that construct what we think of as real. Discourses are ways of constituting knowledge and the power relations that form within these knowledges. They do not exist in seclusion, but rather as part of a larger discursive matrix. They can be thought of as productive, as they are ways of making sense of the experienced world. Individual discourses operate in a discursive field wherein not all discourses carry equal weight; some account for or will justify the status quo. (For example, gender may exist in the discursive practises of sexuality, medicine, and public space.) As such, discourses can also be traced historically; indeed, Foucault's theory of discourse insists upon historical specificity. A poststructuralist approach attempts to understand how normalising truths are produced, for whom, and for what purposes. In order to 
have a social effect, a discourse must at least be in circulation (Weedon, 1987). Analysing discourse bridges social, cultural and historic levels of analysis.

The effects - or sets/matrices - of discourse(s) are naturalised as the way we think within a particular context. For example, we can assume there is a set of discourses that shape what we think of as masculine and feminine and this is reified by, for example, the fact that there are different attributes that define the parameters of the gendered, corporeal subject, thus the masculine-feminine binary is produced through discourse. Knowledge and power is a discursive practice of truthformation that stabilises and naturalises gender(/sex); our understandings of the "truth" of gender seems natural and based on biological difference. In the analysis of discourse, it is not the interest of which discourse is true - or the representation of the real - it is the social mechanics by which a discourse is (re)produced as the dominant discourse, or a metanarrative of truth, that shapes our subjectivities. One of the major effects of discourse/knowledge/power is the construction of subjectivity. This sort of subjectivity calls into question the all-knowing humanist self by suggesting agency and choices are subject to the very discourses that shape choices and question what the self may or may not be aware of based on their location within a sociopolitical discourse. In other words, within a poststructuralist epistemology choice is not free, but is constrained and constituted within a subject's sociopolitical positioning.

Political scientist and commentator Andrew Sullivan argues that the "sheer radicalism of the Foucauldean agenda mandates an apolitical politics" (1995: 88), an impossible revolution of sociopolitics that reduces people to discursive puppets. 
This is something that gender activist Riki Anne Wilchins (2004: 1) is aware of: "as queer theory retreated further into academic arcana, it became of increasingly less use to the people who needed it." However, while discourses may seem all powerful and resistance is futile, within discourses there are still possibilities for resistance. In The History of Sexuality, Foucault offers one such possibility:

There is no question that the appearance in nineteenth-century psychiatry, jurisprudence, and literature of a whole series of discourses on the species and subspecies of homosexuality, inversion, pederasty, and "psychic hermaphrodism' made a strong advance of social controls into this area of 'perversity'; but also made possible the formation of a 'reverse' discourse: homosexuality began to speak on its own behalf, to demand that its legitimacy or 'naturality' be acknowledged, often in the same vocabulary, using the same categories by which it was medically disqualified. (Foucault, 1978: 101)

This reverse discourse has important implications in the resistance of dominant discourses it seeks to subvert: It allows for the development of new, resisting discourses. If gender and sexuality are produced to feel natural and not the effect of diffuse power relations, then reverse discourses allows gender nonconformists to resist and form new discourses of resistance. Reverse discourse allows for the production of resistance and new discourses to be developed. In the 1999 edition of Gender Trouble, Butler (1990) addresses some of the criticisms concerning her theory of agency. She states, "The iterability of performativity is a theory of agency, one that cannot disavow power as the condition of its own possibility" (ibid.: xxv). Indeed, even in Gender Trouble, Butler assures the reader that to be constituted by discourse is not to be determined by discourse, thus foreclosing any possibility of agency. Instead, agency is deployed through how signification and resignification work; agency is "located within the possibility of a variation on that repetition" of gender (ibid.: 198). 
For Foucault, power/knowledge aimed to produce a discourse "which had to model itself after that which spoke, not of sin and salvation, but of bodies and life processes - the discourse of science" (1978: 64). This can be thought of having been achieved achieved through the medicalisation of the effects of confession from the priest to the psychiatrist, which re-encode the notion of non-normative expression of sexuality/gender as pathological/medical, from the confession of $\sin$ to the confession of psychical abnormality. As an extension of this, what Foucault terms "bio-power" works through the technologies of power operating on both the individual and the social body, because "power is situated and exercised at the level of life, the species, the race, and the large-scale phenomena of population" through a series of regulatory controls, guaranteeing the effects of hegemony (ibid.: 137). One effect of bio-power is surveillance and pathologisation of deviant bodies, disciplining the body and regulating populations. Policing gender and privileging "proper" expressions of gender secures heterosexuality in a way that makes a binary materiality of sex seem natural and taken for granted.

I will begin this chapter by discussing the ways gender "deviant" bodies have been constructed, engaging specifically anthropologist David Valentine's Imagining Transgender: An Ethnography of a Category. Next I will discuss the progression of (trans)gender/sexual theory and ways in which reverse discourses may be formed. I will historically place the contemporary New Zealand/Aotearoa transgendered subject through a discussion of the Human Rights Commission's 2007 report, To Be Who I Am: Report of the Inquiry into Discrimination Experienced by Transgender People. This report reviews the first inquiry regarding transgendered individuals by any country's Human Rights Commission (HRC). While this 
research is not concerned with New Zealand/Aotearoa specifically, the HRC's report can be used as an allegory of Western transgender subjectivities. Finally, I will then analyse the report's findings through the theory of sexual citizenship and access to public and imaginative/virtual space, informed by essays in Kate O’Riordan and David J Phillips' Queer Online: Media, Technology, \& Sexuality, a collection of current research that focuses on queer theory and practices that intersect with online communication technologies.

\section{Becoming Transgender}

Since the early 1980s, when the influential anthropologist Gayle Rubin first suggested that feminism should not be the site of sexual theory and that sexuality should be considered a field of inquiry of its own, scholars have sought to discuss the ways in which gender and sexuality - further burdened by issues of race, class, and colonialism - have come to intersect (Valentine and Wilchins, 1997). David Valentine (2007), in his text Imagining Transgender: An Ethnography of a Category, concerns himself with a genealogy of transgender, a possible site of intersection. Transgender as a term came into prominence in the early 1990s as a collective term for any and all gender variance, refusing "the stability the term 'transsexual' may offer to some folks and embrac[ing] more hybrid possibilities for embodiment and identification" (Halberstam, 2001: 20). However, the notion of gender variance has a much longer history largely positions within sexuality. The early pathology of homosexuality was also constructed through visible evidence of non-normative gender expression, which caused early sexologists to construct (male) homosexuals as a third sex. While Valentine spends little time describing 
early theories in sexology, I believe this sociomedical model deserves a more thorough discussion.

The human sciences, such as psychiatry and medicine, have played important roles in shaping the way individuals think about bodies, identity, and social practices. Clinical thought refined its methods and scientific norms to produce "a pure Gaze that would be pure Language: a speaking eye" that would turn into

speech that states and teaches; the truth, which events, in their repetitions and convergence, would outline under its gaze, would, by this same gaze in the same order, be reserved, in the form of teaching, to those who do not know and have not seen. This speaking eye would be servant of things and the master of truth. (Foucault, 1973: 114-115).

Foucault is discussing here the dissemination of medical knowledges throughout early health practitioners, though the same process is still in place today. Foucault points out that "the medical gaze circulates within an enclosed space in which it is controlled only by itself; in sovereign fashion, it distributes to daily experience and knowledge that it has borrowed from afar... In that experience, medical space can coincide with social space, or, rather, traverse it and wholly penetrate it" (ibid.: 31 ). We see here the privileged role medical knowledges hold in shaping not just how we think about our bodies, but how these knowledges shape discourses that produce the terms of larger social relations. In fact,

medicine must no longer be confined to a body of techniques for curing ills and of the knowledge that they require; it will also embrace a knowledge of healthy man, that is, a study of non-sick man and a definition of model man. In the ordering of human existence it assumes a normative posture, which authorizes it not only to distribute advice as to healthy life, but also to dictate the standards for physical and moral relations of the individual and of the society in which he lives." (ibid.: 35 )

Here we see an early formation of Foucault's notion of biopower and how it may operate. Medical knowledges seek to maintain a physically and psychically 
normative (nonpathogenic) individual that dictates physical and moral standards for society. Medical bipolarity develops in such a way that normal and pathological are mutually exclusive. It is in this way medical knowledge (re)produces the heteropatriarchal nation-state that presumes heterosexual, normatively gendered citizens.

Medical sociologist David Armstrong suggests a postclinical direction in medicine called surveillance medicine, which involves a spatial reorganisation of the framework of illness and the inclusion of extracorporeal space. What is striking in its difference to hospital medicine is its negation of healthy as an inclusionary tactic; surveillance medicine presumes everyone is ill, or at least in a constant state of risk. It made itself the dominant medical paradigm by suggesting that if everyone had a pathology, everyone would need to be monitored.

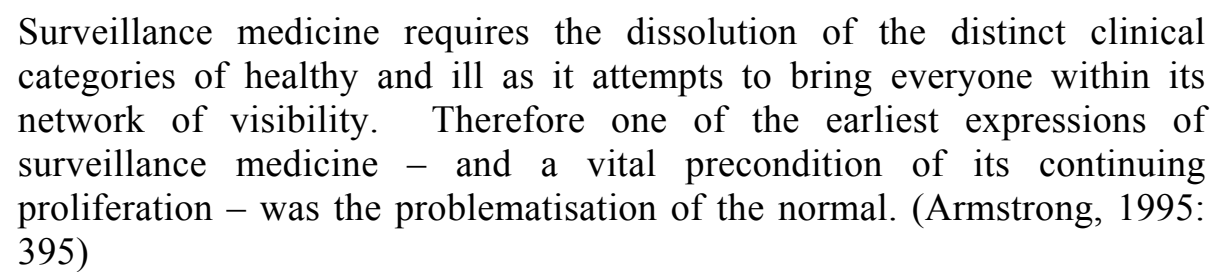

In the discourse of surveillance medicine, health is a precarious, vulnerable state. Armstrong's basic example of the power of surveillance medicine is that of the child, the first target of this form of power. The child is under a constant state of growth and development and the risk of medical deviance can occur at any time during this development, leading to the establishment of postnatal care, baby clinics or plunkets, and nursery schools, which ensured the healthy early development of a child. Surveillance medicine concerned itself not just with the development of the body, but the development of a healthy mind. Informed by the works of Freud and psychoanalytic theory, it is at this point the medical gaze 
turned its focus to the vulnerable, unformed mind of the child, to monitor psychological wellbeing as well as classify any abnormal behaviours, thus creating the shy child, the oversensitive child, and, of course, the gender/sexually-confused child (which is at risk of developing into an adult homosexual). Another important feature of surveillance medicine is its reconfiguration of extracorporeal space. With a new importance based on risk factors, surveillance medicine turns to the material and social spaces of individuals to identify the precursors of inevitable illness. If one person is vulnerable to something in their environment, then all bodies may be vulnerable to that same thing, leading to an epidemic.

For psychiatrist and sexologist Richard von Krafft-Ebing (1882), in Psychopathia Sexualis, an early medico-forensic text on sexual perversion, the etiology of sexual perversion can be attributed to masturbation, which "despoils the unfolding bud of perfume and beauty, and leaves behind only the coarse, animal desire of sexual satisfaction" that depraves the patient from wanting "that aesthetic, ideal, pure and free impulse which draws the opposite sexes together" (ibid.: 189). The patient then degenerates into "a process of physical and mental transformation" (ibid.: 190).

Krafft-Ebing identifies four degrees of sexual inversion: The first is the simple reversal of sexual feeling, where a person is attracted to a member of the same sex while also being able to be attracted to members of the opposite sex; the second degree is eviration (feminisation of males) and defemination (masculinisation of females); the third degree is the transition to change of sex delusion, in which personal sensation is transformed to the opposite sex; the fourth 
degree is metamorphisis sexualis paranoica, the delusion of sexual change and the total inversion of sex. English scholar Jay Prosser (1998) recategorises these degrees as bisexuality, homosexuality, transsexuality, and intersexuality. KrafftEbing's case of the Hungarian doctor is an example of what we would now consider to be transsexuality (in contemporary terms) and what would later be called gender identity disorder. He tells the doctor:

I feel like a woman in a man's form; and even though I am sensible of the man's form, yet it is always in the feminine sense. Thus, for example, I feel the penis as clitoris; the urethra and vaginal orifice, which always feels a little wet, even when it is actually dry; the scrotum as labia majora; in short, I always feel the vulva. And all that that means one alone can know who feels or has felt so. But the skin all over me feels feminine; it receives all impressions, whether of touch, or warmth, or whether unfriendly, as feminine, and I have the sensations of a woman. (Krafft-Ebing, 1982: 207)

For Krafft-Ebing, the doctor's feeling were a psychical anomaly, with the sensations of a sexual change now dominating his consciousness. Prosser asserts that sexual inversion was what we would now call transgender and that the category is a much more broad gender-inverted condition that also included homosexuals.

Sex reassignment is considered by some health professionals to be the most effective treatment for gender identity disorder (Bower, 2001). According to psychiatrist Herbert Bower there are two components essential for the diagnosis of gender identity disorder: cross-gender identification and discomfort in regards to one's assigned sex. Bower notes that the majority of male-to-female transsexuals are attracted to males and desire heterosexual male partners, thus medical science reinforcing heterosexuality as part of the treatment for gender identity disorder through sex reassignment surgery. (Interestingly, Bower describes the drag queen as having "aggressive and histrionic behaviour which is often accompanied by drug 
dependency and soliciting" (ibid.: 7).) In this way, the medical establishment seeks to rectify and/or cure ambiguity of any kind and so sex reassignment and hormone therapy is a normalising and corrective means of regulating ambiguous bodies and gender dysphoric subjects. And it is in this way that medical knowledge establishes "a wrong body" discourse that produces a transgender - and specifically the transsexual - subject: transwomen are women in a man's body and not merely women who happen to have a penis.

Given the privileging of medical discourse in bodily matters, perhaps it is not surprising that some of the earliest work in geographical analyses of bodies appears in the subdiscipline of medical geography. Early medical geographers concerned themselves with a conceptualisation of the body as a vector of disease, a site of contamination, and an organism of ill health. While it has been noted that the human geographer has tended to discount the non-human sphere of nature and physical objects (Bakker and Bridge, 2006) some feminist and queer geographers have turned to exploring the materiality of the body, how subjectivities are constituted through the body, itself a site of knowledge production. Research in bodily geographies has concerned itself with the biological and psychical materiality of the situated self, how subjectivity and identity form through the social experience of the physical body and through discursive practices. For example, some geographers have studied the norms of eating practices and body bigness, deconstructing the medicalisation of body size and obesity discourses (Evans, 2006; Colls, 2006). 
David Valentine questions whether the distinction between gender and sexuality is simply a description of the way things are, or if the claim that gender and sexuality are distinct is productive of such a distinction. The simple categories of sexuality or gender orders certain experiences while erasing some complications. From a Foucauldian perspective, the distinction of gender-normative (homo)sexuality and transgender is a modern technology of power/knowledge. Valentine argues that the separation of gender and sexuality as two separate and distinct ontological categories was exploited by gay and lesbian activists under a new system of homonormativity. Homonormativity has emerged as an artefact of the assimilationist agenda of respectability of many gay and lesbian citizens, in opposition to the radical queer rejection of heteronormative values. Counterpublic sexualised spaces such as leathersex bars, cruising areas, and other spaces of queer territoriality are now deemed by the gay community as embarrassments, the least desirable and assimilable zones of (male) homosexual culture, as gay conservatism is a moralising politics that calls for the self-policing of "deviant" behaviour. Such politics would rely on gays' invisibility within public spaces. Left politics have no place in this scheme and lesbians are often excluded, given their legacy with radical notions of feminism. Gay conservatism is about white, middle class men who demand the privileges promised to them at birth (but are stripped of in adulthood because they happen to have sex with men). Passing is also important here, as passing is the key to sexual citizenship (discussed shortly) and assimilation (Bell and Binnie, 2000). Indeed, for gay conservatives invisibility and assimilation are key components to their politics. Assimilationist gays and lesbians' political projects aim to minimise the difference between heterosexuality and homosexuality, as gender-normative homosexuals show no publicly visible signs 
(such as male femininity) of that which is a private exercise of sexuality. Indeed, it is the overt visibility of that which is transgender within the queer community that calls into question the gender stability of gender-normative gays and lesbians. Further to this, the emergence of the category of transgender discursively removes the stigma of gender deviance from gay and lesbian. As Wilchins (2004: 18) puts it: "For many gay men, gender is yet another closet to come out of."

In an early text, written with Wichins, Valentine (1997) discusses the social construction of the body and is specifically concerned with not only the ways people alter their bodies but the construction of identities around bodies that are not culturally understandable in terms of existing binary categories. To him, the altering of bodies calls into play new questions of difference and power, specifically the policing of these bodies by cultural means. In policing social space and the bodies therein, Foucault's use of Jeremy Bentham's panopticon as a metaphor for surveillance is of particular interest. The panopticon is an architectural technology of a building in the form of a ring. In the centre of this ring is a tower facing the inner face of the ring. The outer building is divided into cells, each the width of the building itself. Each of these cells has two windows: one facing the tower, the other on the opposite wall, allowing light to seep in. The tower's surveiller surveys the silhouettes of the cell's captives (see Image 1, next page). It was considered an easy and effective exercise of power. This policing produced a politics of space and visibility inscribed in architecture. Visibility is organised around a dominating gaze and the technology of the panopticon was not so much to punish wrongdoers as to prevent even the possibility of wrongdoing, by immersing people in a field of total visibility where the opinion, observations and discourse of others would restrain them from harmful acts. (Foucault 1980: 153) 


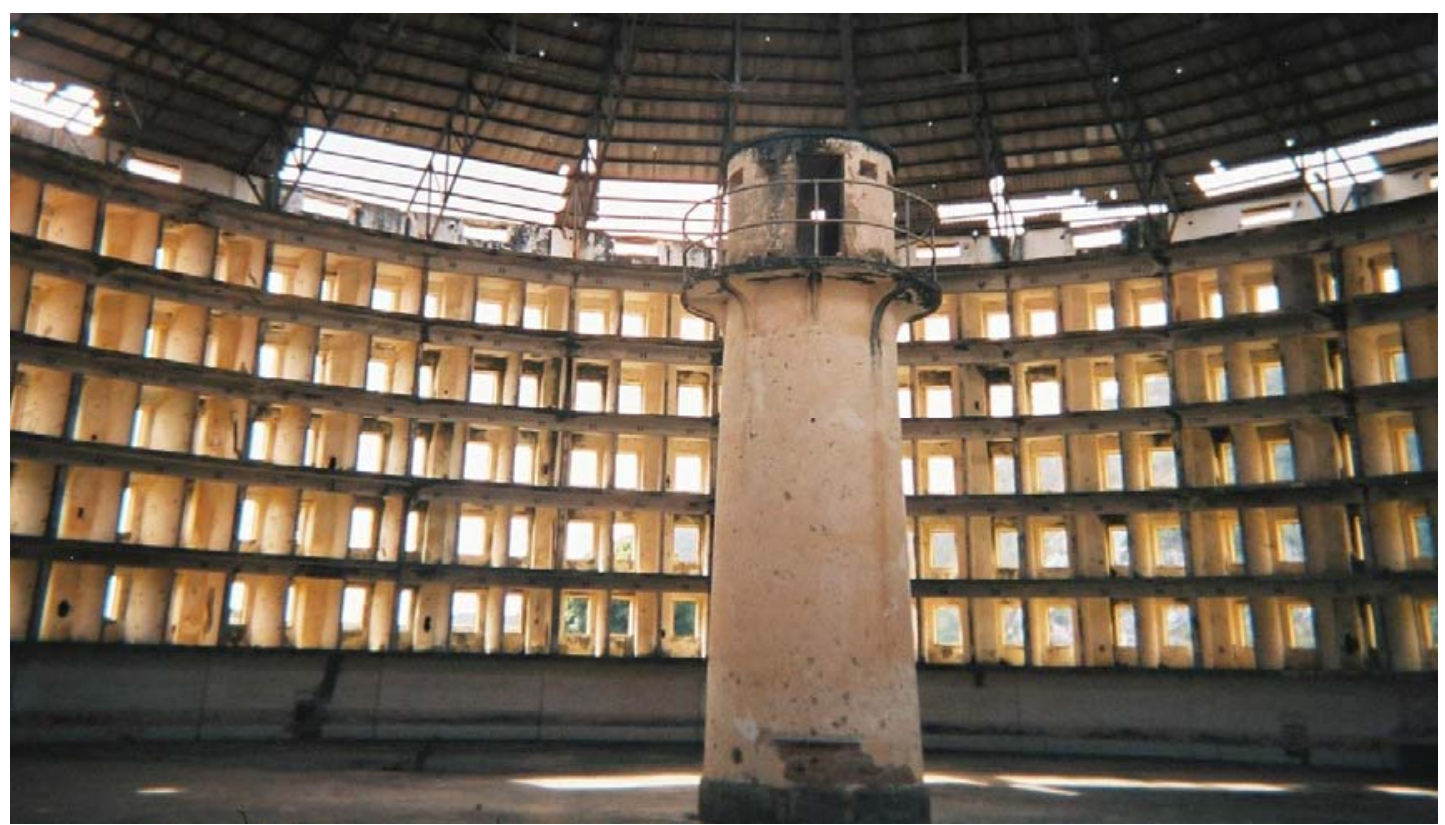

Image 1. Interior of Cuba's Presidio Modelo prison, an example of panoptic architecture.

Silhouettes of prisoners would be surveilled by the watchtower. DigitalCrossRhodes.com (2009)

The only downside of the panopticon was the fear of darkened, and thus unregulated, space which prevents the visibility of the person being regulated. It is in this sense that visibility produces surveillance (Thompson, 2004).

Indeed, it is the technology of the panopticon that allows for interiorisation of a total, omniscient gaze. A surveiller need not watch the cells, as the potential for surveillance will result in each individual interiorising the gaze so that the individual will exercise surveillance over - and against - themselves. This ideal surveillance cancels human agency; it is this penetrative element of the gaze that polices gender "wrongdoing" and produces a "good citizen" within a certain knowledge/power matrix. The assimilationist agenda has privileged the internalised gaze as part of its politics: Gender-normative gays and lesbians selfpolice their gender in such a way that it cannot be questioned or misinterpreted, thus demonstrating that their sexuality is distinct from their gender. 
Of course, the panopticon metaphor is not without its critics. Stephen Green (1999) prefers plague management to the panopticon to socially police. Plague management assumes every person is susceptible to any effect and aims for categorisation, not normalisation like the panopticon. He argues that plague management is a more effective tool since the technologies of surveillance are located within the community, with the community socially policing all members in a particular space and aligning abnormalities to categories for treatment or eradication. However, though plague management does not shift the gaze internally, it can be conceptualised as a more obvious model to socially police a strict gender dualism through community regulatory practices rather than selfregulating practices; imagine, for example, violence on effeminate men resulting in all men acting to remove any traces of effeminacy.

However, positions of gender and sexuality as distinct, but related, demonstrate that that which is gender and that which is sexuality have ontological status that may or may not act upon the other (along with race, class, culture, and nationality, of course). For Valentine, though, this ontological seperateness ignores the complexity of lived experience. He demonstrates this through interviews with people that activists and social service providers would categorise as transgender, but whom complicate the notion of a transgender identity. For example, Valentine described Anita as transgender in his understanding of the term, as she had been taking female hormones since she was a teenager:

Anita: I consider... yes, yes, but I know what I - I know what I am, but I... I... you know, I treat myself like a woman, you know. I do everything like a woman. I act like a woman, I move like a woman, you know. I do everything like - everything like a woman.

DV: Do you consider yourself to be gay, then?

Anita: Yes!

DV: Yeah. 
Anita: Yes.

DV: Yeah. Um

Anita: Yes.

DV: Even though you live as a woman.

Anita: Yes.

DV: Right, ok.

Anita: I know I'm gay and I know I'm a man. (Valentine, 2007: 115)

Anita shows the complications of lived experience upon the transgender category and the limits of transgender as an identity. Anita knows she is "gay" and "a man," but she also knows that everything she does is "like a woman" and is therefore read as transgender. In fact, in his field work at the New York Lesbian and Gay Community Services Center and the surrounding areas, Valentine found many people on whom the transgender category would be placed, but identified as gay men and saw their gender variance as part of their (homo)sexuality - and this was not limited to male-bodied women. Jade, an older female-bodied individual who identifies as a "mother," "lesbian," and a "man," found the word transgender not representative of her experience because "the word 'trans' was only used in 'transsexual,' meaning you were flipping over, changing your organs" (ibid.) Valentine considers that this is not merely a mis- or non-education issue and that some gay-identified people would adopt the transgender label and abandon their gay identity if they were better informed of it. Rather, for many gender-variant people, personal experiences cannot be accounted for so easily by the categories homosexuality or transgender; both sexual and gendered experiences exceed the boundaries of their categories.

\section{Being Transgender}

In 2007, the Human Rights Commission published To Be Who I Am: Report of the Inquiry into Discrimination Experienced by Transgender People (Human Rights Commission, 2007), the findings of its inquiry of everyday struggles that 
affect the transgendered community. Launched in 2006, it was the first inquiry by a national human rights organisation to look at transgender issues regarding health services, citizenship, and social policy. While my research is not centred on the transgender subject within Aotearoa New Zealand, the inquiry provides insights into the public experiences of the transgender subject within a Western cultural framework in various areas:

- Education. The inquiry recognised that transgendered children face barriers to education and participation in school life in respect to preferred name use, sexspecific school uniforms, safety, and participation in sports. While some trans youth will seek assistance and participation in on-campus groups designed for gay, lesbian, and bisexual students, many heterosexual trans youth may not seek support as they do not identify as gay, lesbian, or bisexual, suggesting the ontological separation of gender and sexuality.

- Public life. The inquiry recognised that access to employment and housing is negatively affected for transitioning (and transitioned) transpeople. A number of participants in the study were not able to obtain employment and felt moved out of current employment through increased workloads or other measures. Limited access to employment led many participants into prostitution and illegal activity.

- Safety. Discrimination and harassment was measured on a scale of low level (such as avoidance, insults, and denied access to public places) to high level (such as physical and/or sexual abuse). While the report acknowledges most instances of discrimination and harassment were low level, violence remained a constant theme amongst participants.

- Health. Diagnosis of Gender Identity Disorder is required for a patient to be referred to secondary health services (for example, hormone treatment). Many 
patients with pre-existing mental health conditions were told their gender issues were a symptom of their pre-existing condition. Many transpeople also believed their primary health practitioner was ill-educated in trans health, with one patient reminding her doctor to conduct regular tests of liver function once hormone therapy commenced. District Health Boards required patients to fit under restrictive criteria for free, public treatment, leading most to pay for all health-related treatments that are deemed cosmetic out of pocket. ${ }^{2}$ Additionally, for transwomen, surgery is available in only one New Zealand city.

Four out of five submissions to the inquiry described some form of discrimination from school, work, in public space, by government agencies, and by health practitioners. Further to this, most simply expected to be discriminated against as it was so common in their experiences. While many participants noted positive relationships with their primary health practitioner, others described the difficulties they experienced. Some transpeople did not feel their primary health practitioners had sufficient knowledge on hormone treatment and wanted to speak directly to an endocrinologist, however doing so is made near impossible without a previous diagnosis and referral. Additionally, district health boards' prioritisation criteria exclude many patients on the grounds that trans-related services are seen as cosmetic. The Ministry of Health conducted a survey in 2003 requesting information from district health boards regarding the treatment of transpeople, with only seventeen of the twenty-one boards responding. Eight boards responded that no services are provided and two provided services if the patient met criteria. Only one board provided comprehensive services. This has caused many individuals

\footnotetext{
${ }^{2}$ In 2003 the Ministry of Health changed the guidelines for the Special High Cost Treatment Pool to fund four sex reassignment surgeries every two years, three for transwomen and one for transmen.
} 
who wish to begin transitioning to circumnavigate the public health system and seek private care at cost, both domestically and through medical tourism.

Additionally, it was noted that some health practitioners discussed whether or not gender identity disorder was a mental health illness: "Psych assessments are required because it is in the DSM-IV. But it is not a mental disorder. Someone who is transgender is normal and more normal once they have had surgery" (59, emphasis mine).

The term sexual citizenship is often used to describe the sexual rights and access to general rights of groups and how these impact sexuality and the agency of the state. Sociologist Kenneth Plummer (1995) further describes this as an intimate citizenship concerning people's rights to choose their relationships, gender, desires, and what they wish to do with their bodies. This is a concept that queer-politics-asantinormalisation has essentially used in terms of demanding space(s) for dissident sexualities and questioning the "good gay" model of assimilable citizenship (Monro and Warren, 2004).

In part, sexual citizenship demands a reconfiguration of public and private and a (re)negotiation of the public/private divide (Bell and Binnie, 2000). The home of normative heterosexuality is the typical "private" space, whereas politics, commerce, and anything that exists outside the home is public space. Traditionally, sexuality is prescribed to the private sphere and is therefore reduced to the presumptively apolitical (Martin, 2000). Queer politics subvert the divide between private and public and the supposed inappropriateness of the private in the 
public. Cultural theorist Fran Martin (ibid.) describes the reconfiguration of public and private spaces in Taipei's New Park, which also illustrates the idea of "good" and "bad" queer sexuality:

[T] he rhetoric of the City Government effectively produces two kinds of sexuality. One is characterised by class-bound practices of consumption (attendance in commercial gay venues), and constitutes the imagined subject of US-influenced minority rights discourses cited by the administration in order to project an image of Taipei as a 'modern democratic city.' The second kind of homosexuality, by contrast, ....is the rather declassé kind of homosexuality, whose subject is imagined not to be a 'white-collar worker' but rather to be a student or unemployed, and to utilise free, public space for the practice of his sexuality, rather than commercial leisure spaces. (ibid.: 85-86)

Taipei's New Park demonstrates the ways in which neoliberal urban restructuring and the politics of homonormativity work in tandem. For Martin, the degree of "good" or "bad" queerness is bound up in class and consumption practices. Geographers David Bell and Jon Binnie (2004) also suggest the queer consumer is more acceptable than the (queer) sexual citizen, as seen in the pink economy discourse. Global gay tourism and the proliferation of globalised Pride and Mardi Gras events are just two examples of the queer consumer's placement in public space. However, gay commercial spaces place emphasis on "appropriate bodies, clothes and behaviour" (ibid.: 1814) which produces more possibilities of homonormative exclusion. In this way, gay gentrification and gay spaces of consumption are acceptable, but leathersex bars and spaces that are utilised for public sex are not.

The act of coming out itself is a statement that sexuality is not simply a private affair designated to only the domestic space of one's life. It is in this way that private space is seen in part as a space of oppression and invisibility. Sullivan (1995) argues that heterosexuals are tolerant of private queers, but not public 
queers and suggests that a public disapproval and private tolerance is sustainable. It is important to discuss queer visibility in public space since visibility is privileged in identity politics and homosexuality (concomitant with a presumed gender variance) is assessed visually. While becoming visible is to render one's subjectivity legitimate and legible in discourse, it may not always be the safest political device for subversion. There is safety and acceptance in choosing to occupy a less or non- transgressive space and/or a fixed, stable (gender) identity.

\section{From Public to Virtual Space}

With the limitation afforded to queer individuals in public space, it is not surprising that queer subjects have looked to alternate concepts of space. Utilising virtual space is a way for queers to claim their own space(s) of sexual citizenship, their own multiplicity of identities and subjectivities. Marginalised groups have turned to the internet for the expression of unconventional, so-called deviant behaviours (Hegland and Nelson, 2002).

The internet provides an avenue in which people can create a virtual social space to meet and interact with others. Various scholars have noted that communities have assigned communications media a prominent role in maintaining social spheres. Media provides a way for knowledge to be (re)produced and dispersed since it "helps people maintain contact with members of their social network or group, cultivate ties, and garner aid and resources, including information" (Kavanaugh et al., 2005: 119). Internet services can be utilised to strengthen social ties and exchange information. However, it is important to note that internet services are not simply a commodity, but a form of cultural production 
that produces its own consuming subjects. Its users, then, are discursive effects themselves that perpetuate their own terms of reference.

Exploring cyberspace as a site of expression provides new opportunities for examining issues that surround gender, sexuality, and identity. Cyberactivism has expanded possibilities for resistance, potential to advance efforts for social justice for all so-called cyberqueers and cyber-ethnography has developed as a tool for understanding online communities and individuals (Snyder, 2002). Counterhegemonic groups have the possibility to use information for political action, as dispersed individuals with similar interests or politics can connect in cyberspace. With virtual space, individuals are liberated from the constraints of public space and have the potential to produce new social geographies. In this way, the virtual community emerges as a result of the social implication of internet use. Virtual space is less of a fiction than a new way of communicating with individuals and communities and is reimagined as territorial systems analogous to neighbourhood, city, etc. (Graham, 1998)

Creating and colonising virtual space is an act of political disturbance, a demand for a utopian imagined community. While it creates a safe environment for users to take advantage of visibility and advocacy, online networks have indefinite boundaries, shifting and dynamic and the centre/periphery dichotomy is potentially deconstructed. Indeed, the possibilities of virtual space may queer ontologies of space, as it is a site of identity, multiplicity, performativity, and resistance. 
The internet is also a place to reflect on how queers represent ourselves. Representations by gays and lesbians online tend to be constructed in essentialist notions, with the articulation of queerness as central to the user's life (Alexander, 2002). This is in direct contrast to the potentiality of virtual space as a site of multiplicity and contradictory subject formation.

One instance of looking at transgendered subjects online is cultural theorist Mark McLelland's (2002) study of the Japanese "newhalf." Newhalf (nyuuhaafu) is an Anglo-Japanese term used to describe transgendered men that typically perform in the sex industry offering services to gender normative men. Whether pre- or postoperative, newhalf see themselves as an intermediate sex. Newhalf sites are typically run by transvestite/transsexual cabarets and bars that both promote the bar itself and allow a space for newhalf to discuss who they are. One site McLelland identified promoted its services to gender normative men as follows:

"We, the newhalf at Aventure, try to ensure that all our customers feel satisfied and secure so that [they can experience] enjoyable sex by using our hearts, bodies, skills and magic. We respectfully wait for your visit from the bottom of our hearts. Credit cards accepted." (ibid.: 172)

While the newhalf market themselves to gender normative men, there is no mention by McLelland that these men are homo- or heterosexual-identified, but that is not necessarily the point. What is important is that the newhalf use the internet as a resource to promote their subjectivity, embodiment, and services to a public audience.

Sociologist Nina Wakeford (1997) is concerned with the political economy of cyberqueer articulation, though warns the reader to not think of the cyberqueer 
as "a celebration of parody and performance, or the simplistic application of an author's reading of Gender Trouble" (ibid.: 412). Additionally, media scholar Kate O'Riordan (2007) seeks to consider ways in which both cyber and queer discourses have "offered/produced subjectivities, both as identities and as imagined positions" (ibid.: 13). She examines the ways in which the cyber and queer metaphors and discourses intersect with the imagined and material body. Challenged by Wakeford to not rely on simplistic readings, O'Riordan asserts that the mapping of cyber on queer and vice versa will expose the ways in which cyberqueer is performative, a project that refuses to reduce performativity to mere expression. In this way the mapping of the cyber subject on and to the queer subject provides moments of what Butler calls productive "slippage."

Considerable attention is given to the way the internet can allow for new constructions of identity. Internet users can construct a multitude of identities in forums and blogs and on message boards and homepages. In virtual space, identity is malleable and fluid. Internet users sound curiously similar to Donna Haraway's (1991) conceptualisation of cyborgs, chimeras that are simultaneously human and machine. As hybrids, cyborgs call into question that which is normatively human by breaking down the boundary between human and non-human (machine). Cyborgs are at once virtual and imaginative and material reality. As humans and machines become more interdependent, the fine line between the human and our non-human extensions (for example, the internet) is queered. Most importantly, cyborg internet users can disestablish conformist identities while online. 
Technoscientific innovations have changed the ways in which we communicate and reconfigure physical space, procreation and intimacy and the internet is increasingly becoming embedded in our world (Graham, 1999 and Wilson and Peterson, 2002). The internet is expanding our lexicon and reshaping the way people communicate and interact. Importantly, the internet is reconfiguring how gendered identities are negotiated and (re)produced. The internet is of particular use to feminism and queer theory since "it is the nonhierarchal nature of cyberspace, and its nature as network, which makes it a protofeminist medium" (Graham, 1999: 430). Situated histories of sociocultural practices and ideologies of technoscience emerge along with new technologies.

As demonstrated in this literature review, poststructuralist critiques can provide a way to rethink ontological categories and consider marginalised and problematised perspectives. Poststructuralism is critical of an autonomous human agent and considers subjects as constitutive of and constituted by a multitude of discourses and cultural meanings, for example cultural meanings of male and (only) female. While newer political understandings of gender developed within the early gay/lesbian liberation movement, gender has subsequently been denied a place within gay/lesbian politics that have produced - and been (re)produced by - a contemporary ontological separation of sexuality and gender, which effectively reified homosexuality as unproblematically, politically gender-normative. A return to conservative, assimilationist sexual politics have marginalised some gays, lesbians, and transpeople. The proliferation of virtual space may be a queer, postpublic possibility for these marginalised categories, but brings with it its own, newer discursive practices. 


\section{METHODOLOGY}

Even in the worst of times, however, we must not simply succumb to the institutional forces recreating hierarchy. We must always push at the margins, push at the limits, push at ourselves.

-Sherry Gorelick, Contradictions of Feminist Methodology (1991)

Geography's seemingly androcentric nature effectively either renders gender invisible or has discussed it as something exotic and/or tangential. However feminist critiques by geographers have recognised the positivist nature of the discipline (for examples see Rose, 1993 and 1997, Nash, 1996, and Longhurst, 2008). The subdiscipline of feminist geography has emerged and appropriated poststructuralist feminist theory and methodology to reinvigorate geographical inquiry and the discipline's knowledge-claims and suggesting that identity is "riddled with - even formed through - mistakes, misrecognitions, fantasies, instabilities and contradictions" (Rose, 1993: 6).

For sociologist Sherry Gorelick (1991) feminist methodological critiques have three interrelated levels: philosophical, moral, and practical. At the philosophical level lies a critique of positivism's pretense of value-free research and knowledge production based on empirical fact-finding. At the moral level is the critique of the objectification of subjects and their exploitation by the researcher who studies them as things, thereby reducing "human beings to social facts" (ibid.: 460). As feminist researchers, we need to reject the researcher/researched dichotomy. At the practical level is a critique of dominant 
methodologies that may not realise that the researcher and the researched may have different agendas that can lead to distortions in the research project, as "a subject population does not tell the truth to those in power" (ibid.: 461). It is in this way that feminist approaches interrupt the knowledge production of the truth factory, to not only describe oppression but to challenge it.

While feminist geographers have argued that patriarchy and whiteness maintain their privilege by operating in a state of unawareness, queer geographers add that both heterosexuality and cisgender privilege maintain themselves in similar states of unawareness through presumed heterosexuality and presumed congruence of social gender and biological gender assignment. Poststructuralist by nature, queer theories insist that space is not only gendered, but sexualised, as well; space is not naturally heterosexual, but rather is produced and heterosexualised. Queer geographies would seek to challenge the heterosexism of geographical knowledge. Since a queer epistemology would inform methodological questions, it is important to establish what queer epistemologies might be within the structures of geography.

Similar to feminist geographies, queer geographies insist it is a heteromasculinist notion that the researcher can distance him/herself from the object of research (Binnie, 1997). The researcher must recognise his or her own subjectivities and its possible bias. Not surprisingly, queer epistemological approaches would remain cautious of positivist claims, especially considering the pathologisation of sexual and gender deviance within dominant discourses informed by biology, medicine, and psychiatry. For geographer Jon Binnie (ibid.), 
a queer epistemology would be based on not only a commitment to embodiment in research, but a recognition of the value of camp, which appears to reminds people that what we see is only a view of life, and a disavowal that those who produce cultural landscapes know more about this view of life than those who inhabit cultural landscapes. For the purposes of this thesis, I define camp as in line with to Binnie, as well as utilising media scholar Andy Medhurst's (1991: 156) definition of camp as a new and complex relationship to the serious, to be "serious about the frivolous, frivolous about the serious," in a manner to delegitimate hegemonic points of view through allusion. Camp appeal can facilitate visibility of queer subjects and undermine values and truths, such as the presumed heterosexuality - and I would argue the cisgendering - of social space. Camp, too, is a relief that "offers a space to those dissatisfied by the sharp edges of fixed boundaries of identity politics" (Binnie, 1997: 231). Instead, queer approaches can be "full of camp, attitude, and anger" (ibid.: 232).

Queer's use of combining camp playfulness and political messages is perhaps best illustrated through anthropologist Margot D. Weiss's discussion of San Francisco's radical queer group Gay Shame, which uses "humor, satire, and camp to stage street protests, blending theatrical style with a radical political message" (Weiss, 2008: 87):

Some of their recent actions include (1) spray-painting sidewalks with antimarriage and antigentrification messages; (2) organizing a protest to the "Cutest of the Castro" beauty pageant; (3) participating in the city's large Iraq war protests; and (4) holding two award ceremonies, targeting institutions and individuals who should be ashamed of their disservice to the queer community, progressive politics, and social justice. In 2002, for example, Mary Cheney (Dick's daughter) won the "Helping Right-Wingers Cope" award for acting as a liaison between the gay and lesbian community and Coors Brewery. The same year, the Pottery Barn at the intersection of Market and Castro Streets won the "Making More Queers Homeless" award 
for contributing to population displacement in the ongoing gentrification of the queer neighborhood. (ibid.: 91)

And in 2005

when the San Francisco Department of Public Health papered the Castro neighborhood with posters featuring a shirtless, muscular black man with the caption "Don't be a bitch - Use a condom," Gay Shame produced a counterposter, retorting, "Be a bitch." The poster read, in part: "By reasserting stereotypical notions equating femininity with passivity, the Department of Public Health is rolling back decades of bitches fiercely confronting male power... this ad campaign makes effeminate, queer black men, gender non-conformists, and trannies invisible or powerless... masculinity doesn't protect anyone from HIV. What we need is a sexual culture that encourages respect, open communication, flamboyance, gender transgression, creativity, collective pleasure, celebration, experimentation, and transformation. Turn it out, honey. BE A BITCH.” (ibid.: 92)

I employ queer theory not simply to address how sexuality may or may not be implicated in gender, but also because, whether cisgender or transgender, all individuals have some type of sexuality (even if that sexuality is a lack of sexuality, or asexuality), and also because of the limits of some feminists to male inclusion, excluding the possibilities of men as feminists. For example, for Liz Stanley, a sociologist and feminist auto/biographer,

feminism is not merely a 'perspective' or viewpoint on the world, not even an epistemology or a theory of knowledge about it; feminism constitutes ontology, a different way of being in the world which is rooted in the facts of oppression... I argue that men cannot share a feminist ontology nor its resultant epistemology. Consequently, men cannot write feminist auto/biography in the sense that I understand it. (Stanley, 1992: 251)

I would argue that self-reflexivity can allow males to not only realise, but also attempt to reject privilege, even if they are the benefactors of patriarchy themselves. Men can also critique structures of Euroheteropatriarchy, which I define as those structures that privilege whites, heterosexuals, and males - and especially the combination of two or all three - and have a politics of equality between gender(s), race, and class, not to mention subversive politics that seek to undermine these structures. Further to this, her essentialist and limited feminism 
ignores the possibility of a male-bodied woman (or male-bodied bi-/nongender person) engaging in the broader third wave feminisms and also erases the effects and marginalisation heteropatriarchy has on queer men and the coalition and mutual understanding of two entities patriarchy equally despises: women and feminine men. Additionally, Stanley's view has the potential to perpetuate the feminazi view of feminism as angry, man-hating, and focused on a new superiority (that of women) with its own exclusionary discourses. All said, however, it is less arguable that men can have a queer ontology, even if Stanley wishes to exclude them from a feminist ontology.

Self-reflexivity is also a feminist practice in destabilising positivist research. Feminist philosopher Sandra Harding (1987: 6) notes that "the origin of scientific problems or hypotheses is irrelevant to the "goodness" of the results of research." That is, inquiry can come from magic, religion, or observation; all that matters is the measurable scientific logic of the resulting knowledge and it is in the test that our faith lies. For feminists, reflexivity and embodiment leads to the very questions that are asked. Might I even care about homonormativity or the oppression of transpeople if I weren't queer? If I were heterosexual, would my inquiry lie elsewhere? Since reflexivity figures in both feminist and queer praxis, I will discuss my own positionality through the following intertext.

\section{Intertext: The Life of an American Gay}

I decided to unwind by watching an episode of Friends, in syndication on TVNZ, and the pervasive mainstream fear of gender transgression showed its face again. This particular episode, titled The One with Chandler's Dad, left me a bit 
unsettled. In one of the first scenes, Joey notices that Phoebe's new boyfriend is wearing women's panties. He confronts Phoebe about this as follows:

Joey: Listen, you know how, uh, when you're wearing pants and you lean forward I check out your underwear?

Phoebe: Yeah.

Joey: Well, when Jake did it I saw that... he was wearing women's underwear!

Phoebe: I know. They were mine.

Joey: Oh. (Laughs.) No! No wait, that's weird!

Phoebe: No, it's not! We were just goofing around and I dared him to try them on.

Joey: That's weird!

Phoebe: I'm wearing his briefs right now.

Joey: That's...kinda hot.

Phoebe: I think so too. And that little flap? Great for holding my lipstick.

Joey: Yeah, I wouldn't know about that.

Phoebe: And! Y'know what Jake says? That women's underwear is actually more comfortable. And he loves the way the silk feels against his skin.

Joey: Yeah well next thing you know, he'll be telling you that your high heels are good for his posture!

Phoebe: There is nothing wrong with Jake, okay? He is all man. I'm thinking even more than you.

Joey: Oh yeah, he looked like a real lumberjack in those pink lacies.

Phoebe: I'm just saying that only a man completely secure with his masculinity could walk around in women's underwear. I don't think you could ever do that.

Joey: Hey! I am secure with my masculinity. (Friends, 2001)

Awkwardly discussing another man's masculinity, Joey is secure enough with his own masculinity - so secure that he will not spiral into a troubling femininity like Phoebe's boyfriend might - that he later borrows a pair of roommate Rachel's panties and tries them on. But after he confides in Phoebe to liking them, they decide he has gone too far. Why should the show's hypermasculine ladies' man be so ashamed of having gone too far in discussing how women's panties might feel? Is there something essentially female about silk in one particular shape? Would that make his masculinity suspect? And what would that say about his sexuality, if he liked womanly things? Perhaps I was so unsettled by the episode because the show was one of the most popular sitcoms of its time and reached a very broad audience globally, and in this case obviously relied on and reified notions of proper 
masculinity and proper femininity. Simply put, Joey is scared of being thought of as gay because of gender deviance. ${ }^{3}$

More importantly, will people know I'm queer from my own femininity? For most of my teenage and adult life, my relationship with my body has been regulated by a need to be accepted by The Gay Community, a disavowal (both scholarly and emotional) of even a "gay community," an envy of women's bodies, psychotropic medication ranging from antidepressants to antipsychotics, OCD, dysthymic depression, eating disorders, weightloss aids, shame, and a need to be validated by others. I suppose queers are more aware of their embodiment than straight, cisgender people. Gay men's bodies are often regulated by "the scene" and/or a need to classify their materiality as twinks, bears, otters, cubs, etc. ${ }^{4}$ Similarly, I suppose, transgender people are acutely aware of their physicality as a bodyscape written by gender performance, whether they are genderfucking or feeling they are in the wrong body.

I am not manly. I am not "straight-acting" - or gender normative/hegemonically masculine - as many, mostly conservatives, in the gay community often seem to fetishise and prefer. Like the transpeople David Valentine encountered, "I am what I am." I may not fit idealised models of the gay/queer male, and it has taken a long time to feel happy with who I am, but I am what I am: a non-normative gay man that loves his "feminine side" as much as his

\footnotetext{
${ }^{3}$ It is also the episode where we first meet Chandler's gay, drag queen father, played by Kathleen Turner. Kathleen Turner's husky voice and slight butchness was, strangely enough, the source of her sexiness in the 1980s, similar to Joey's finding Phoebe wearing men's underwear "hot." But now, as an aging, presumably postmenopausal actress, her suspect femininity is the stuff of sitcom jokes: She is a "manly" woman playing a man pretending to be a woman.

${ }^{4}$ A quick internet search will provide information on the proliferation of corporeal types in gay preference, lifestyles, and erotica.
} 
"masculinity" - and I often feel there is no one interested in my experience. I do not really embrace ontological notions of the gay community (always in italics or quotes) or the transgender community(s). I love the subtlety and floweriness of Britney Spears perfumes (I hate overpowering male colognes), but... well, there is not much of my masculinity I am proud of, to be honest, though maybe I am too much of a feminist to be truly objective (eat your heart out, Liz Stanley!). I understand a hegemonically masculine performance may be fetishised, but it is certainly not me, not who I am.

Growing up in the United States, I had always had female friends. I never noticed anything wrong with my sense of my masculinity until my sisters noted that all my friends were female (and consequently I should have male friends) and I was called a tomgirl in sixth grade. I had never heard the term before, but I immediately knew its reference: tomboy. Just as a tomboy was a masculine girl, I, as a tomgirl, was a feminine boy. Tomboy was a derogatory term, so surely tomgirl was, as well. I felt shame. I felt embarrassed. I failed at what I knew was expected of me. And as someone who knew he was gay, I was scared that I would have to bear the burden of being emblematic of an entire people when I was only a child myself.

I met my first close male friend in fifth grade when I was 9 years old. Though I was (looking back) rather camp and he was camp, we insisted on our heterosexuality: he told me of the female classmate he had a crush on and I told him of the female classmate I had a crush on. In fact, I didn't become aware of his admitted (confessed?) homosexuality until after university, long after we had lost 
touch, when we reconnected rather superficially on a social networking website facebook.com - in which he listed himself as "interested in men" and in a relationship with another man. While there is much preliminary discussion of the internet as anonymous, real-life use of internet resources, such as this, show that the internet is a way of announcing one's real-life identity in a way that may be difficult or complicated in real life. Take him or leave him, meet with him again or not in "real life," he proclaimed who he was proud to be.

But our campness - or anyone's campness - is directly related to an ontology of gender, but is more complicated than the notion of gender alone. Female femininity is typically not camp, but male femininity is. Before we were even sexual, what would be seen as our sexual identity was coded as gendered. I was, after all, a tomgirl. Whether we realised it at the time, we occupied a certain social space that played with both sexuality and gender. I was certain of my sexuality, but still in the gender closet because I assumed masculine gays are somehow better than effeminate gays. I mean, that's what TV and movie characters, the few I did see, taught me.

I met the first out gay people at university. The first few I met helped to build my understanding of - and perhaps isolation from - the local gay community. They went to New York City gay clubs, perfected their appearances in mirrors, used expensive skin and hair care products. They were, I remarked, a great deal like gay characters on television, which, looking back, can easily be forgiven for lack of a diverse reference. This was the pre-out Ellen DeGeneres 1990s when a gay kiss had to be cut from the over the top television series Melrose Place to 
avoid viewer outrage and commercial sponsors' sensitivities. Characters were caricatures and one-dimensional and this was how we learned to be what we were supposed to be. I was nothing like that, I was just ordinary, a wallflower. My rejection of and rejection from the scene made me feel inadequate and lost; I wasn't gay enough.

As most lost people do, I searched for answers. I studied physical anthropology, focusing on primatology and social evolution. I became fascinated with the pansexuality of bonobos, one of our closest relatives with whom we share over $98 \%$ of our DNA, as a possible biological source of (my own) homosexuality and I argued to anyone who would listen that selfish gene theory privileged the emergence of homosexuality because gay alloparenting reallocated resources to increase the reproductive fitness and heterosexual siblings' offspring (for further discussion on primate and human social evolution see Jolly, 1999). The biology of it was beginning to make sense, even if the human experience did not.

At the beginning of my fourth year at university, I met Amanda and Stefanie, two straight women (who would eventually politically identify as queer straights), that opened my eyes to the politics within the gay community that I recognised but about which I could never seem to make a cogent argument without appealing to my emotions. We were a radical little group: Who cares about gay marriage? Marriage as a system of privileging certain relationships was the problem and gays and lesbians should want none of that! Gaydar? Isn't that just the legitimisation of gender stereotype in an attempt to excuse the "obvious" claims of someone else's sexuality? I began enrolling in courses that were less based on 
positivist science and more on social sciences, sexuality, and poststructuralism. We began discussing queer theories and postmodernism and the offensive assumptions enlightened people - gay or straight - seemed to always make. And I grew angry and frustrated, but relieved that I could now articulate that frustration.

I suppose I proposed my current topic of research to think about what queer theories can - or cannot - do for me, as well as exploring queer theories that I did not know existed. I'm no longer the devil-may-care, philosophising undergrad. I have a full time job, bills, a stable relationship, desires to travel... Fuck, I'm turning into a polo-shirt wearing gay man and it's only a matter of time before I put money and self-interests first and vote National or Act. This research project gives me a social and theoretical space to remember the importance of real equality.

\section{In/Outsider and For Whom the Research is Designed}

Reflecting on my own experience, I hoped to show how gender and sexuality are deeply entwined. By coming out of the gender closet as well, I propose a politics of reaffirming gay/lesbian politics to transgender politics by way of mutual queer dissent. By claiming a transgenderness through my own articulation of sexuality, I hope to destabilise the gender normativity of homonormative politics, calling to question the privileged stability of gender in some gay/lesbian politics.

In a way, this provides me with a sort of queered insider view of transgender, even though I may not identify as transgender outside of queer politics or academia. However, it is this inability to completely fit in traditional notions of 
transgender that leaves me equally as an outsider. However, what I am claiming to do is to produce what historian Lisa Duggan refers to as bridge discourses, "political languages and strategies that can open dialogue across discursive gaps, generate critical challenges from one location to another, and produce negotiated interventions and actions" (Duggan, 2006a: 2). Bridge discourses can (re)unite the LGBT community not through liberal rights claims, but rather through "the concept of sexual dissent, a concept that invokes a unity of speech, politics and practices, and forges a connection among sexual expressions, oppositional politics, and claims to public space" because "rather than invoking fixed, natural identities and asking for privacy or an end to discrimination, we must expand our right to public sexual dissent. This is the path of access to public discourse and political representation" (ibid.: 5).

These bridge discourses are ways to describe our shared but different narratives. By exposing my positionality, I hope to open my research to trans- and cispeople alike to engage with, even if it evokes some of anger I may have thus far displayed myself - particularly if it evokes any anger. Sociologist Alison Jones (1992) suggests that feminist researchers' explicit partiality is what drives further dialogue. For Jones, when a researcher uses their personal voice

they are present as human beings; it is as though we are in conversation. I see their words immediately as one point of view in our potential dialogue: 'From here, things seem like this...' to which I can reply, 'Yes! I know what you mean!' or 'I never felt like that, rather like this...'. The text, written by the visible 'I', does not merely point, disembodied, to the world out there. Rather, it engages pleasurably shared communication about the world. There is more than just pleasure at steak here, of course, for the politics of the personal voice in these texts is the accessibility to them that it affords, along with some space for response. (ibid., 27)

As a postmodern queer-feminist and an admitted outsider, I would celebrate a transperson telling me I got it all wrong because my own partiality failed to 
recognise an effect. I would also welcome that transperson to tell me the/their "right" version so that I may further reflect on and reshape my own ontologies.

As such, this thesis is not only written for academia, but also for activists. The liberal politics of American gay/lesbian activists has had only variable success when compared to the liberal politicking of women's and civil rights decades ago; rights claims are still towered over by limited access to gay marriage (perhaps the holy grail of liberal LGBT politics), anti-discrimination reform, and the everfrightening post-9/11 conservative turn during the War on Terrorism. For Duggan, it is necessary for activism to engage queer politics and bring "queer questions and knowledges into the domain of mainstream theoretical paradigms" (Duggan, 2006b: 159). For example, queer critiques of the LGBT status quo might give activists to "think about sexual difference not in terms of naturalised identities, but as a form of dissent" and to reflect on the way some political gains come at the expense of some of our constituency (Duggan, 2006d: 182)

\section{Oral History}

Studying the oral histories and positionalities of transgender subjects is cruscial in this project. For the purposes of this research, online discussions are to be considered oral histories of participants, as they provide important auto/biographies. Stanley (1992) uses the term auto/biography to describe the epistemological and ontological notions of writing a life, whether biography or autobiography, that lays "claim to facticity, yet... are by nature artful enterprises which select, shape, and produce a very unnatural product" (ibid.: $3-4$ ) because the biographer is a "socially-located person, one who is sexed, raced, classed, aged" 
(ibid.: 7). Indeed, the author produces a text as though he is of a unique self that creates a "piece of realist ideology which masks the social production of ideas" (ibid.: 16).

Because memory inevitably has limits, the self we construct is necessarily partial; memory ties together events, persons, and feelings actually linked in only such accounts and not in life as it was lived; it equally necessarily relies on fictive devices in producing any and every account of the self it is concerned with." (ibid.: 62)

Auto/biography is to give account to complex and parallel historiographies. Feminist auto/biography locates the product within the processes of its own production. The auto/biography, then, is not the truth, but $a$ truth at a particular moment and disputes the "divisions between self/other, public/private, and immediate/memory" (ibid.: 42). The auto/biographical $I$ recognises that knowledge is subjective, contextual, and historically specific. The self is a fabrication, slowly and selectively pieced together, often in hindsight.

Content analysis is unobtrusive and allows for the study of cultural artefacts, such as life writing, and the analysis of texts and their production. Cultural artefacts "are the products of individual activity, social organisation, technology, and cultural patterns" and are typically not affected by the process of study (Reinharz, 1992: 147). Studying cultural artefacts through the lens of queer theory exposes a heterosexist and even a homonormative culture. Cultural documents shape norms, they do not merely reflect them.

Oral sources in its variety of forms - including aural recordings, (auto)biographies, interview transcripts, diaries and blogs - provide knowledge that has been previously ignored and feminists first used oral history projects to provide 
voices for women. According to oral historian Alessandro Portelli (1998), this allows for the production of knowledge of dispossessed groups whose written histories may be ignored or distorted. Oral histories may provide less information on events themselves, but will provide additional meaning(s) to these events: how they are felt and how they are looked upon; this has lead critics to question the legitimacy of oral history projects (for further exploration, see oral historians Ronald Grele, 1998 and Luisa Passerini, 1998). However, this should not imply that there is not factual basis for oral histories, but rather these histories are (re)shaped by one's subjectivity, as memory itself is an active creation of meanings and it is this act of memory-making that is important.

Luisa Passerini argues that the notion of history as a catalogue of facts is a positivist practise. In this way, the historian seeks to discover facts that will reconstruct the past as it was, to make knowledge-claims on the history instead of $a$ history. For Passerini,

the raw material of oral history consists not just in factual statements, but is pre-eminently an expression and representation of culture that includes memory, ideology and subconscious desires and this may not coincide with hegemonic accounts of 'what really happened' (ibid.: 54).

Oral historian Joan Sangster (1998) is concerned with the ethical issues of oral historians interpreting others' lives and whether the oral historian can separate the cultural discourses constructing that history. Given the influences gender, sexuality, race, and class have on memories and experience, could transgender people (re)construct their memories based on essentialist notions of gender? For Sangster, in order to contextualise oral histories it is important to survey the dominant ideologies shaping individual subjectivities. In using oral history to 
explore the experiences of transgender people, it is important to understand the ways in which ideologies shape their own understanding(s) of gender. I need to also be aware of my research as strangely pornographic, studying the iconography of the transgendered body and my own (cis?)gender and academic privilege to gaze upon it.

\section{Research Resources}

Online resources provide communication possibilities which do not exist in the cultural mainstream. My focus is on how users represent themselves within virtual space, through published narratives and discussions. As a textual analysis, it is believed I would need no further analysis of the text through personal interviews. As such, no human ethics approval was sought since these narratives are published material that is publically available.

LiveJournal.com, discussed in Chapter 4, is a free web logging ("blogging") service that prides itself on community building, self expression, and diversity. It is

a community-building space that allows users to join communities based on a particular theme. Users register with the site and choose a unique username that offers anonymity from their identity in the material world, allowing users full, limitless expression. Users can search for other members and communities by interests and can friend other members or join relevant communities. Users also have the option to post entries as private or "friends only," which means only chosen friends and community members can see and comment on their posts, offering another layer of anonymity and privacy. A preliminary search for 
transgender-related communities shows that there are three-hundred and thirty-eight (388) communities already established on the interest in transgender.

I have chosen the community Transgender Community (" based on its popularity and frequent updates, which offers a wealth of material to be analysed (LiveJournal 2009b). This community does not require an invitation code or moderator approval to join and read. " is moderated by community administrators who can delete or edit posts they deem offensive. As its name suggests, its interest - and presumably its members - covers the wide gamut of the transgender label. This online community "exists to bring together people of all genders for discussion of transgender issues. Everyone who wants to discuss gender in an open and friendly manner is welcome." The community also provides community rules and guidelines in its profile. Chapter Five is interested in Feministing.com, a feminist site that allows users to write blogs on various issues. I look specifically at blogs that deal with transgender issues or concerns. While transgender is a segregated community on LiveJournal, transgender blogs on Feministing are published and interspersed with non-transgender-related blogs. It is in this way that they occupy space within a larger virtual community.

\footnotetext{
${ }^{5}$ LiveJournal communities are designated with the ${ }^{7}$ icon before its name and LiveJournal users are designated by the 1 icon before the username.
} 


\section{MAKING A SPACE ON THE TRANSWEB}

It must be on account of me being Not Trans Enough, or something.

- Dauntysarah (LiveJournal, 2009k)

As with sexuality, the nature vs. nurture debate is implicated in gender. Is gender essential and biological or is it socially constructed? Gender, after all, is given to be a social phenomenon, but it takes place through material means. A social constructionist approach to gender critiques both biological research, as well as socialisation, that presumes a binary category of gender because knowledge claims regarding gender are socially produced through a discursive matrix that includes, for example, the medical sciences, disciplinary biases, and historically specific local cultural appropriations. This chapter focuses on some discourses that produce a new in-community binary similar to the subversive queer/conservative gay and lesbian paradigm: subversive/conservative transgender. Again, it is important to note that the word transgender's prominence grew from the perceived limits of transsexuality. Is transsexuality (as a specific articulation of transgender) truly queer, then? If queer theories insist that lived gender is a social construct separate from sex, why is there a feeling of being "in the wrong body" if lived and idealised gender is the focus of identity formation? Does transsexuality reify hetero- and homo-sexuality and a binary gender at the cost of the proliferation of genders and sexualities? 
While this project does not intend to be quantitative or make exhaustive knowledge claims on numbers, I have looked at some statistics of members of the "ransgender community to determine if any trends of note within the community emerged. Over the one week period surveyed, a total of one hundred sixty (160) LiveJournal users posted in transgender across twenty-eight (28) individual community topics and four hundred seventy-six (476) posts. Seventy-two users (45 per cent) posted only once in the period surveyed. Ten users posted in the community ten or more times, with a moderator, Dauntysarah, posting the most frequently (thirty-three times). Of the one hundred sixty users who contributed to discussion, fifteen were considered frequent users, as they had posted, on average, once a day. As these members maintain the community as a lively place for discussion, they are also perhaps more likely to be friended by members of the transgender community and linking to their own personal journals, to view on individuals' friends page (and have influence on members outside of the "transgender community) and may build relationships that aid in advice and knowledge distribution. And as members that maintain the community as a lively place for discussion, the may hold more influence on members' constructions of knowledge claims. By publishing knowledge claims online, such lay-experts' subjective and anecdotal experiences can be transferred into valued knowledge (Orgad, 2005).

While less than half (37.2 per cent) of the community discussed their gender and/or sex status over the one week surveyed, the majority (79.4 per cent) made their status known through a combination of posts and their profiles, in which they have the option to write a short biography and list their interests. All frequent 
users made their statuses known either through posts or on their profiles. The majority of users were transsexuals at varying points in their transitions, with only seven users discussing their bigender or non-gender reality, none of whom posted more than a few times. Transmen were more prevalent in "Stransgender than transwomen, despite data that suggests transwomen outnumber transmen in Western cultures (for example, see Landén et al., 1996, which suggests a transwomen to transmen ratio of $3: 1$ across multiple countries), with possible exceptions being Serbia (Vujovic et al., 2009), where the ratio of transwomen to transmen is believed to be 1:1, and Poland (Herman-Jeglińska et al., 2002), where the ratio of transwomen to transmen is believed to be almost 1:3.

\section{“We Can Always Use More Trannies!”}

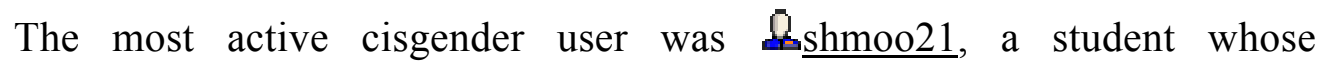
university's Gay-Straight Alliance (GSA), of which she was the vice president, was working on a stage production of The Rocky Horror Picture Show (LiveJournal, 2009o). Her concern was that the president and "pretty much everyone else involved in the show" uses the word tranny: "You can be a random tranny in the background.' 'We can always use more trannies!' She admits she assumed the word was offensive, but as someone who is not transgender she was not certain, and when she approached her GSA she wanted to be sure her rationale for doing so was correct. This polarised the transgender community for a number of reasons, including $\mathrm{Dhmoo} 21$ 's very request for confirmation, the discrimination inherent in the word tranny, and the controversial reclamation of the word.

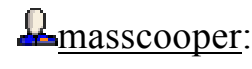

Asking for education about a community in that community's space is itself offensive. Some folks may be glad to take the time to deal with you, but it's no one's job to do and is not really what this 
Lmartin quin:

Lkaedeko:

2fall of sophia:

Stranspose: community is here for. ... Now, of course, you're likely to get a lot of feedback, and some of it will likely not be fun for you. Because yes, that is an awful word, particularly when used by cis people about trans people. But you knew that, right? If you had read back you would know that for many trans women and a not insignificant number of trans men, it's a word that is used to dehumanize and as a precursor to violence. It's not a fun word to have popping up on your friends page because someone can't be bothered to read (not very) old posts in the community they've come to asking to be educated.

When people ask questions like this, they often claim to be "just asking a question" and assert that they "can't learn if no one will tell [them]." When people get mad, justifiably, about posts in which a person such as yourself has come asking to be educated rather than doing some leg work, the $\mathrm{OP}^{6}$ gets upset that people are "being mean" and flounces off, unscathed but all upset about their feelings being hurt. Meanwhile, they've triggered others and stirred up a community that has plenty enough to deal with already, but are able to be totally oblivious to the harm they've caused because of their cis privilege.

"Tranny" is offensive. Very much so. Some people are reclaiming it, but even that is controversial. I for one would appreciate it if no one utters it at that event.

Tranny is a reclaimed word. Some people still hate it, but acceptance and usage within the transgender community has gone up exponentially in the last five years or so.

dubous, and irrelevant to a situation where cis people are using it.

If you're wanting to make your GSA a place that feels welcoming and safe to trans people, you should avoid using words that can be used to degrade them.

Even if nobody who shows up is bothered by the word, and everyone feels that it's been reclaimed, I strongly suggest you air [sic] on the side of morerespectful. Is using the word really worth having to try to explain to an upset newcomer that you "didn't mean it like that"?

\footnotetext{
${ }^{6}$ original poster, the user that begins a discussion in ${ }^{17}$ transgender
} 
Dparmonster:

Ddesiarcy:

Qdglenn:
It's at about the same level as "Faggot" $\mathrm{IMO}^{7}$. Partially reclaimed, but still loaded with negative connotations.

I don't use "Faggot" in conversation or in reference to gay men because I'm not one and it's not my place to reclaim that word. I expect "Tranny" to be similarly unappropriated by cis people who are in no position to be reclaiming a word that doesn't belong to them.

To clarify as neutrally as possible, the reclamation of the term "tranny" is bitterly controversial within the trans community because its derogatory use is almost invariably against trans women, whereas most of the people who say that it has been reclaimed are trans men. Many trans women feel that trans men have no right to reclaim "tranny".

Yah, basically this. Describing it as alreadyreclaimed is premature and glosses over an incommunity ongoing controversy. (ibid.)

Linguistic reclamation, also known as linguistic resignification, is the use of a pejorative word by its targets as an act of resistance to its injurious power. Reclaiming a word is controversial, but is widely accepted by reclaimers as a right to self-define, in spite of - and in opposition to - marginalising discourses that would seem to control the pejorative nature of a word (Brontsema, 2004). It is a Foucauldian reverse discourse that allows for the production of a new resistance and new discourses, for example queer's critique of homonormativity, to be developed. While the reclamation of the word tranny may itself be a result of the queer revolution, the still contested reclamation of the word queer may give some insight.

Queer's origin in the Middle High German twer simply denoted anything not "normal." By the 20th Century its use in a sexual connotation was used almost

\footnotetext{
${ }^{7}$ in my opinion
} 
exclusively to describe male homosexual practices. In terms of self-reference, historian George Chauncey (1994) complicates the notion of queer as referring to masculine homosexual men that considered themselves different from fairies, flamboyant and feminine homosexual men, before the Second World War. Further to this, the queer-fairy distinction was not only based on notions of masculinity/femininity, but also expressed through class as well: most selfidentified queers were middle class and could experience significant professional sanctions if they were flamboyant. Both queers and fairies, Chauncey explains, began to adopt the term gay in the 1920 s as a safe word to denote homosexual desire. Though originally adopted by fairies, queers eventually used gay as a code word for homosexuality, as it provided a knowing double meaning to homosexual men that could be safely used if one did not know another man's sexual preference. According to Brontsema, by the Second World War gay had become the preferred term by homosexual youth, with queer's traditional meaning of "abnormal" being seen as pejorative and a reference to deviance.

Queer experienced a rebirth in the early 1990s by youth who criticised gay and lesbian as limited - and limiting - identities and the use of (homo)sexuality as the foundation of these identities. The first instance of queer reclamation came from the political group Queer Nation, which formed in 1990. Queer Nation chose its name for its confrontational nature and its clear distancing from the essentialising and assimilationist natures of gay and lesbian, moving beyond the limits those terms place on the expression of both sexuality and gender and to include anything outside of the accepted range of "normal." Queer, then, is not simply a replacement for gay and lesbian, but a contestation of those terms that 
includes queer gays and lesbians, bisexuals, trans/bi/non-gender people, queer heterosexuals, fetishists, sadomasochists, etc. As one of the most widely used pejoratives used against "sexual deviants," queer was used by the Queer Nation to precisely highlight homophobia, a sociopolitical power play that attempts to separate the word from its violent past and render it neutral - or even positive.

However, critics argue that the word queer is inseparable from its history of abuse and should not be used because any use is a repetition of hate. To Brontsema, this view is largely adopted by older gays and lesbians, whose wounds are still fresh after a long history of the impact (both psychical and physical) of queer and therefore oppose its in-group use because those who identify as queer may have never had the word used against them. To these critics, linguistic ownership is permanent: linguistic reclamation is not the depletion of power, in some verbal revolution, but its careless repetition. For some queer theorists, it is this potentially inseparable quality that is precisely the need to reclaim queer; the word should be reclaimed by its targets and retain the stigma it holds. Instead of it being a homophobic statement of one's deviance, it is a badge of honour that questions the nature of what is deviant and what is normal. As a critique of "normal," queer necessarily needs to retain its stigma or it cannot confront the construction of "abnormal" and seek to position normalisation, instead of intolerance, as the site of violence against queer subjects.

Tragically, queer as a political contestation of gay and lesbian within ingroup political projects is largely misunderstood or ignored by the out-group. NonLGBT groups and the sexual mainstream often use the terms gay and lesbian and 
queer interchangeably, with the latter often seen as hip and fashionable. For example, queer's purposeful gender inclusiveness, Brontsema notes, is largely ignored by popular media:

Despite the claim that queer is gender-neutral, its use in popular television clearly associates it with male homosexuality. The television program Queer as Folk focuses primarily on the lives of gay men, and Queer Eye for the Straight Guy has five pairs of 'queer' eyes - all belonging to gay men. There is nothing necessarily queer about these gay men... (ibid.: 13)

Brontsema thus shows us that despite queer's reappropriation and the in-group attempts to resignify the word, linguistic ownership is much more difficult to claim: queer is owned by all who use it and mainstream media holds a greater influence than a minority within a minority. That the out-group claims a sort of reclamation of queer-as-chic is itself a problematic, which Jacinda Samuels (1999) blames on the queer's gender-neutrality because it is based on a universal liberal subject that is claimed to be devoid of gender, race, and class. To her, the very elaboration of a queer subject is a liberal project: to move freely in and out of a fluid subject position presumes the liberty of an autonomous subject and both liberty and autonomy are constitutive of liberalism.

Positioned rather precariously between the postmodern critique which spawned its creation, and the liberal strategies which it actively employs in an attempt to distinguish itself from its predecessors, the queer subject is subsequently constitutive not of a genuinely autonomous, anti-essentialist subject, but rather the unwitting reproduction of the very liberal humanist subject which it was originally intended to critique. (ibid.: 97)

Further, she argues that the politics of reclaiming the word queer is facilitated through liberal premises inherent in the liberal tradition of terms such as gay and lesbian.

Comparing the reclamation of queer to that of nigger/nigga amongst African-Americans, queer ownership can be claimed by the out-group because 
queer assumes a universal liberal subject that is genderless, colourless, and sovereign, while nigger, a term that's use also highly contested in-group amongst African-Americans, "always already signifies blackness" (ibid.: 102) and therefore does not model the liberal premises of equality, liberty, and autonomy; the reminder or race negates presumed equality. Queer, on the other hand, can refer to both men and women (and is therefore gender-neutral) and all races (and is therefore race-neutral). Thus, the liberal premises that underlie a queer subjectivity positions the queer subject as closer to the universal liberal subject than the racialised subject can be positioned. This, Samuels argues, is the reason racial pejoratives continue to be taboo in the cultural mainstream and why we should not expect a sort of Nigga Eye for the White Guy. However, Samuel ignores queer's mainstream history that "always already signifies" sexuality and instead invokes a universal liberal subject that clearly does not have sexual intercourse, heterosexual or otherwise. Because her notion of the universal liberal subject ignores its presumed heterosexuality, she does not position the queer subject as distant as the racialised subject.

Similarly, for acceptance within the transgender community and an out-group careless use similar to queer. Tranny received its mainstream use primarily through the ustilisation of the word in the sex industry as it fetishised and exoticised the transwoman's body, presenting transsexual women and male transvestites as both not really women and sexually hungry like men, a kind of pathological erotics. Further popularised through pornography, tranny also framed transwomen as 
sexual commodities. The word has particularly targeted transwomen, who remain the most opposed to its reclamation.

Qdglenn best describes the status of the word: describing it as already reclaimed, as other users had, is premature and ignores a far wider debate within the community, both online and offline. What was almost universally agreed upon by the community is that whether or not it is reclaimed or reclaimable, no one outside of the transgender community should use the word the way queer is used in the cultural mainstream.

What would the reclamation of tranny look like? Of course, it would celebrate the diversity of those who experience cisgender oppression, to denote a politics of gender difference, but so can the word transgender. Let us not forget transgender itself is queering of transsexual and is already a term that incorporates transsexuality and transvestism, so tranny would not emerge as a more inclusive term for trans subjectivities, especially as it may alienate, for example, intersexed subjectivities. Queer was mostly successful because it is gender-neutral, and therefore a gender-inclusive, pejorative; it would be difficult to imagine women feeling part of a Faggot Nation or men part of a Dyke Nation. But there are numerous queer alternatives to transgender: genderfucker, transgifted, and genderqueer, to name a few.

If tranny, or indeed any alternative to transgender, is to emerge as a generally accepted reclaimed word, it would be to expose the limits of transgender, to critique a normativity from which transgender suffers similar to the queer critiques of gay and lesbian as essentialist and assimilationist. It would be a 
project of unqueering transgender. The rest of this chapter deals directly with normative notions within the transgender community.

\section{A Space for Critical Queer Ontology? Discourse as Violence}

David Valentine (2003), a non-transgender man, discussed the problematic of what is ethical when studying a transgender community. He forwarded a draft of a paper he had submitted to Social Text to a transsexual friend who was beginning her transition. In the subsequently published article (Valentine and Wilchins, 1997: 218), Valentine describes a seminar gender activist Riki Wilchins held in which she invited people to inspect her clitoris and describing hirself $f^{8}$ as "just your average, straight white guy with a cunt who really digs lezzie chicks like me." The friend responded with the following email:

[...] I've been attacked by someone who calls themselves a male lesbian... If she defines the terms of the debate, then I want no part in the arguments. In that way, Riki's words, Riki's definitions rape me because they undermine the credibility of my take on myself and Wilchins has 'power over' me... And if Wilchins can rape me by having power over me, then Wilchins is indeed, very much a man. Assertions can be violent and debilitating in that they make one size fit all. (ibid.: 218)

Though his intentions of sending his friend a copy of his article were noble in gesture, the resulting critique demonstrates the ways in which research and the queer academy can commit an act of violence towards its subjects. This further complicates my own research when I am a non-transgendered man observing a community that, though publicly available, is unaware of its observation within my project. Yes, textual analysis is ethically safe and unobtrusive (Reinharz, 1992), but a recognition of my own privilege in studying an Other is important in feminist

\footnotetext{
${ }^{8} \mathrm{Hir}$, zir, hirself, and zirself are terms frequently used by gender nonconformists as they are gender neutral.
} 
debates, not to mention the fact that this project exposes "stransgender to the reader, who would have otherwise not been aware of its existence.

Queer theorising has raised several issues in regard to identity categories and challenging these categories, itself privileging theories of sexual and gender fluidity against essentialist, static identities. My own critical epistemology itself is informed by a sort of "upmarket" theories from expensive universities and the queer/feminist intelligentsia. I have had the opportunities to move from a gay-bypraxis to a theorising queer, exposed to critiques as a critical queer scholar that might seem to undermine the comfortable systems whose margins I wish to understand. While I recognise and am grateful for the political and social advancement of these oft-critiqued socially conservative gays, lesbians, and second wave feminists, it is easy - and perhaps important - to almost snide them of their limits as a critical queer feminist scholar, to give voice to the silent subalterns that gays and lesbians unwittingly create. This often puts me at odds with members of my community. But has - or even can - queer theories leave the academy and alter the public consciousness to create or reinvigorate a queer activism? And do nonacademic members of the LGBT community see themselves as queer in the ways that queer theorists describe?

Once again, referring to the use of tranny, is this following dialogue

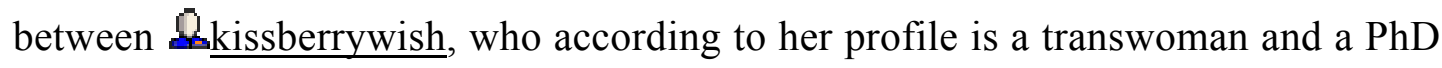
student that focuses on queer and gender theories, and $\mathbb{g}$ gymx, a gay transman. 
Dkissberrywish:

Dgymx:

Akissberrywish:

you'll find a lot of college aged trans $\mathrm{ppl}^{9} \mathrm{rly}^{10}$ dont find it offensive at all. so it depends, ask the trans ppl who are actually apart of your community and not ppl online who really don't interact on your campus and know what the vibe is there. $\mathrm{i}$ personally think its a dumb word but not rly offensive to my $\sim$ trans sensibilities $\sim$, $i$ just equate it to being a hot mess so dont rly wanna be called that $\mathrm{lol}^{11}$.

Where the fuck are you getting the data to make this conclusion?

$1 \mathrm{mao}^{12}$ right because there's actual data on this and everyone in this bitch isnt speaking from personal experience alone, pleeeease. it isn't a conclusion its an OBSERVATION.

idk $^{13}$ why ppl are acting all "omg hdu ${ }^{14}$ suggest such an inplausable thing" when yall KNOW there are tons of trans ppl bouncing around self id-ing as trannies (and no i dont mean only trans guys) and using that word all the time like its nothing. i find the hyperbole in here suggesting every and all trans ppl loathe this word and that its never appropriate kinda bullshit. actually, complete bullshit.

Dgymx:

I don't know this. I've never observed it. As far as I'm concerned it's a complete fabrication. So please, won't you provide something corroborate this observation of yours? Some statistics, say, showing that college-aged trans people self-refer as "tranny" significantly more than older trans people? If you make an outrageous claim like this, back it up or shut up.

By the way, could you explain to me how what words trans people use in self-reference have any bearing on what words cis people use to refer to trans people? $\mathrm{B} / \mathrm{c}^{15}$ really, your original comment was off-topic as well as inane.

Qkissberrywish: $\quad$ My data are friends and me and the dozens of trans ppl I hang out with and the more hundreds I associate with on a regular basis.

Because many don't give a fuck if cis people use it either. It isn't the trans equivalent to racist/sexist terminology. We really don't care.

\footnotetext{
${ }^{9}$ people

${ }^{10}$ really

${ }^{11}$ laugh out loud, a designation that something is humourous

12 laugh my ass off, a designation that something is humorous

${ }^{13}$ I don't know

${ }^{14}$ Oh my God, how dare you

${ }^{15}$ because
} 
My comment my have been inane by your standards but your comment is pretty ridiculous and unnecessarily hostile, grow the fuck up $\mathrm{plz}^{16}$.

Dgymx: The plural of anecdote is not data.

There's no other way to say this: you're stupefyingly ignorant.

Then leave the conversation to the people who do [care].

\section{Dkissberrywish: Great argument!}

Oh but I do care about this discussion. If the OP (not you, a trans man whose place it really isnt to tell me, a trans woman, to fuck off on this discussion) doesn't wish to hear my opinion then I'll bounce. (LiveJournal, 2009o)

Dkissberrywish's own anecdotal experience resonates with my own, insofar as sexuality is concerned. Undergraduates and postgraduates I have known who have taken Gender and Women's Studies courses and/or had other access to queer theories (for example, in English) tended to have a different view of the "queer radical" than did students studying, say, business or Japanese. Granted, these courses may have appealed to the interests of a more radical LGBT subject, but the academic pursuit of such theories did alter the understanding of some students' self-identities.

Political scientists Joe Rollins and H. N. Hirsch (2003: 291) ask, "Do academics and activists mean the same thing when they use the term queer?" Using the queer analogy again, does tranny have a more nuanced theoretical framework and meaning that the transgender mainstream might not catch? Surely the theoretical splits that queer theories recognise, for example, essentialism/social construction, assimilation/liberation, raise important questions about strategies of

\footnotetext{
${ }^{16}$ please
} 
political engagement. LGBT activism typically relies on an ontological reality that presumes a stable sexual identity that is individually and historically static, visibility, and that sexual minorities will gain acceptance through activism. However, its insistence on essentialism and focus on gay and lesbian politics has turned the "LGBTQ" community into the LG(BT)/Q dichotomy. Rollins and Hirsch also suggest that self-defined queers are likely to be outside of the LGBT mainstream and are expected "to be younger, less affluent, less conventional, and more radical in their politics" than their nonqueer LGBT counterparts (ibid.: 295). Given that queer theories have had their greatest peak in the 90s, scholars of such theories will likely to be ever younger, less conventional, and more radical in their politics as queer theories develop. While degree-earning, university-educated adults tend to be more affluent, a queer's politics may marginalise them professionally.

The intelligentsia/activism divide is nothing new for academics, especially those feminists and gay/lesbian scholars who helped to establish university departments of (Gender and) Women's Studies and Gay and Lesbian Studies. Geographer Nicholas Blomley says academic activists are faced with conflicting responsibilities and difficult questions.

These include personal questions of self-validation (who gives a damn about academic angst anyway?), institutional dilemmas (our status as highly paid professionals in a rapid proletarianizing world), and political or intellectual issues (what is our work supposed to do?). (Blomley, 1994: 383 , emphasis in original)

He suspects more activism is not pursued by academics because activism is not seen as intellectual and is external to their professional academic work, as well as a "postmodern humility [that] cautions against speaking for the Other" (ibid.: 384). 
Indeed, geographers Duncan Fuller and Rob Kitchin suggest that the shift to postmodernism and poststructuralism has created "a political field in which justice and rights become slippery and relative" and undermines "organised resistance as they destabilise the very categories (e.g. class gender, race, sexuality) around which mobilisation might occur" (Fuller and Kitchin, 2004: 3). They also suggest that the academy strategises to maintain its own authority as the university has made neoliberal shifts from learning institutions to knowledge businesses whose job market "breeds conformist and 'safe' research" (ibid.: 8).

Political scientists John Grundy and Miriam Smith suggest that there is discordance between queer scholarship and LGBT activism in that queer theoretical positions often compete with ontological politics of "real people" and the performative nature of LGBT social science "makes some queer realities real at the expense of others" (Grundy and Smith, 2007: 299), producing the social realities that are discovered. Academic language is also "steeped in technical vocabularies that require years of training to fully understand" (Duggan, 2006c: 167); philosophical debates on what is just gay/lesbian and what is allowed to be counted as queer (illustrated earlier with Brontsema stating there is nothing queer about the gay men on Queer Eye for the Straight Guy) complicates the ability of academics to engage with the ontological politics of activism.

Thus, Dkissberrywish's response can be read as not just as a transwoman who is more affected by the history of the term tranny than gymx as a transman, it can also be read as a radical and critical queer academic that is being held accountable for her politics and placement in a privileged space of theory whilst 
also being accountable to the transgender community, which may be conservative by comparison. Indeed, tranny does not make reference to her 'trans sensibilities' and therefore she is not likely to take offense by its use and is perhaps more bothered by the insistence by other community members that it is offensive and not be used since "yall KNOW there are tons of trans ppl bouncing around self id-ing as trannies (and no i dont mean only trans guys) and using that word all the time like its nothing." For her, limiting the ability to self-identify as a tranny especially if one is a transwoman - is an abuse of power by the larger transgender community, whose own 'trans sensibilities' would be offended by such an act. To this, gymx's reaction to what he considers an offensive word demonstrates the polarisation of the word's queer usage.

While the word tranny does not offend Dkissberrywish's sensibilities, she does, however, associate the word with being a "hot mess," and so she does not want to be called a tranny. This in itself is a value statement, ironically coming from a queer scholar that epistemologically would celebrate the proliferation of queer ontologies, even those that can - and probably will - be seen as sloppy or tragically hopeless. It implies that certain transgender performances are privileged at the expense of others, which suggests a normativity within gender transgression.

However, we should not assume the non-academic/academic or practical gay/theorising queer divide is devastated by Sullivan's notion of postmodern "apolitical politics," as Rollins and Hirsch note that those who identify as queer in their survey still supported the LGBT inclusion in institutions such as marriage and 
the military since their very participation in these institutions is itself a radical move. Geographer Don Mitchell also notes that

a commitment to radical scholarship requires making a commitment to something postmodernism simply cannot make a commitment to: truth. There are most certainly truths, as best we can know them at this time and in this place, and as conditioned as they may be by our limited ways of knowing and vantage points. And it is only by revealing these truths - of exploitation and oppression, or more accurately of systemic exploitation and oppression, of inequity and the unfair workings of power - and showing why they matter to people that a real commitment to radical, progressive, and revolutionary change can be made. This means making a commitment to real, live human beings, not to 'subjects', not just to 'bodies', not to radically decentred psyches, but to people, with thoughts and feelings, loves, needs, desires, and dreams, and (maybe) with jobs and mortgages and trouble meeting their monthly bills, staving off the sexual advances of a supervisor or coworker, or getting their child a decent education despite deeply racist, regressive schoolfunding systems. (Mitchell, 2004: 28, emphases in original)

For Mitchell, radical scholarship must identify inequalities, but must also be allowed to be strategically used to work with the truths that ontological politics require for mobilisation. Indeed, in the preface of the 1999 edition of Gender Trouble, Butler remarks that the mobilisation of identity for the purposes of politics remains problematic due to identity being an effect of power, but it is no reason not to "use, and be used by identity" (xxvii). In this sense, we can strategically accept a broader LGBTQ identity to position our politics because "some identities have been recuperable for political agency" (Hoad, 2007: 515). It is therefore important to understand the lived truths of transgender experiences.

\section{The Transsexual Patient}

The medical sciences carry a great weight in terms of people thinking about their bodies, identities, social practices, and mental health. This is especially the case for transsexuals, who must undergo gatekeeping psychological diagnoses before undergoing prescribed biomedical interventions to change the body, which typically begins with a cycle of hormones, followed by further diagnostic care, and, 
if chosen by the patient and accepted by medical professionals, sex reassignment surgery (SRS). This process allows biomedicine to treat the pathological and ensure a healthy outcome; in other words, sex reassignment can be a treatment for gender identity disorder, to ensure ambiguous bodies are less so.

Though the transperson has been theorised as an ideal queer subject, the transsexual problematises this notion of a fluid gender, as their own gender is thought of in essentialist terms. I argue that "wrong body" discourses produce transsexuals as their effects, mitigated by medical techniques to fix the body as appropriate to one of only two sexes. For example, neuroscientists Mikael Landén, Jan Wålinder, and Bengt Lundström (1996) found transsexuality to be exclusively neurobiological and therefore can be treated through biomedical interventions. This has reified a body/mind dichotomy in which the mind is wholly separate from the body. Rather than self-identifying as "a woman with a penis," wrong body discourses, dispersed through the hegemony of medicine, allow one to identify as "a woman in a man's body" and can subsequently be treated.

Intervention and bodily change therefore become necessary for transsexuals for their identity and mental health, part of the transsexual narrative whose terms of reference are informed by medicine. Dereme fraiche had been administering testosterone from illegal, unregulated sources for years prior to proper medical care. He did not condone this potentially dangerous approach, but it "was necessary for my sanity at the time" (LiveJournal, 2009h). 
In fact, many of the posts were users seeking advice about hormone replacement therapy (HRT). A number of users were pre-transition or at the start of their transitions and wanted information from people who experienced HRT firsthand. The wealth of knowledge regarding the biology of different hormone drugs was astounding and it was not surprising that many participants in the Human Rights Commission's To Be Who I Am: Report of the Inquiry into Discrimination Experienced by Transgender People found they knew more than their doctors. After meeting with hir endocrinologist, Ddidactic cudgel began a discussion on HRT (LiveJournal, 20091):

Ddidactic cudgel: During my feminization HRT, I would like to retain my sexual function, I would like to reduce the hormones I'm on to maintain a bigendered body (for lack of a better descriptor - it fits my Gender Identity, but I'm not sure it applies to physical bits as well) and I would like to be able to obtain and maintain erections.

I know most MTF-spectrum people are heading towards SRS, which is not my goal, but I was wondering if anyone has used Lupron for any significant time and/or has stoppped using it and what zir sexual function has been.

Dbaglieg:

Dauntysarah:
All the t-girls I know use spiro or androcur. Taking lurpon is unusual for adult trans people.

However, I have heard of lurpon being used to delay puberty in both FtM and MtF children.

I can talk about my experience on Zoladex, which is a GnRH agonist depo like Lupron. As I understand it, the effects of the two drugs are similar, but Lupron is a slightly older drug. Mileage will obviously vary, but the Zoladex did seem to have quite an atrophying effect on my penis. I could still get erection, up until the point I had SRS, but after a few months on Zolade they hurt.

Maintaining sexual/erectile function whilst feminising is something of a tightrope act, and while everyone's experiences will likely differ, it may be that you want to investigate not using an antiandrogen at all, and see how that goes. 
Ddidactic cudgel: This definitely sounds like something I want to avoid.

Later, Ddidactic cudgel began another discussion about hir visit to the endocrinologist (LiveJournal, 2009n).

Ddidactic cudgel:
I saw the endo today and it was not as smooth as I would have liked.

Her initial questions made it clear that she believed me to be on the standard TS SOC ${ }^{17}$ path, so I had to stop her to explain that I didn't want SRS and that I am not a transsexual. She was quite confused by the statement and I had to explain that I identify as both male and female at once. She became somewhat ... confrontational, I guess. I had a very difficult time explaining how I felt, because I was so thrown off by her somewhat antagonistic tone.

"Normally, this treatment is for someone who wishes to live full-time as a woman, for a period of a year or so and then have gender reassignment surgery."

"I know this," I said, "but that is not my goal. I simply want my body to match my brain. It feels incomplete to me."

"Perhaps your desire to express your femininity would be better served through cross-dressing or getting a push-up bra?"

I told her that I'd been cross-dressing since I was five and that it wasn't cutting it. "As I told my therapist, I'd rather be a feminine bigendered person who has to work at passing as male than a masculine bigendered person who has to work at passing as female."

She did order blood-work and told me to schedule another appointment in two weeks, but at the last minute, changed her mind and added a karyotype in addition to a CBC, liver enzyme panel, testosterone level and estradiol level she had already ordered and amended it to one month out. I went to the blood draw, scheduled the appointment for Sept. 25 th and left. I wonder if she thinks I have a genetic abnormality causing my bigendered identity. Seems dubious...

Dranka: I have no personal experience, but it doesn't really surprise me. Most people have a very binary view of gender, so the idea of someone wanting to be something other than fully male or fully female is perplexing to a lot of people.

${ }^{17}$ stream of consciousness 
Lbaglieg:

Lellyrouge:

Lmercurychaos:
Yeah, it's easier to get hormones if you let them think that you see yourself as a woman and intend to get surgery. A lot of them don't understand anything else.

I had a quite similar experience, although not that "far", because I told my endocrinologist that I wanted to "feminize my body" and he was like "uugh, but those treatment is not for people who want to be more feminine, it's for people who know they are women since they are 2 and want to go all the way"

And he went on explaining to me what transsexuality was, cause he knew better of course.

But I stepped back and said "yes, that's what I mean", even though it was a lie (I didn't define as woman and didn't want surgery).

My doctor who prescribes me $\mathrm{T}$ is amazing and $\mathrm{I}$ really like her, but I am still not going to tell her details about my identity (or my sex life, unless it's relevant), because she simply does not need to know those things - all she needs to know is that I've seen a therapist, who has cleared me to begin HRT, and I need that prescription now please. (ibid.)

Online communication with a lay-expert regarding treatment options has the potential to challenge traditional doctor-patient relations. Being able to post hir experience online and initiate discussion is one way that hir can challenge impersonal medical discourses. The cissexim of Ddidactic cudgel's endocrinologist reiterates Foucault's notion of biopower, the process through which dominant discourses of medico-transsexuality operate. After the gatekeeping process of seeking a psychological evaluation prior to bodily changes ("all she needs to know is that I've seen a therapist, who has cleared me to begin HRT..."), Ddidactic_cudgel now faces a new regulatory body: a medical professional that is confused by hir desire to be neither wholly male nor wholly female. Describing hir plans to be a third gender in a two-gender system, hir endocrinologist suggests cross-dressing may satisfy hir desire. The problem lies in 
the fact that the patient's planned outcome is that which is still "pathological": HRT (leading to presumed SRS) cannot "cure" hir of hir gender dysphoria and give hir the female body that neatly reifies the gender binary. In short, hir is encouraged to lie or mislead hir endocrinologist to believe hir is a more appropriate hormone-treatable patient, to fit into the endocrinologist's frame of reference.

Ddidactic_cudgel experiences a multipersonalisation quite unlike the depersonalisation that transsexuals feel and is part of the Gender Identity Disorder diagnosis. Disee_spots initiated a discussion of her feelings of depersonalisation, of feeling detached from and in the wrong body (LiveJournal, 2009k). Eleven users described similar feelings they encountered before they began their transitions and assured 2 isee spots that it is common for transsexuals.

Qvlmitchell:

\begin{abstract}
As with the others, yes this is how most of us have felt at one time or another, myself being a somewhat extreme example (schizo crap materialized here). Some of us knew that we were GID (or some approximation of the idea) and some didn't. This is a general symptom of dysphoria in general and not necessarily GENDER dysphoria. If you think you might need to talk to someone, you'll be best served going to a regular therapist who also does GID work at first to find out whether or not you need to look further into this. (ibid.)
\end{abstract}

Dvlmitchell's response exposes the essentialist, prediscursive nature of transsexuality. Widely believed to have a biological and universal basis, transsexuality begins to expose itself as an essentialist identity, supported by overwhelming (positivist) medical evidence, and that gender variance is legitimate and treatable. The transsexual will experience a sort of dysphoria, which can later be diagnosed and treated through various methods, which, as we have seen with 
Ddidactic cudgel's endocrinologist, can be quite biased and limiting. Again, the body/mind dichotomy is a recurring trend in discussions:

Dhaviomally: We are not changing our soul, just our bodies so they can align with our mind. (LiveJournal, 2009f)

Dkeiboy: I guess we've just come to realize that if it can be so wrong from the day we were born then it's not just a big thing, because in our eyes, we know who we are. (LiveJournal, 2009h)

Qhj1002: When the hell will people realize transgenderism is as biological as sexuality?! (LiveJournal, 2009q)

Dsyvilan: $\quad$ I can't tell them the reason we can't see eye to eye is my forbidden secret: My feminine personality. (LiveJournal, 2009u)

Qvlmitchell: $\quad$ I sincerely hope you are not limiting your options based on either financial or geographic notions. Both can be changed at the drop of a hat, should you be motivated enough to seek your happiness. (ibid.)

Again, we see the effects of wrong body discourses: a "feminine personality" trapped in a male body and the pursuit of happiness and fulfilment that comes with having a body congruent with the mind. What comes from this is a strategic politics based on a biological model, devoid of choice, and since transsexuals did not choose to be in their predicament, they should have access to taken-for-granted cisgender rights and privileges. As a result, transsexuals wish to be accepted for who they care and to get on with their lives.

\section{Don't Be a Hot Mess}

The act of "passing" allows the transitioned transsexual to do just that: to more or less carry on with his or her life. Passing is a concealment strategy because it allows the body to be read as the transsexual's preferred, lived gender and thus gains and sustains mainstream inclusion (Bell and Binnie, 2000). 
Ultimately, realness is the transsexual condition (Halberstam, 2001). Dkesnit is a first-year law student and his university sends out a weekly email about student organisations meetings. The morning of his post, he was sent an email about a meeting for gay, lesbian, bisexual, and transgender students at a local pizzeria as an informal meet and greet for new students.

Dkesnit:

I pass very well as male. My legal name is still my (female) birth name, but $\mathrm{I}$ am in the process of changing it and when I introduce myself, I use my chosen name. I identify as a straight man. I plan to live stealth as much as possible. (LiveJournal, 2009c)

He is undecided about going to the social, as he does not want to come out. Instead, he wishes to hide his trans status, which he could do successfully since he passes as male. However, he also notes it would be a good way of meeting someone who can point him in the direction of a trans friendly endocrinologist. He began the discussion on thansgender for advice.

Dereme fraiche: My partner is also a law student, and I can tell you by observing her experience that law school is a strange environment in terms of social interactions. There tends to be a lot of emphasis on public image because people tend to look at every social event as a potential professional networking opportunity. If it's a higher priority for you to make sure that your future colleagues and potential employers do not have that information about your history, I'd recommend seeking out trans community support outside of your law school.

Dmasscooper: $\quad$ I would not trust in members of an LGB(T) campus org to keep someone's trans status a private matter. Not only are their many gay and lesbian people likely not to understand why your trans status is a private matter, there's also the fact that law school can be very cut-throat, and if you are hoping to be stealth, you don't want to give this information to people who will be competing with you for jobs. (ibid.)

Though he passes well enough as male, Dcreme fraiche and confirm his fears that he could be eventually outed, by either his very attendance or 
because his profession is "cut-throat." Outed as a transsexual, he might lose some privileges gained through the successful passing as a cisgender male, subjecting him to hostile situations and violence.

For passing to be successful, the subject must not only perform their gender correctly, but their corporeality must be read as unambiguous, hence the desire for HRT, even when administered illegally and without a doctor's support. But to critics, passing reifies binary systems: the sexed body is either male or female and the lived gender is either masculine or feminine. In opposition, a public queer identity consists of an "active or wilful negation of passing" (Schlossberg, 2001: 3) and passing "threatens to call attention to the performative and contingent nature of all seemingly 'natural' or 'obvious' identities" (ibid.: 2). Passing is conservative by nature and reaffirms various social hierarchies because passing is a mimesis, the art of appropriating power by imitating it (for example, is it the intention or desire of transsexual subjects to undermine patriarchy and heteronormative notions of gender and sex or is their desire to just feel right in their own bodies?). On the other hand, queer politics seek to celebrate difference rather than having transgender sexual bodies pass into a comfortable invisibility.

The majority of passing, I would argue, can be described by communication theorist Charles E Morris III's (2005) notion of "passing by proxy," which is the acceptance of an open secret, a supposedly ignorant silence performed with a knowing wink. It is a practice undertaken by both the one who wishes the pass and the one(s) that will allow them to pass, despite the obvious: I came out, but we don't really talk about it, or, How could my mother not know I was gay! And 
silence itself is discursive, as "difference in a closet culture is a collusive, open secret. By this I mean more than varying degrees of knowledge that 'it' exists" (ibid.: 267). The silent feature of ignorance can therefore satisfy heteronormative expectations and erase any contestations even in the face of those very contestations, and "if only straights could keep their mouths shut, this artful silencing might be complete" (ibid.).

In one post, 且keiboy, a married FtM who is now transitioning, wrote, "I pretty much have realized that I'll never get surgery as long as I'm with [my husband] and I've come to accept that. We've talked about it off and on and come to the conclusion that this is just something that is one move at a time" (LiveJournal, 2009i). Prior to any surgery, his Mormon husband can feign ignorance as long as his wife, who he presumed was cisgender when they married, does not break this silence with, for example, his postoperative penis. Instead, Dkeiboy has accepted that surgery is not an option because this silence protects his husband's sensibilities; He can ignore his wife's queerness only up to a point. Another discussion was initiated by $\mathrm{g}$ glazedlife to ask if any MtF transsexuals that have not undergone SRS have any "wonderful stories of meeting a guy that was completely straight" and aware of the users' trans status (LiveJournal, 2009z). A few FtM weighed in on their experiences and the only MtF users at first were lesbian transwomen. Dfall of sophia offered her rationale for this as follows:

queer female sexuality isn't quite as prone to being "threatened" by attraction to/dating a trans woman as male heterosexuality most of the time. not to say that cis guys who are secure enough with themselves don't exist (they do), and that there aren't plenty of cis lesbians who will freak the fuck out and have an identity crisis (there are), but this is something general about how heterosexuality is constructed. (ibid.) 
According to Dfall_of sophia, women are generally more accepting of queer bodies, even though some women, such as a cis lesbian, would feel "threatened" by a transwoman, and this is primarily because of notions of male heterosexuality and heteromasculinity. This is not to suggest transwomen can never have a "wonderful story" with a straight cisgender man, as there are "cis guys who are secure enough

with themselves." \$parmonster added,

[No straight cisgender male lovers] pre-op, but I've dated (and slept with) a cis man after surgery and he really didn't blink an eye over where my genitals came from. I *think* he's the sort to have been able to work around pre-op bits, but I guess we'll never know. fwiw ${ }^{18}$, this guy is Dutch, and they tend to have...less prudish views of sex than American men.

Everyone else I've been involved with has been queer to one degree or another (trans, bi, and/or lesbian). (ibid.)

However, passing by proxy's will to ignorance is not complete. If body and performance are read as (too) incongruent, the transgender, whether transsexual or genderqueering, may be positioned within a site of violence, especially if it a threat to one's heteromasculinity. Indeed, Dfall of sophia may be on to something about how male homosexuality is structured since most transphobic violence is perpetrated by heterosexual cisgender men.

\section{Violence as Consciousness-Raising}

On 26 August 2009 at 2:33PM, police and ambulatory services responded to a report of an assault outside of 209 Q Street in Washington DC. They found two transwomen with multiple stab wounds. One, Tyli'a "Na Na Boo" Mack, was sent to Howard University Hospital and was pronounced dead at 3:02PM. (Hess, 2009) As of this writing, the police, who are exploring the possibility of this attack as a hate crime, are still investigating. 1 mindtheft notified the community that

\footnotetext{
${ }^{18}$ for what it's worth
} 
Transgender Health Empowerment, Inc was organising a candlelight vigil for the victim.

Qshrines:

Lgennee:

Lhj1002: i'm almost for sure going to be at the vigil, i'm not far at all from the 200 block of q. this is horrible in the MIDDLE OF THE DAMN DAY. ugh ugh ugh.

I read about it this morning. A horrible crime indeed. I can only imagine what the family is going through. I pray many will come $t$ the vigil in a show of support.

What the fuck is wrong with people. Daytime? That's downright chilling. (LiveJournal, 2009q)

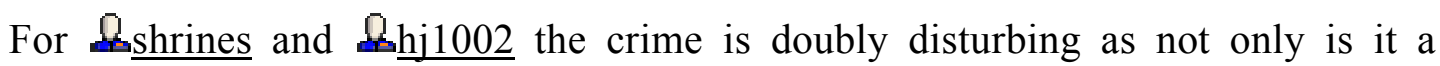
horrific example of violence against other transgender people, but that it happened boldly and in broad day light. This reiterates the violence that all transgendered people face when the body and performed gender are read as incongruence. This is easily illustrated by 2 sylvian: "I consider myself to be as feminized as I can without being endangered by transphobia" (LiveJournal, 2009u).

However, I do not wish to mistake violence as merely physical. Attempts to humiliate and out transgender individuals are just as devastating to one's psychical form as a knife is to one's physical form. Dhockeyraven posted a link to a blog from Weird Universe (2009) that was written about Caster Semenya, a champion South African runner whose "manliness" resulted in calls for her gender-testing (LiveJournal, 2009g). Hir noted that the blog's comments had taken a transphobic turn and hir wanted to express in the comments that the word tranny is offensive, but felt hir could not articulate the argument well enough. First the article from Weird Universe: 


\section{The Subtleties of Gender}

"Extremely complex" is how a world amateur athletics spokesman described gender verification testing (commenting on the suspicions raised about the champion South African runner Caster Semenya, who is, said her daddy, his "little girl," even though she appears to some like daddy's little boy). Complex? Hey, just pull her pants down, huh?. Or measure her androgen and estrogen levels? Or see if she's got a Y? Well .. no. For athletic-unfairness purposes, those things are indicators but aren't conclusive. Some genitalia are actually in conflict or inactive, and anyway, it's not the dick itself that improves female athletes' performance. It's the hormones, but men can still tilt high on estrogen and women tilt high on androgen. Even the chromosome thing doesn't always work out right. And the hormone deal, itself, gets you into a gray area because so much of superior performance emanates from the body one acquires at birth. World-class athletes are (and I use the term lovingly) freaks of nature, as are sexually-confused transgenders. [On the other hand, just because I'm sympathetic doesn't mean I'm necessarily for letting trannies decide, all to themselves, which restroom they're gonna pee in.] (ibid., italics in original)

It does not particularly seem as if any comments took a transphobic turn, as the transphobia began with the blog itself as the blogger "lovingly" refers to "sexuallyconfused transgenders" as freaks and trannies and does not want a tranny in his bathroom, not to mention the fact that this news is clearly considered weird enough to post on a blog called Weird Universe. The comments from readers are typical of what one would expect. Some community advice:

Dauntysarah: $\quad$ Sarah's first rule of "Trans stories on the Internet" never read the comments, they will most likely rob you of your will to live, and make you cry. :-(

The Semenya case made worldwide headlines, making something private (and, at most, a sport-wide issue) a global, public soap opera. Improvements in her running led the International Association of Athletics Foundation (IAAF) to test Semenya for both drugs and genetic sex. Feeling "humiliated" and "like a leper," she almost boycotted the medal ceremony and told the president of Athletic South Africa, "No one ever said I was not a girl but here I am not. I am not a boy! ...Why did you bring me here? You should have left me in my village at home" (BBC News, 2009). 
These were not the only reference to recent headlines in

There was a discussion on the transgender anarchist Ariel Attack, who was suspected in being involved in vandalising the Democratic Party's headquarters in Colorado (LiveJournal, 2009t). From the original article:

DENVER - The suspect arrested Tuesday morning on charges of smashing 11 windows at the state Democratic Party headquarters is a transgendered "Denver-based anarchist" who goes by the name "Ariel Attack," according to postings on numerous anarchist and radical gayrights websites. A fundraising plea circulated by the self-described "radical queer group" Denver Bash Back! seeks donations to raise the $\$ 5,000$ bail set for 24-year-old Maurice Schwenkler...

The postings asked "people to NOT call the jail and potentially out Ariel, which would create a very dangerous situation," noting that "Jail is a dangerous place for everyone, but especially trans people." (Colorado Independent, 2009, italics mine)

"Itransgender users showed both support for Ariel and a condemnation of her as a criminal. There was some discussion on the outing of her by the newspaper:

Dzanyassmask:

Dpandalicious:

Dshadowchild: well the bigger issue, $i$ think, is why this newspaper felt the need to out this person while simultaneously repeating the info that it could be dangerous to out them. i'm not sure why the person's trans status means anything to the outside world--it's a lazy reporter that justifies something's newsworthiness simply on the basis that 'other people are discussing it'

My dad mentioned something along these lines. Why was it important that she was a transwoman? It just reinforces the "need" to put someone's "real" gender on paper, as if to say, "Haha, you can't fool us." :!

Yeah, it was wondering the same thing. "Don't call the jail it could be dangerous for her - oh, btw, here have a pic and her full name!" Um.... (LiveJournal, 2009t).

The Colorado Independent shows reckless disregard to Ariel's safety as it posts her name immediately before noting calls to not out Ariel as jail can be dangerous 
especially for transpeople. While outing can obviously be dangerous for Ariel, the act of coming out and keeping the personal private is representative of assimilationist discourses and the LGBT community. Ariel would eventually have the felony charges against her lifted, ordered to pay a fine of US\$5,600, and be sentenced to a year of unsupervised probation.

The discussions on violence have the transformative potential of affecting users offline through its consciousness-raising power. The process known as consciousness-raising is meant to encourage social change as the product of "rethinking the relationship between social and political structure and human agency in other words, social change brought about through mass individual change" (Stanley, 1993: 44). Offline personal truth can coincide with an online shared imagination to prove an avenue for consciousness-raising and political action (Portelli 1998). While discussions are framed as individual experience, they mediate a sense of community, belonging, and commonality.

Communication scholar Tasha N. Dubriwny (2005: 397) explains that collective rhetoric "should have the scope to explain the ways in which new vocabularies take form" through the interaction of individuals. Interaction within "transgender can therefore be thought of as a collective rhetoric. If collective rhetoric can develop into collective persuasion, it has the potential to create a consciousness-raising paradigm. Dubriwny positions consciousness-raising as originating in second wave feminism when "consciousness-raising groups rejected the traditional concepts of the rhetorical process" (ibid.: 400) and demonstrated the necessity of legitimising individual and collective experiences as a political tool. 
Individual action thus creates a larger collective narrative. However, this experience of collective narration is not limited to news stories, of course, but includes the entirety of all individual narratives.

Consciousness-raising is effective because "each subject position holds a partial knowledge" (Montenegro, 2002: 512) and so a collective rhetoric is the coalescence of all subject knowledges to achieve what is believed to be a more total understanding of "the ideological conceptions concealing reality" (ibid.: 513). Through consciousness-raising and political action, transgender groups can engage the cultural mainstream and expose the ways in which taken for granted notions of gender (generally) and transgender (specifically) are understood and to confront the conditions of oppression that are produced through this taken-for-grantedness.

transgender provides a virtual space for transpeople to discuss trans issues, which partly explains Dmasscooper's reaction toward cisgender Dshmoo21's post about the word tranny. Further to this, the invisibility of trans issues in the cultural mainstream has framed transgender narratives as isolated and individual. Online interaction can facilitate publicity of issues that might otherwise remain peripheral. For example, Dimmortal_lights beginning a discussion on a call for narratives to support the Employment Non-Discrimination Act (LiveJournal, 2009e).

\section{Thinking Transnormativity}

Gay and lesbian historian Lisa Duggan coined the word homonormative to describe what she saw as the neoliberal shift towards a mainstream gay and lesbian 
centre critical of extremist views on the far Right and far Left that resulted in a new gay/lesbian paradigm informed by AIDS activism and militant queer nationalism (demonstrated by ACT UP and Queer Nation) in the 1980s:

\begin{abstract}
Alongside radical and progressive AIDS activism a new strain of gay moralism appeared - attacks on "promiscuity" and the "gay lifestyle" accompanied advocacy of monogamous marriage as a responsible diseaseprevention strategy. In this fertile ground, the coterie of writers attached to the [Independent Gay Forum] began to spread the word about their new gay politics - a politics that offers a dramatically shrunken public sphere and a narrow zone of "responsible" domestic privacy, in terms arguably more broadly antidemocratic and antiegalitatrian than the homophile movement at its most cautious and assimilationist. (Duggan, 2002: 182)
\end{abstract}

Piggybacking off the liberal and nationalist politics of equal "rights" for a "minority" and the end of discrimination, this new political shift used the familiar language within public discourse to negotiate a space between the conservative and religious Right and liberal centre-left politics. This homonormativity is a politics that does not condemn or seek to destabilise heternormativity as a now villainised queer Left advocates, but rather upholds most of its structures, privileging monogamy, private/domestic sexuality, gender normative performances, and patriotism, to name just a few. Certain articulations of homosexuality are rendered appropriate while others are framed as ridiculous and shameful: If homosexuality's far Left would just disappear, heterosexuals would see we normal gays really are just like them.

The discussion of Ariel Attack is also useful for representing several points in this chapter. She has written blogs for the radical Queers Against Obama (www.queersagainstobama.org, which frequently uses the word tranny with pride)

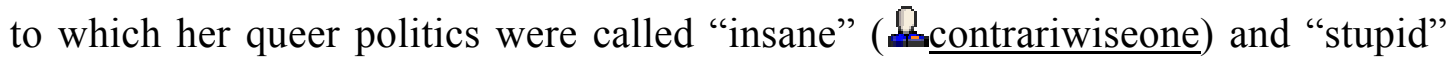
( 1 whisperkit), demonstrating the polarising nature radical queer politics and queer theorising can have on conservative transpeople; her genderqueering, 
nondetermination to pass, and anarchist politics becomes conflated with queer ridiculousness and extremist Left terrorism. And while she wants her body to be read as in between, this leaves her open to very real violence, especially when public discourses name hir as transgender. Morris' notion of passing by proxy, which he based on newspapers not explicitly referring to murderous lovers Richard Loeb and Nathan Leopold as homosexuals (though the public knew the sordid details) does not work for Ariel because her politics refuse to be silenced, to be kept a secret: her radical queerness is detailed in a growing tabloid culture.

In this chapter I sought to achieve a discussion on the normative nature of some articulations of transgender as produced in the way that the assimilationist agenda of some gays and lesbians expose the homonormative and value-laden hierarchy of queer citizenship. The discussion of essentialist identity, physical bodies, and conservativism in the privileging of certain articulations and practices, a normativity within the transgender identities: a transnormativity. This transnormativity is a conservative politics that creates new binaries for transpeople:

\begin{tabular}{r|l} 
passing & incongruent body and gender \\
stealth & obvious \\
respectability & looking like a "hot mess" \\
in the wrong body & genderplay with my body \\
trans status is biological & trans status is constructed \\
static gender & fluid gender \\
tranny is offensive & tranny has subversive potential
\end{tabular}

The desire to pass is not only an issue of the vulnerability of public readings of the body and gender, but a privileging that exposes gender nonconformists can threaten the transsexual passing project. And so certain articulations of transgender prefer to be stealth, to pass completely or by proxy, and live in the cisgender mainstream. 
Nonconformist transpeople, the hot messes of the trans world, pose a danger to the respectable transpeople who reify a dichotomous nature of both sex and gender and did not choose to "be born this way." 
BorRowed SPACE AND TRANSPHOBIC FEMINISM ON FEMINISTING.COM

Imagine that you've just met a new group of friends. At first, they seem nice and share a number of interests in common with you. Your friends decide to throw a party each month at one of their houses. They decorate the house, decide what food to serve, and choose the music. You politely ask if you might help out in some of these tasks and the response you get is, "Well... OK." Admittedly, their response is a little lukewarm, but you really like them, so you dismiss the response as a fluke and continue to hang out with them. After a few months, you begin to notice a pattern. Somehow, the house always manages to be decorated before you arrive to help. The food you bring always seems to be shoved to the back of the buffet table, behind other dishes, or worse: it gets put into the refrigerator without being served. Whenever you make a suggestion for the music, it gets ignored, or someone turns it off after people complain about how horrible it is. At one party, you accidentally overhear several of your friends laughing at how outlandish your tastes and interests are. After a while, you're feeling pretty hurt. You explain to your friends that you feel excluded. Some of your friends tell you that you're imagining things. A few others, responding in anger, inform you that you are a troublemaker and ask you to pipe down or leave. ... This is what it feels like to be a trans woman in many feminist spaces. -timberwraith, Feministing.com

If transgender subjects already hold a precarious relationship with the gay and lesbian machinery of social politics, their position within some feminist theories and praxes is no more comfortable. This may seem surprising given feminism's third wave, which embraces contradiction, multiplicities, and individuality. With its roots in women of colour insisting that "woman" is only one of their many (oppressed) identities, feminist scholar Jennifer Gilley suggested that "the third wave's insistence on the ability to embrace contradiction, and its refusal to fit into neat categories, makes it the perfect home for a new theory of transgenderism" since "postmodern feminist theory has deconstructed the category of "woman" to the point where it can barely be said to exist" (2005: 190). Further 
to this, she suggests that the experiences leading women, and men, to the third wave are different from - and because of - those that lead to the second wave:

First, both popular culture and personal experience gave young women the notion that contemporary feminism was unnecessary because equality had been achieved. They grew up knowing about feminism and benefiting from its gains... Many third-wave writers talk about how their feminist mothers or fathers gave them the sense of entitlement that made them feel feminist struggle might no longer be necessary...

A second predominant message of the time was that feminism had gone too far and, in fact, was to blame for the exhaustion of women trying to do double duty as career women and wives and mothers. Media stereotypes of the hairy-legged, bra-burning, anti-male, strident feminist permeated the culture. This led to the phenomenon of "I'm not a feminist, but..." syndrome, beginning in the late ' $80 \mathrm{~s}$, in which young women refused to identify themselves as "feminist" even though they agreed with feminist political views...

The third stone in the bedrock of third-wave feminism is that, contrary to being unnecessary or having gone too far, the movement had not gone far enough, limiting itself to the narrow interests of its white, liberal majority. (ibid.: 188)

The second is of particular note, as it reminds the reader that there exists a shame within feminist circles of those ridiculous archetypes not unlike the gay embarrassment of the queer leather/sadomasochist subcultures and promiscuous and/or effeminate gays. However, the third reason, that feminism had not gone far enough, suggests the continued potential for coalitional politics and the recognition and celebration of multiplicity, a politics that can and should include transmen and transwomen.

The Feministing website (www.feministing.com) was created in 2004 to give young feminists a presence on the internet and to discuss issues that affect their own lives and futures. According to their media and press kit, the website receives more online traffic than the websites for Ms, Bitch, and Bust magazines, the Feminist Majority Foundation, and NOW, presumably making it one of the most influential places on the World Wide Web for young and emerging feminists. 
Blogs can be published by users and can be collected under key words, such as Transgender Issues, War, and Television, amongst others. For example, one can click on Transgender Issues and access the archive of transgender-related posts and their responses, with each having multiple keywords themselves, based on the content of the blog entry.

On the website, user vexing published a blog entry called Feminists who attack trans women, offering her opinion on the position in which some womanborn feminists place transwomen.

However, I've come to the conclusion that this particular brand of feminist attacks trans women specifically because they are easy targets, emotionally and psychologically. They lack the gumption to attack cis males, so instead they focus their energy on trans women - as though we're some kind of magical 'back door' into the Patriarchal Complex.

Unfortunately, were not. We have been thoroughly disowned by the patriarchy, as something disgusting, false, vile and traitorous. Ask any garden gnome misogynist and he'll tell you that trans women deserve to be shot or drowned - and he'll do just that if one ever touches him.

But despite this, trans women are supporting the patriarchy, according to these radical feminists.

How? Well, but embracing a gender stereotype, of course. Everyone knows that all trans women embrace everything stereotypically 'girly' and 'femme' things which re-enforce gender conditioning and damage women and feminism as a whole. (Feministing.com, 2010)

The first thing one will notice is that the community blogs are less about seeking advice, as in the attitude of the site represented by its logo - the affectionately referred to "mudflap girl," giving the reader her middle finger (next page). In fact, the first blog read as part of this research used the kind of terminology and phrases that hold academic capital: performativity, normativity, misreading, and even a Judith Butler 
reference (Feministing.com, 2009e), potentially illustrating a Dugganian marriage of liberalismbased activism and critical theory.

Any Feministing user can post a blog and all users have access to comment upon

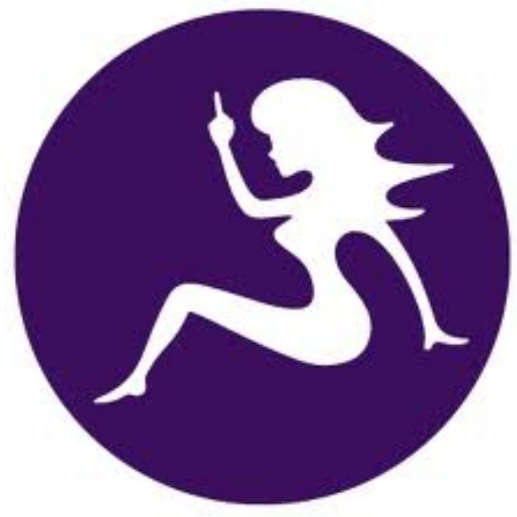
them. Unlike "transgender, one segregated community of thousands of communities

Image 2: Feministing.com's mudflap girl logo.

available on LiveJournal.com, Feministing's transgender-related posts are published as they come in, interspersed with non-transgender-related blogs; transgender posts may be sandwiched between unrelated posts and articles. This leaves Feministing's transgender community's blogs open to the audience of the entire site and thus gives a sense that transgender occupies a borrowed space on a feminist site. While there were only a few cisgender user comments in "transgender, the proportion of cisgender users commenting on Feministing's transgender-rated blogs is much higher. Thus the audience for vexing's criticism of transphobic feminists is not largely transgender, as it would be in " but cisgender, including those very transphobic feminists that she criticises. This chapter is concerned with how Feministing's transgender community negotiates a sense of community in "borrowed," and heavily-cisgender, virtual space on a feminist website.

\section{Transphobia and Feminism}

In 1979 Janice Raymond, in her text The Transsexual Empire: The Making of the She-Male, made the bold statement that "all transsexuals rape women's bodies by 
reducing the real female form to an artefact, appropriating this body for themselves" (1979: 104). Feminine transwomen were singled out for their celebration of femininity and "oppressive" beauty practices and their invasion of "women's spaces" (Green, 2006). Feminists that support the woman-born woman mandate often argue that transwomen have benefitted from patriarchy and male privilege before transitioning and that they have not felt of full experience of femaleness and female embodiment. The "particular brand of feminist" to which vexing refers sees transwomen as mocking femininity and perpetuating patriarchal female stereotypes, while transmen are often disowned for giving up on the fight and seeking patriarchal privilege instead. Controversial women-born women-only events and spaces, such as the Michigan Womyn's Music Festival and the Vancouver Rape Relief and Women's Shelter, have sparked transgender activism and arguments that womanborn woman policies are transphobic exercises in cisgender privilege.

In Beauty and Misogyny: Harmful Cultural Practices in the West radical feminist Sheila Jeffreys attempts to position transgender issues within the beauty practices of women. To her, the feminist project and transgender/queer project differ on "what is to be done with gender after the revolution," as radical feminists want to abolish gender while queer theorists "are all interested in milking the performance of gendered behaviour for its sadomasochistic excitements" (Jeffreys, 2005: 65-66). She suggests that genderqueer political projects are based on a simplistic reading of Judith Butler's work that regards performativity as merely performance, that gender play and cross-dressing is the revolution itself. Her knowledge claim on transpeople and queer theorists assumes all queer political projects rely on binary sex/gender and refuses to recognise the vastness of genderqueer projects that include, for example, 
gender duality and androgyny. Further to this, her theory of transgender is exclusively transvestic and absolutely fetishistic.

Behind the choice of femininity on the part of men lies in their fascination with playing the subordinate role of "woman" for the sexual satisfactions of masochism that this offers... Transvestism, transsexualism and transgenderism can be seen as being sexual practices rather than making those reared as "men" into "women." (ibid.: 49)

Transwomen thus support the patriarchy, as vexing's feminist enemies claim, through their insistence on abusing gender for its sexual worth and thus maintaining the oppression that results from binary gender. Throughout her discussion of transfemininity, Jeffreys continues to conflate all female transgender (transsexual, transvestite, and genderqueer) subjectivities and reduces them all to perverse fetishism. While there is rich psychiatric literature on transvestism and "pathologies" of fetishism, many transgender subjects are not likely to define their gender strictly through their sexual practices and its occasional few minutes of sexual pleasure (though Valentine's work suggests this is possible for some). One wonders how Jeffreys would define an asexual transwoman, as certainly that particular articulation of gender/sex/sexuality would exist.

Scholars like Raymond and Jeffreys treat femininity, whether innate or symbolic, as a commodity that belongs to female-bodiedness which can be traded for privilege. The idea that transmen can trade their femininity for male privilege, for example, ignores the very real conditions that transmen often face: loss of employment, family, and friends, violence, etc. Judith Butler argues that these feminists do not consider gender as historically constructed and the "attribution of femininity to female bodies... takes place within a normative framework in which the assignment of femininity to femaleness is one mechanism for the production of 
gender itself" $(2004,10)$. In other words, they are (re)constituting gender as they are abolishing it.

Activist, scholar, and transman Pat Califia suggests the problem of trans inclusion is much more problematic because it call into question the notion of "woman" and radical feminist politics.

Nothing upsets the underpinnings of feminist fundamentalism more than the existence of transsexuals. A being with male chromosomes, a female appearance, a feminist consciousness, and a lesbian identity explodes all of their assumptions about the villainy of men. And someone with female chromosomes who lives as a man strikes at the heart of the notion that all women are sisters, potential feminists, natural allies against the aforementioned villainy. (Califia, in Green, 2006)

Additionally, as third world women and women of colour have critiqued second wave feminism as to how some feminisms cannot work for them, transwomen, and to a less recognised degree transmen, are in a uncertain position of having to argue how feminism can work for them whilst still being feminism, a strategy of engaging feminism despite the transphobia of some feminisms. Again, we must keep in mind that at one historical moment lesbian feminism was excluded from some feminism, as well.

\section{Transfeminism}

Judith Butler suggests that the New Gender Politics that have emerged in the recent two decades is based on advances in transgender, transsexual, and intersex theorising and the complex relationships they each hold with queer and feminist theories. For her, there is no narrative to illustrate the epistemological shifts from feminism to queer theory, and on to trans theory because "none of these stories are the past; these stories are continuing to happen in simultaneous and overlapping ways as we tell them" (2004: 4). In The Transfeminist Manifesto, activist Emi 
Koyama describes a notion of transfeminism that she wants available to all people: feminists, queers, transpeople, and cis- allies. Transfeminism is not about "taking over existing feminisms," but extending feminism and coalition politics to transpeople, standing up for the oppression of all (types of) women and asking "nontrans women to stand up for trans women in return" (2001: 3). To this end, Koyama finds the question of male privilege crucial to transfeminism.

When confronted with such an argument, a natural initial response of trans women is to deny ever having any male privilege whatsoever in their lives. It is easy to see how they would come to believe that being born male was more of a burden than a privilege: many of them despised having male bodies and being treated as boys as they grew up...

However, as transfeminists, we must resist such a simplistic reaction. While it is true that male privilege affects some men far more than others, it is hard to imagine that trans women born as males never benefited from it. Most trans women have "passed" as men (albeit as "sissy" ones) at least some point in their lives, and were thus given preferable treatments in education and employment, for example, whether or not they enjoyed being perceived as men...

What is happening here is that we often confuse the oppression we have experienced for being gender-deviant with the absence of the male privilege. Instead of claiming that we have never benefited from male supremacy, we need to assert that our experiences represent a dynamic interaction between male privilege and the disadvantage of being trans. (ibid.: 5)

Thus, male privilege must be recognised to establish coalition politics for transfeminists. The accusation should not be met with denial, but rather seen as a new space of theorising, just as white feminists have had to address their own privilege. And like feminists, transfeminists must address the oppressions of body issues, violence, and medicine. This could be one way of opening discussion and possibilities with anti-trans feminists.

Koyama also recognises that the ontological separateness of sexuality and gender is socially constructed and historically specific and that the distinction between the two is "artificially drawn as a matter of convenience" and transfeminists 
must resist any essentialising notions within wrong body discourses (ibid.: 6). To be in the wrong body privileges ontologies of sexual difference that can be used against all women, as it reifies sexual difference.

\section{Engage and Enrage}

Occupying space on a feminist site means confronting feminisms that may actively exclude transpeople, as well as (re)shaping those feminisms that are ignorant of or unconcerned with transgender concerns. In this way, Koyama's project of transfeminism may be developed and deployed. Given "transgender's relative hiddenness on LiveJournal, as well as its demographics, one might question if it actually engages the public; perhaps, despite a few already invested cisgender members, it is a digital closet. This would not be the case on Feministing, which is overwhelmingly cisgender. What is more, the internet allows for "a more systematic form of self-selection" that allows users to avoid certain issues (Nah et al., 2006: 233). Those engaged or enraged by the issues in the Transgender Issues section of Feministing elect to read and comment on the blogs.

Nettle Syrup published Transwoman to be transferred to women's prison to notify members of a case in the United Kingdom where a transwoman in prison was being transferred to a women's prison (2009a). Activism for transgender rights in prison has a long history with the LGBT coalition, including continued activism from American Civil Liberties Union's (ACLU) National Prison Project, Transgender Law and Policy Institute, Transgender Law Center, and the Transgender, Gender Variant and Intersex (TGI) Justice Project, amongst others. The main concerns for transgendered inmates include safety and health. Whilst recognising the arguments 
against medical models of transsexuality, Law scholar Alvin Lee suggests that "when trying to secure trans-specific health care for inmates, trans advocates are specifically requesting medical care" (2008: 468, emphasis in original). Furthermore, "demedicalization of gender identity would have disruptive short-term consequences for these ethical obligations" in inmates. (ibid., 470).

Most disturbing is the legacy of transgender prison rape that has long been ignored. In 2002, Kelly McAllister, a pre-operative transsexual who lived as a woman for several years, was placed in a cell with a male that violently raped her. In her case against Sacramento County, California she claimed the sheriff was aware of her transgender status but still placed her in the cell. This longstanding practice of placing prisoners in prison based on their genitalia has resulted in many rapes and deaths and in cases involving transsexual people, the court determines whether the person is a genuine transsexual, which is made even more difficult since "many transsexual people spend a significant period of time in transition" and may not fit neatly into limited categories at the time of trial (Peek, 2004: 1217). The first federal recognition of transgender prison rights in the United States was in 2001, though most federal prisons do not have a formal policy (ibid.). Transwomen or effeminate men in men's prisons can only choose "to act submissive or be beaten into submission" within rigid sociosexual prison hierarchies (ibid.: 1229).

The case mentioned in Nettle Syrup's blog involved a transwoman convicted of manslaughter and attempted rape. Having spent most of her incarceration in a vulnerable inmates wing of a men's prison, she was now being moved to a female prison. The prisoner in question had begun transitioning prior to his arrest and had 
breast implants whilst in prison. This victory for human rights was quickly countered with:

SomeCommenter: This is taking 'human rights' too far... This is sickening.

I don't think the guy should have been moved. If he is really trans he's waited however long, he can wait until he is released to get treatment, but I just don't think he is.

What about the women prisoner's rights? (2009a)

The obvious note is SomeCommenter's comment demonstrates that transwomen are still - and possibly will always be - men. Moreover, her increased risk for rape, murder, and other victimisation in a men's prison is left unacknowledged. How dare "his" human rights be considered, despite that fact that woman-born women that attack other women are placed in women's prisons.

One blog opened discussion of an article in Seventeen, a magazine marketed to teenaged females, called "My Boyfriend Turned out to Be a Girl." It involved a young woman who met and fell in love with a man, with whom she was not intimate as he wanted to take things slow. Her boyfriend left for university, met another girl, and returned to the protagonist's house to pick up his belongings. In the ensuing argument, the police was called and the officers outed her boyfriend as "really a woman." The discussion led to the notions around the disclosure of trans status and intimacy, with some cisgender users claiming it is essentially rape to not disclose one's trans status.

KBZ: $\quad$ Obtaining consent under false pretenses is not consent. If someone consents with the understanding that they are consenting to sex with a ciswoman, and their significant other is hiding their transgendered status ... that isn't consent.

You simply do not have the right to withhold information that would be fundamental to your partner's decision as to whether to consent to sex. Fundamentally, my argument is as follows ... 
ElanaFulana:

If I don't know, I can't consent. If I can't consent, you can't have sex with me. Thus, if I don't know ... you can't (ethically) have sex with me. It is as simple as that.

I don't have a right to know anything about you, and you don't have the right to have sex with me until I can give informed consent. If you don't want to tell me ... that's your business. You must choose between telling me and having sex with me, or not telling me and not having sex with me. The choice remains yours as to whether to come out or not.

ElanaFulana:
It is never the job of a transgender person to cater to
their partners transphobia.
Lets take you're argument to its logical conclusion,
shall we?
If I don't want to have sex with blonds, and a blond
with dyed hair has sex with me, by your argument
they've raped me.
If I don't want to have sex with anyone who has had
surgery, and someone who had surgery to correct a
facial deformity has sex with me, by your argument
they've raped me...
It's not rape, I'm not entitled to know that
information, and my prejudice is not their
responsibility.
The idea that you need to know private information
about a person such as their race, medical history, or
transgender status, in order to consent to sex with
them, is a product of your prejudice and bigotry.
That's your problem, not theirs.
No one has the obligation to cater to your prejudice.
KBZ- you're transphobic comments indicate that
you just don't get it.
Personally I'm bisexual, so I don't really get the
hang ups some people have about having sex with
someone with the wrong shape body. It's the person
that matters, surely?
Your heterophobic/homophobic comment shows
you just don't get it. Heterosexuality and
homosexuality are not "hang-ups"... they are sexual
orientations and they are just as valid as your
bisexual orientation. The gender of a sexual partner
does matter to some people. Heterosexuals and
homosexuals have the right to their sexual identities,
and they have the right not to have those identities
exploited by a transgendered individual that is not
being forthright. (Feministing.com, 2009g)
KBZ:

The arguments about sexual orientation, illustrated by KBZ, was echoed by other cisgender community members, that heterosexual women deserve to know if the 
penis of their seemingly male partner is "genuine" or constructed. Other members attempted to remind them that post-operative males are physically male and postoperative females are physically female; the problem lies in the insistence that postoperative transpeople are still their initial biological sex. This argument was probably best countered by Sarah B:

Sarah B: $\quad$ The argument in this thread which keeps recurring despite its obvious transphobia seems to be basically that "no trans people allowed" is a sexual orientation. No. Sorry. Stop for a second and think about that one. (2009j)

For KBZ, a postoperative male needs to inform her that he was once a female, or he has raped her because he is a woman that coerced her into an act that she, presumably, would not perform with a woman.

Feeling the magazine blog entry had been hijacked by the issues/accusations of rape, ElanaFulana began a new blog criticising the claims of transpeople having to come out before intimacy, called Coming out as Transgender to Romantic Partners (2009h). In it she states

ElanaFulana: When a trans man transitions he isn't being deceptive - just the opposite. He is being himself, despite everything he was socialized to believe about who he is.

If he uses medical interventions, it's not to deceive people, or even to "become" a man. He's always been a man. The purpose is to bring his body into congruence with who he really is. It's his unmodified body that had been the deception (ibid.).

The debate continued:

Icy Bear: $\quad$ I am all for informed consent, but I think people describing this as an issue of informed consent is rather ridiculous, because generally people have no right or reason to assume a person's anatomy based on their gender. If we have a tendency to assume that all women have vaginas and all men have penises, it's our duty to STOP ASSUMING THAT, 
not our partner's obligation to tell us if they don't happen to fit into our assumptions.

xoros:

You want trans people to be upfront? In an ideal world everyone ought to be. In an ideal world people would / know/ the gender binary and its concepts of sex and gender are rubbish. But it isn't ideal. And that is not our fault and neither is the onus on us to personally educate everyone all the time. So people wait until a few dates in, maybe a few months even to mention it, then you have issues of fear of rejection, fear of being called a liar, all of the things you all have been discussing. And yes, people have made some valid points. But those points take no account of the trans person in your scenarios as a feeling, fearing emotional being who is way, way more likely to be rejected and even physically hurt /just for being trans/. Do you really wonder why trans people don't want to own up on the first date? The second, third? Anyway why should we? Oh yes, otherwise we are lying...

So here we get to the meat of it. Liars. Am I lying when I pass as cis? Or only when someone else thinks I am cis and wants to fuck me? I haven't told them I am cis, they have assumed it. I haven't told them if it is ok to be attracted to me, they have assumed it. Why is that the trans person's fault? We have not created the assumption.

ffyona: I think an issue like this - until we learn, as a group, to change how we view gender - is going to be a minefield of privilege and mis-understanding. I appreciate you taking the time to explain a trans perspective.

[Your comment on assumption] needs to be read over and over again. How the assumption is dealt with is going to be different for every couple, but acknowledging that the assumption is a result of a cis, heteronormative binary rather than a deception on the trans person's part is crucially important. (ibid.)

Claiming a space on a website or in an online community that does not deal with exclusively transgender issues leaves these community members vulnerable of transphobia. One cisgender member, April, even argued that trans users "demand that cis people figure out [the term cis-] on their own" (2009j, emphasis in original). When confronting feminists, who by nature would intimately aware of oppression and oppressive structures that are often taken for granted, is this difficult, how does 
one even consider confronting the mainstream? Those enraged by transgenderrelated blogs have a history of making their prejudices known and this much is evident in comments in various threads:

xoros:

timberwraith:

gudbuytjane:
Feministing is not very transfriendly unfortunately. Many trans people are still boycotting it. I myself refrain from commenting unless I really, really feel moved to. (2009h)

As a trans person who has read this blog for years, I'll second what xoros said. Feministing is generally unfriendly territory for trans folks. The main posts are usually thoughtful and well written, but the comment threads are often disastrous. (ibid.)

I think the only things I am going to ask potential hookups from now on is:

1. Are you cis*?

2. Are you a regular reader of Feministing?

Cuz, really, the violence in the words folks have for trans women here are as good an indicator as any that they're a potential threat. (20091)

\section{Educating Feminists?}

The ability to engage in debate with a larger community means that real change can happen. In addition to ffyona, SociologicalMe, another cisgender user, added,

SociologicalMe: That made plenty of sense, and was all very well said. Thank you for your perspective. I can't imagine how frustrating it must be to have one's own truth be called a lie, and of course if that's what going on the "you're a liar" meme would be a hardcore trigger for trans people. I'm gonna go contemplate what equal responsibility for disclosure would look like if we actually had it in society. (2009h)

They were not alone:

Gular:

I think that this topic has challenged a lot of unexamined privilege of my own and it's really been an eye opener. I have a lot of work to do because theoretical me is like "the cis person just needs to 
accept!" but the realistic part of me is "the trans person may be a big help in this". (2009k)

However, requests for information were criticised as privilege.

xoros:

There are places and times to ask questions about wider or more basic info. It isn't in the middle of a discussion about a specific topic. What happens is that people /constantly/ require us as minority to start over with the basics /every single time/. We never get to move on to discuss the details, the consequences, the issues of our lives and the problems we face - and how people can be good allies. And instead of talking about the issues we end up having a discussion about this very thing. It's derailling.

You insisting that you have a right to have the basic information served up to you on a plate, on demand, by a minority is imposing your privilege. The privilege of not needing to know these things. Of not having your life negatively affected by these things. It is not our responsibility to educate you about trans 101 things in the middle of a thread that does not have that as its purpose. (ibid.)

It is true that in most blog entries, cisgender users would often request additional information and recognised their own ignorance on trans issues. The frustration this caused for some users is demonstrated above, not unlike some of "transgender's users. In fact, the original discussion in Transphobia in Seventeen... Wait Not So Much (Feministing.com, 2009g) was derailed by accusations of transpeople deceiving partners, which led to ElanaFulana posting the new blog Coming Out as Transgender to Romantic Partners (Feministing.com, 2009h) five days later to focus on where discussions from the previous blog led to, which led to ElanaFulana posting the new blog Having Sex While Stealth is Not Assault (Feministing.com, 2009j) five days after that, to silver_unicorn resteering discussion to Being Transgender is Dishonest (Feministing.com, 2009k) three days after that. KBZ, the cisgender female that insisted indisclosure of trans status is rape remarked,

KBZ: $\quad$ The never ending debate continues with thread \#4 (I think... maybe its 5). Holy moly. My position remains unchanged, but I've grown tired of the 
alixiana:

rootedwillow: back-and forth. It seems to have devolved into accusatory bickering at this point. Agree to disagree, I suppose. Live and let live.

If you've grown tired of it, I imagine it's because you have the luxury to do so.

It's not the responsibility of EVERY person in a minority group to educate the majority but how do you expect change from the majority if you refuse to inform them? In fact how you expect the majority to be interested enough to go get educated about these issues if they don't see/hear/experience these issues.

There are a lot of people on this site who take an elitist attitude about "what you should already know" about feminism, LGBTQQIA issues and so forth. If you were never exposed to those issues how the hell are you supposed to know about them? And if only "those who are informed" are supposed to hang out on this site then it's just preaching to the choir...that wont change anything.

Then there is no point in activism.

Activism is demanding rights and actions based on the experiences that set you apart from the majority. Activism is an extension of the day-today, but I don't believe that I, as a gay man, should have to tell you about the entirety of my experiences as a gay man just because you want to know.

I can certainly demand protections and be an activist for that, but it doesn't obligate me to educate you about everything it means to be gay in my experience.

What you need to know from activism is the exact information you're being told. From there you can inquire as to the need for action and inquire, but to ask or demand people to educate you about themselves isn't the core of activism.

That is not to say the presence of transgender concerns on Feministing does not facilitate education on trans issues and concerns. Various posts had comments of cisgender people acknowledging their own lack of knowledge and how appreciative they were to learn about their own oppressive structures:

Gular: I think that this topic has challenged a lot of unexamined privilege of my own and it's really been an eye opener. I have a lot of work to do because theoretical me is like "the cis person just 
needs to accept!" but the realistic part of me is "the trans person may be a big help in this". (2009k)

dirty democrat:

Thank you for this post. I'm embarrassed to say that even as a long-time feminist activist, gay rights supporter, and all-around progressive, I myself only even learned what the term "cisgender" MEANT a year ago. I and others in the cisgender group of people have a lot to learn about transgender folks and issues, and I appreciated this opportunity to learn. (ibid.)

b:

Thank you very much for posting this. I think it's really important to speak up about these issues in a forum that fosters debate and highlights the issue rather than simply replying to a transphobic comment. You are incredibly articulate and insightful and I appreciate all the work you are doing in exposing intolerance within the feminist community. (20091)

saresailis:

Thank you.

I didn't realize that I had some transphobia to unpack, and reading your piece has helped me take a step in the right direction to being a better ally and better person.

Please keep writing, educating, and working to make this a better community. (ibid.)

\section{The Other's Other?}

Violent transphobia and being read as trans, Butler contends in Undoing Gender, must be understood as a response to correct any deviance and re-establish a dichotomous gender structure. What remained missing was how these structures impact intersexed people, whose existence was noted only three times and in passing comments (2009f, 2009h, 2009m). Intersexuality, being born with both male and female internal organs and/or external genitalia, also destabilises the notion of woman-born woman - and man-born man, for that matter - by illustrating a sexual binary is not entirely natural and stable. However while intersex and transsexual subjects are occasionally classified together under the rubric of transgender, there has been some debate as to how related they are, if at all. 
The argument for classifying transsexualism as a kind of intersex condition is evidence that at birth an individual's sexual identity is fixed in the brain. In other words at birth the individual's brain and genitals are not congruent and this is as much an intersex condition as a person whose gonads and genitals are not congruent. (Chau and Herring, 2002: 333).

On the surface, it would seem to make sense that those assigned the wrong gender and those in the wrong body would make for obvious bedfellows. However, while transsexuality is often based on wrong body discourses, much contemporary intersex theory and activism questions the classification of a body into only two distinct categories, something that is often the project of normative transsexuality. Intersex theories would criticise transsexuals for reifying a binary sexual system. Thus the sociopolitical agendas of transsexuals and intersexed individuals may compete, further marginalising them each from the heterosexual and gay/lesbian mainstreams. Opinions in medical interventions divide transsexuality and intersexuality: the former advocating for corrective, elective procedures, the latter rejecting the imposition of such procedures. So it is not surprising to see the following sarcastic comment because the ontologies of transgender and intersex are so separate:

Borea: I REALLY like how this article basically ignores Intersex people. Nope! They don't exist! (2009m)

Intersexuality demonstrates what intersexed cultural theorist Iain Morland (2001: 528) calls "an excess of sexual difference - perhaps a vagina and penis rather than a lack of differentiation," with medical management programmes designed to "create sexual difference out of intersexed flesh" (ibid.: 529). Medical models demonstrate four types of somatic sexual difference: genetic sex, gonadic sex, brain sex, and genital sex. Genitals, to Morland, are the most problematic to medicine because misdeveloped intersex cells threaten a binary sexual difference, a bodyscape that may not match the body's true sex. Further to this, gonadic sex is almost as problematic, as a child could be born with a mixture of gonadic tissue 
(ovotestes) or one ovary and one testis. Genetic sexing is not an exact science, either, as a child could be XY (a normal male), XX (a normal female), or a number of genetic "abnormalities" (for example, XXY, XYY, XXX, and XO karyotypes, cellular mosaics such as 45XO/46XY, and gene translocations on non-sex chromosomes).

Despite this, medical discourse reifies sexual difference through its own terminology, an effect not dissimilar to medical discourses of transsexuality. The majority of intersexuals are classified as pseudohermaphrodites, as they may display ambiguous or dual genitalia, but their gonads suggest what was meant to be a wholly male or wholly female body. These intersexuals are described as male pseudohermaphrodites or female pseudohermaphrodites, suggesting that their confusing bodyscape is simply masking a real, true sex and the language of pseudohermaphroditism means that "intersexuality remains only a pseudo-threat to maleness and femaleness," as it names and neutralises the threat of inbetweeness (ibid.: 536).

Medical discourse and intervention seeks to, in Butlerian language, reiterate sexual difference in intersex newborns; through assignment and surgical "correction," sex is produced through a discursive repetition of sexual difference that is taken to be natural and dichotomous. Intersexed bodies demonstrate that sexual difference is not static, but needs to be (re)produced. This begs the question, Are some women-born women born truly women themselves? At what point should women with a large clitoris or who have had some dead, excess testicular tissue removed after birth be excluded? 
In a joint article, biochemist P-L Chau and medical law scholar Jonathan Herring (2002) briefly discuss the history of intersexuality. They describe that during the Renaissance and Middle Ages an intersexed person was allowed to choose their sex upon entering adulthood, but once made their decision could not be reversed. By the beginning of the $20^{\text {th }}$ Century, medical technology and knowledge had advanced far enough that doctors were left to examine the individual and determine the true sex of the patient. This later shifted to the doctor determining the best sex of the patient, a medical approach largely influenced by psychologist John Money, whose claim was based on one case study of one patient, "Joan/John," that was not even intersexed at all.

"John" had been born a male, but his penis was severed during what was supposed to be a routine circumcision. Money advised the parents to raise the boy as a girl and further surgery was performed to further feminise "John" into "Joan." The girl, Money argued, would successfully live as a woman as long as she had been raised as a female and is not informed of her history because gender identity is a product of socialisation, though she would need hormone replacement therapy and follow up care. Though the case did not involve an actual intersexed child, Money used the case study as a recommendation for how to treat intersexed children. Sex assignment surgery should be performed as quickly after birth as possible and, when possible, parents should not be told of their child's intersex condition so as to raise the child appropriate to its assigned gender. Instead, surgery should be described to parents as "completing" unfinished organ development. 
Despite Money's assurance in writings that "Joan" was a happy, feminine girl she never truly identified as a girl and suffered depression. Clinically depressed at fourteen years of age, her parents confided in her regarding her birth, failed circumcision, and subsequent sex reassignment and she decided to live as male. Money never published anything to indicate the experiment ultimately failed.

In 1997, David “Joan/John” Reimer published his story. Between “Joan's” outing, research on intersexed people that did not have surgery, and research into intersexed people's complaints regarding their own surgeries, Chau and Herring note that doctors in the UK are increasingly taking a "wait and see" approach to treatment.

John/Joan was used for framing various debates about the social construction of gender, especially as it pertains to intersexuality and transsexuality - is gender learned? Is it biological? Can relearning be successful? However, I wish to remind the reader that David was neither intersexed nor transsexual.

The medical criterion of sex assignment was based on genital size, a sort of "too small now, too small later" approach: a penis was feminised if smaller than $2 \mathrm{~cm}$ at birth, as too small a penis - or too large a clitoris - would affect a person's self esteem in heterosexual practices later in life. The emphasis, Chau and Herring argue, was not based on fertility or future sexual satisfaction. For example, Cheryl Chase, founder of the Intersex Society of North America, notes

From my birth until the surgery, while I was Charlie, my parents and doctors considered my penis to be monstrously small, as well as lacking a urethra... Then, once the intersex specialist physicians had announced that my "true sex" was female, my clitoris was suddenly monstrously large, all without changing size. (as quoted in Morland, 2001: 539) 
Cheryl's resulting clitorodectomy to reassign her body to its "true" form with a more aesthetic clitoris left her incapable of orgasm (ibid.). In support of Chase, Riki Wilchins described Chase and her ordeal to a women's organisation:

To help board members of the women's organization to understand, I showed them how to make a diagnosis. Holding up a thumb and forefinger about a quarter inch apart, I said, "female." Moving them about threeeighths of an inch apart, I said "intersex." I repeated the finger movement from "female" to "intersexed" over and over until heads began to nod.

Since many intersex infants are "really" women, this made [intersex genital mutilation] a women's issue. (Wichins, 2004: 80)

Further to this, Wichins describes intersex genital mutilation (IGM) to gay and lesbian groups:

Some doctors perform IGM out of an antique fear that girls with large clits (which no man likes) will repel potential husbands (which every woman needs), interfere with penetration (which every woman enjoys), and increase their chance of growing up to be masculinized lesbian women (which practically no woman wants to be). IGM was no longer an intersex issue or even a women's issue; it had become a gay issue. (ibid.: 81)

After bringing IGM to transgender groups, who also bargained that IGM is a transgender issue, Wilchins laments about the lack of political activism from IGM's new allies; Women were not outside hospitals protesting against infant clitorodectomies and gays and lesbians were not protesting against using hormones and surgeries to erase potential future queerness, because "an arbitrary definition means that these infants aren't female or possibly lesbian or even transgender. They're this other thing called intersex" (ibid.: 82). The intersexed are just another letter to be added to the LGBT coalition, to be used when politically necessary, but ignored when too politically problematic.

Indeed, while intersex and transsexual subjects are occasionally classified together under the rubric of transgender, there has been some debate as to how related they are, if at all. 
The argument for classifying transsexualism as a kind of intersex condition is evidence that at birth an individual's sexual identity is fixed in the brain. In other words at birth the individual's brain and genitals are not congruent and this is as much an intersex condition as a person whose gonads and genitals are not congruent. (Chau and Herring, 2002: 333).

On the surface, it would seem to make sense that those assigned the wrong gender and those in the wrong body would make for obvious bedfellows. However, while transsexuality is often based on wrong body discourses, much contemporary intersex theory and activism questions the classification of a body into only two distinct categories. Intersex theories would criticise transsexuals for reifying a binary sexual system. Thus the sociopolitical agendas of transsexuals and intersexed individuals may compete, further marginalising them each from the heterosexual and gay/lesbian mainstreams. Opinions in medical interventions divide transsexuality and intersexuality: the former advocating for corrective, elective procedures, the latter rejecting the imposition of such procedures.

\section{(Re)Thinking Transnormativity}

Accusation and prejudice on what should be thought of as a "virtual safe space" plays its part in the perpetuation of transnormativity. In "transgender, users could take advantage of an overwhelmingly trans space to discuss hormone replacement therapies, coming out, and how best to pass, among other normative concerns. This does not exist on Feministing. As davenj explained it, "On Feministing the one group that's required to explain itself and its issues is trans" (2009h). Community-building is a luxury for interlopers, even online. Threads regularly resorted to trans users confronting transphobia and insisting on having a place on the site, as transpeople and feminists. 
In her blog titled Facsimile of a Woman (2009b), vexing laments on her trans status and that she'll never be treated like a real woman. She describes the inability to go "stealth" without major sacrifices that include family and friends and needing to "regularly stick a series of graduated plastic dildo up [herself] to keep [her] surgically created vagina from closing up and making [her] a new kind of freak."

vexing: It's the pain of still having dreams in which you are male, despite years of living as a woman.

It's the unconscious betrayal of your biology against your gender identity.

And there's precious little I can do about any of this.

Still, even being a passable facsimile of a woman is better than living an even faker existence as a completely miserable man, on the brink of insanity. (ibid.)

She is then naïvely counselled by a cisgender user to embrace her transsexuality, to which she responds, “I don't want to embrace, celebrate or own being transgendered... It's not something to be proud of. The goal is to be treated like any other woman, not differentiate yourself from other women" (ibid.) Further, the reimagining of her subjectivity as a third gender is not sufficient: "it's not acceptable for people like me who want to be treated as strictly 'Female'." This is in stark contrast to ejgs402, for example, who states, “...I try to explain that, yes, I'm all woman, dick included" (2009h).

While trans users of Feministing tended to represent themselves through essentialist biomedical models, this, I argue, is less about one's understanding of one's body and mind than about legitimating one's subjectivity when confronted with users that undermine that very experience. The evocation of transnormative 
articulations acts differently within borrowed space and I wish to elaborate on and problematise the critical understanding of transnormativity from Chapter Four.

Queer geographer Natalie Oswin attempts to undermine the queer critique of complicity and the presumed radical character of queerness. She argues that at the core of these critiques is the stereotype of the affluent gay white male, a phantasm of commodification and idealism that is not a member of an existing, living group. When describing stereotypes, Oswin evokes Edward Said's concept of Orientalism insofar that "one ought never to assume that [its] structure is nothing more than a structure of lies and myths which, were the truth to be told, would simply blow away" (quoted in Oswin, 2005, 82). Critical queer theories suggest the "fiction that he is always and indeed the only figure embroiled in a complicit relationship" while queer Others exist "outside spaces of complicity, and therefore harkened to as the source of a rejuvenated queer republics" (ibid.: 83). Instead, we must see the complicit gay(/lesbian) as appropriating opposition of dominant representations through normativity-producing structures of commodification: the gay cowboy is still a queer parody/resignification of heteromasculinity.

Thus, while homo-/transnormativity dequeers the subject for his or her embrace of normative structures, the process is not - cannot be - complete. The monogamous, married, suburban gay man at his neighbourhood's PTA meeting is still a gay man at a PTA meeting. Even the best passing postoperative transwoman shatters rigid gender assumptions should she disclose her male past. That queer politics can only exist outside of complicity/normativity is troubling for Oswin because 
complicit queerness can still present a threat. But it is not the threat we thought it was, we may have to look harder and in different, unforeseen places to detect it, and we may not always like what we find. (ibid.: 82)

For example, the importance of passing and going "stealth" is illustrated in vexing's next blog, in which she describes the reactions of people to Facsimile of a Woman:

vexing: Here's a few gems from the waterfall of bullshit that poured into my inbox:

"You look like an average gay boy who decided a play dressup, dude

You're just mad you're not passing enough... "

"Transwoman? You sound more like a dude jacked up on testosterone injections... you have to lay off those steroids.

I could say a lot more wat I really think about yer looks.. but don't want to hurt you too bad..."

"You're trying to be bitchy... but still you come off as 'cocky'."

I wish I could just brush this all off, but one of the things about being trans is, well, being horribly insecure about how you look. So of course, while making brave replies which looked all the world like I was calm and in control, I sobbed my fucking heart out and cursed ever posting on Feministing on the first place and inviting this torrent of shit into my rather fragile world. (2009c)

The brutality of anonymous responses to vexing's email address demonstrates why passing is so privileged. For Butler, transphobia seeks "to renew the social world on the basis of intelligible gender, and to refuse the challenge to rethink that world as something other than natural or necessary" (2004: 34). To reduce transnormativity to a conservative transsexual v. queer transgender paradigm simply ignores the critique of sexual dimorphism within various transsexual movements and the livability of real transpeople. 
Transsexual activist Kate Bornstein rejects gender dimorphism and invokes transsexuality as a gender politics of transformation and her Gender Outlaw: Of Men, Women, and the Rest of Us is a call to reject a binary system of gender. She remarks, "I live pretty much without a gender, which paradoxically means I can do many genders" (1995: 135). It is a politics of playful becoming, rather that that of what one has been or what one aspires to be. Rather than create a phantom past, Bornstein states, "I need my male past as a reference point in my life. Discouraged from examining our past, transgendered people are discouraged by growth" (ibid., 127). In this way Bornstein describes the recognition of maleness that is later articulated in Koyama's manifesto. We must, however, be cautious of idealising itself a kind of normalisation of - this kind of queer gender play at the expense of other, perhaps more mainstream, articulations of queering gender.

The livability of one's life as a transsexual, however normative, however selftheorised, is one to be respected, even if one's agency and subjectivity as a transsexual is a condition of hegemonic discourses. For vexing, detransitioning, becoming a man again, is "worse than a death sentence" (2009b). Considering the disproportionate rates of depression and suicide amongst transpeople (Wyss, 2004), this cannot be taken as mere hyperbole. In fact, despite all of her theorising, Bornstein comments

There's a reward and punishment mechanism to passing. As much as I go on about this stuff, and as out of the closet as I am on a very broad public level, I still make an effort to walk down the street and pass on a very private level. I do this because I don't want to get beaten up. I do this because all my life it's been something I've wanted. (ibid.: 125, emphasis mine)

Passing, then, is not simply a means to avoid violence, but it plays a crucial role, psychically. It is the pain, as vexing explains it, of having dreams wherein she's still 
male. It is the pain that arises in KBZ's implicit statement that ElanaFulana will always be male and sex whilst masquerading as a female is rape. It is the pain of the accusation that xoros is a liar for passing. It is the pain of some feminists excluding you because you're not really a woman or not woman enough. And, quite frankly, it is the pain of a critical theorist telling you that you pass too well to really be queer, if that happens to be the way you identify.

Critiques of normatively certainly have their place and merits; it is vital for coalition politics to recognise colonising forces amongst its members. It is vital, too, for the sake of LGBT politicking, that bisexuals, transgendered people, intersexed people, butch dykes, flaming faggots, queer Christians, s/m practitioners, sex economists, queer people of colour, HIV+ people (the list goes on) feel their dissent, needs, and experiences are not ignored by those normal-identified gays and lesbians that are often the smiling faces of our movements.

Borrowed space on Feministing shows that cyberspace is not easily the utopian ideal of communication and activism. Though it is online and physical violence is significantly reduced, we see psychical violence from those we hoped to be our sociopolitical kin. Whether one uses normative approaches to experiencing their body or not, all transgendered people contest the ideals of what bodies should be like (Butler, 2004) and perhaps this politicking is substantial in and of itself. Just as homonormativity has its critiques, some of its politics, for example gay marriage, provides social and legal change that upholds equality, even if one's queer politics rejects that option for marriage oneself. Likewise, the ability to present as in between (as opposed it an opposite pole) is locally and socially contingent; one may 
be able to safely genderfuck in, say, an underground New York City punk scene, whilst opting to not pass as any gender in Oklahoma may result in death at the hands of homo- and transphobia. 
CONCLUSION

This research originally began as an intention to explore the ways in which transgender people can use the internet as a "queer space" wherein they can articulate their own subjectivities. However, a preliminary reading of "ghtransgender suggested the story is much more intricate and complex. While discussions supported my view of virtual space as a space of queer belonging and community-building when denied public space for one's gender expression, the issues of respectability and politic-claims not dissimilar to homonormative gay/lesbian politics began to emerge.

The first recognisable trend was the often-quoted narrative of the "true personality" at odds with bodily betrayal. Transsexual people often cite a biological etiology of transsexuality that is preclusive of simple gender "choice"; they are (wholly) women or men, and separately gay, lesbian, or bisexual, but in the wrong body. A whole diverse literature of medical sciences even suggests that the body can be changed to suit the psyche - and with an amazingly low "regret ratio" of less than 1 per cent (Michel, et al., 2002). The cultural privilege of these medical discourses means they become hegemonic and develop the very terms and vocabulary of transsexual articulations. These discourses are then reified by various transsexual narratives that rely on those vocabularies for their own formation. This is in opposition of the transgender subject that is idealised in Queer Theory for its fluidity and desire to playfully pick and choose from hir 
allusions with a sociopolitical ambivalence to the corporeality of the body. I would like to note that the members of "transgender that identified as bigender or nongender received no crimination of their identities, but the overwhelming majority of the community was transsexuals with an idealisation of passing biotechnologies, such as hormone replacement therapies, and an aversion to radical queer theorising that questioned their own identity formation and knowledge claims.

In Chapter One, I introduced the nature of this project: the ways in which a marginalised community within a marginalised community can make claims to knowledge and space, as well as situating gender queerness as a (homo)sexuality issue. It was suggested that feminist and queer theories are one way to look at the nature of the paradigm and transgender subjects may search out alternative spaces, such as the internet, for community formation.

Chapter Two described the production of transgender (specifically transsexuality) and sexualities within medical knowledges and discourses and how the Foucauldian notion of the internalised gaze allows subjects to self-police their gender performance. To demonstrate the discrimination and limited political resources of transgender people, the New Zealand transgender experience was discussed. It was then demonstrated that this discrimination is perpetuated not only by heteropatriarchal structures, but from conservative gay and lesbian "allies" ashamed of gender deviance and its problematics to respectable, liberal rights claims. 
In Chapter Three I discussed both my own queer epistemological approach and my own ontology of being within the "queer community." I justified the use of feminist and queer perspectives to expose the heterosexual and cisgender natures of knowledge claims. I describe the use of oral histories and the new ways of meaning that can produce and describe the use of internet posts as written, conversational oral histories.

Chapter Four's discussion of "transgender on LiveJournal.com described the various themes of discussion during a one-week period. Active discussion centred around linguistic reclamation of perjoratives (tranny), psychiatric and somatic issues, including diagnosis and hormone therapy, consciousness-raising, successful passing, and the anger and disillusionment faced when feeling let down by the larger LGBT community. The community described in Chapter 5 consisted of a larger cisgender demographic and the discussions were strikingly different and defensive; in borrowed virtual space, like public space, there is a need to validate one's subjectivity. And while this can been done with minimal physical harm, there is still potential for emotional violence in the "utopia" that is cyberspace.

Wilchins' suggestion of the gender closet (Chapter 2) is a way, I believe, to strengthen activism from gay-lesbian dominated "LG (and B and T) politics" to a broader LGBT/queer community. If a discourse of the gender closet can be established within gay and lesbian ontologies and our own gender shame addressed, we can fully appreciate the transgender subject and how important we both are to a politics of queer dissent. I do not mean to suggest a superficial engagement with gender (Diet Tranny: Same great discrimination, fewer 
hormones!), but to actually engage theory on the intersectionality of our own sexuality and gender(s) analogous to the transgender intersectionality of gender and sexuality(s); to appreciate - and use politically, effectively - the transgender subject's coming out as a gendered and sexual being, we need to come out not only as gay/lesbian, but (trans)gendered as well, as fairies, faggots, and butch dykes, as well as the preferred gender normative masculine gay and feminine lesbian. Coming out of the gender closet allows us to regain the importance of gender and gender play to our politics of dissent - and reaffirm our political commitments to our transgender kin.

However, this project has also raised several questions for future research. The methodological limitation of the project was that the analysis was based on one community over one week. While this resulted in almost five hundred individual posts to analyse, the period may not have been long enough to capture the greater nuances of the community and notice the emerging relationships of users.

It is the LiveJournal users' ability to interact with other transpeople whilst disembodied and anonymous that has the potential for them to express their real and idealised selves. But that their gender variance and personhood is communicated in an anonymous means suggests that to a certain extent, trans issues remain invisible. For example, few people may know LiveJournal exists and even fewer may know "transgender exists, or have the vested interests as a LiveJournal user to actively search for the site and engage in discussion. It is in this way that transwebs may not have the opportunity to engage the larger public 
and to make known the oppressions these anonymous people face on a regular basis.

Other researches may be elaborated by performing a cross-community analysis, for example looking at posts on transsurgery versus posts on genderqueer to further analyse or refute the conclusions of this particular project, or to look to niche communities such as "transangst or "tranny rage to analyse the consciousness-raising potential of the online communities hosted on LiveJournal.

Further to this, future researches may wish to employ interviews with users to determine the ways online communication transformed offline selves. For example, while the post regarding the candlelight vigil for Tyli'a Mack in Washington DC indicated one user was going to attend, was this user aware of the vigil before the post on LiveJournal? Was this user the only community member to attend? And if a user in Washington DC opted not to attend, why?

While this project has framed its position to the sciences as sceptical, I would tentatively support sociologist Riki Lane (2009: 137) in her call to "get past binaries of gender in general and trans in particular, such as essentialism versus constructionism and subversive versus conservative gender identities" and to develop a new conceptual framework to replace dichotomies and upon which new theories of all gendered articulations can emerge that recognise that biological determinism and social construction alone may not be adequate to describe bodies and gendered subjectivities. 


\section{BIBLIOGRAPHY}

Alexander, J (2002). Homo-pages and Queer Sites: Studying the Construction and Representation of Queer Identities on the Web. International Journal of Sexuality and Gender Studies, v 7(2/3): 85-106.

Apple, M (2003). Strategic Alliance or Hegemonic Strategy? Conservatism Among the Dispossessed. London Review of Education, v 1(1): 47-60.

Armstrong, D (1995). The rise of surveillance medicine. Sociology of Health \& Illness, v 17(3): 393-404.

Bakker, K and G Bridge (2006). Material worlds? Resource geographies and the 'matter of nature'. Progress in Human Geography, v 30(1): 5-27.

BBC News (2009). Birth Certificate Back SA Gender. Retrieved 30 September 2009 from http://news.bbc.co.uk/2/hi/africa/8215112.stm.

Bell, D (1995). Pleasure and danger: the paradoxical spaces of sexual citizenship.

Political Geography, v 14(2): 139-153.

Bell, D and J Binnie (2000). The Sexual Citizen: Queer Politics and Beyond. Cambridge: Polity Press.

--------- (2004). Authenticating Queer Space: Citizenship, Urbanism, and Governance. Urban Studies, v 41(9): 1807-1820.

Binnie, J (1997). Coming out of Geography: towards a queer epistemology? Environment and Planning D: Society and Space, v 15(2): 223-237.

(2007) Sexuality, the Erotic and Geography: Epistemology, Methodology and Pedagogy. Geographies of Sexualities. Ed. by K Browne, J Lim, and G Brown. Ashgate Publishing Limited: Hampshire.

Blomley, N K (1994). Activism and the Academy. Environment and Planning D: Society and Space, v 12(4): 383-385.

Bornstein, K (1995) Gender Outlaw: Of Men, Women, and the Rest of Us. New York: Vintage.

(1998). My Gender Workbook. New York: Routledge.

Bower, H (2001). The gender identity disorder in the DSM-IV classification: a critical evaluation. Australian and New Zealand Journal of Psychiatry, v 35: 1-8.

Brontsema, R (2004). A Queer Revolution: Reconceptualising the Debate over Linguistic Reclamation. Colorado Research in Linguisitics, v 17(1): 1-17.

Butler, J (1990). Gender Trouble. New York and London: Routledge. 2006 edition. (1997). Merely Cultural. Social Text, v 15(3-4): 265-277. 
(2004). Undoing Gender. New York and London: Routledge.

Chau, P-L and J Herring (2002). Defining, Assigning and Designing Sex. International Journal of Law, Policy and the Family, v 16: 327-367.

Chauncey, G (1994). Gay New York: Gender, Urban Culture, and the Makings of the Gay Male World, 1890-1940. New York: Basic Books.

Colls, R (2006). Outsize/Outside: Bodily bigness and the emotional experiences of British women shopping for clothes. Gender, Place and Culture, v 13(5): 529-545.

Colorado Independent (2009). Transgender anarchist 'Ariel Attack' suspected in Dem vandalism. Retrieved 2 October from

http://coloradoindependent.com/36568/transgender-anarchist-ariel-attack-suspected-indem-vandalism.

Digg (2009). Matrix director Larry Wachowski now walks as a woman in L.A. Retrieved 4 May 2009, from http://digg.com/celebrity/Matrix_director_Larry_Wachowski_now_ walks_as_a_woman_in_L_A

DigitalCrossRhodes.com (2009). Panopticon. Retrieved 24 May 2010, from http://www.digitalcrossrhodes.com/2009/10/panopticon/.

Dubriwny, TN (2005). Consciousness-Raising as Collective rhetoric: The Articulation of Experience in the Redstockings' Abortion Speak-Out of 1969. Quarterly Journal of Speech, v 91(4): 395-422.

Duggan, L (2002). The New Homonormativity: The Sexual Politics of Neoliberalism. Materializing Democracy: Toward a Revitalized Cultural Politics. Ed. by R Castronovo and D D Nelson. Durham: Duke University Press. 175-194.

Duggan, L (2006a). Introduction. Sex Wars: Sexual Dissent and Political Culture. Ed. by L Duggan and N Hunter. New York and London: Routledge. 1-13.

Duggan, L (2006b). Making it Perfectly Queer. Sex Wars: Sexual Dissent and Political Culture. Ed. by L Duggan and N Hunter. New York and London: Routledge. 149-163.

Duggan, L (2006c). Scholars and Sense. Sex Wars: Sexual Dissent and Political Culture. Ed. by L Duggan and N Hunter. New York and London: Routledge. 165-169.

Duggan, L (2006d). Queering the State. Sex Wars: Sexual Dissent and Political Culture. Ed. by L Duggan and N Hunter. New York and London: Routledge. 171-183.

Evans, B (2006). 'Gluttony or sloth': critical geographies of bodies and morality in (anti)obesity policy. Area, v38(3):259-267.

Feministing.com (2009a). Transwoman to be transferred to women's prison. Retrieved 12 August 2010 from http://community.feministing.com/2009/09/04/transwoman-to-betransferred-to-womens-prison.

------- (2009b). Facsimile of a woman. Retrieved 12 August 2010 from http://community.feministing.com/2009/09/12/facsimile-of-a-woman.

(2009c). Why this is my last Feministing post. Retrieved 12 August 2010 from http://community.feministing.com/2009/09/16/why-this-is-my-last-feministing-post. 
(2009d). Transphobia in Pundit Kitchen. Retrieved 12 August 2010 from http://community.feministing.com/2009/09/24/transphobia-in-pundit-kitchen.

(2009e). Heteronormativity and Transgender Identity. Retrieved 12 August 2010 from http://community.feministing.com/2009/09/30/heteronormativity-and-transgenderedidentity.

(2009f). Lady Gaga's Speech Puts the "it" in "Hit," but Takes Them From "LGBTIQ". Retrieved 12 August 2010 from http://community.feministing.com/2009/10/12/lady-gagas-speech-puts-the-it-in-hit-buttakes-them-from-lgbtiq.

(2009g). Transphobia in Seventeen... Wait Not So Much. Retrieved 12 August 2010 from http://community.feministing.com/2009/10/23/transphobia-in-seventeen-waitnot-so-much.

(2009h). Coming Out as Transgender to Romantic Partners. Retrieved 12 August 2010 from http://community.feministing.com/2009/10/28/coming-out-as-transgender-toromantic-partners.

(2009i). Why RAD isn't so "rad" for people who are at the highest risk, and other tales of collegiate fail. Retrieved 12 August 2010 from http://community.feministing.com/2009/11/01/why-rad-isnt-so-rad-for-people-who-are-atthe-highest-risk-and-other-tales-of-collegiate-fail.

(2009j). Having Sex While Stealth is Not Assault. Retrieved 12 August 2010 from http://community.feministing.com/2009/11/02/having-sex-while-stealth-is-notsexual-assault.

(2009k). Being Transgender is Dishonest. Retrieved 12 August 2010 from http://community.feministing.com/2009/11/05/being-transgender-is-dishonest.

(20091). Transphobic Victim Blaming. Retrieved 12 August 2010 from http://community.feministing.com/2009/11/09/transphobic-victim-blaming.

------- (2009m). “A Gender Identity Disorder Goes Mainstream.” Retrieved 12 August 2010 from http://community.feministing.com/2009/12/03/a-gender-identity-disorder-goesmainstream.

(2010). Feminists who attack trans women. Retrieved 12 August 2010 from http://community.feministing.com/2010/04/25/feminists-who-attack-trans-women.

Foucault, M (1973). The Birth of the Clinic: An Archaeology of Medical Perception. Translated from the French by A. M. Sheridan Smith. New York: Vintage Books.

(1978). The Will to Knowledge: The History of Sexuality Volume 1. Translated from the French by Robert Hurley. London: Penguin Books.

(1980). Power/Knowledge: Selected Interviews and Other Writings, 1972-1977. Colin Gordon, ed. New York: Pantheon Books.

Franck, KA (1995). When I Enter Virtual Reality, What Body Will I Leave Behind? Cyber_Reader: Critical writings for the digital era. Ed. by N Spiller. London: Phaidon Press Limited. 
Freiwald, BT (2001). Becoming and Be/Longing: Kate Bornstein's Gender Outlaw and My Gender Workbook. Biography, v 24(1): 35-56.

Friends (2001). Produced by Kevin S. Bright, Marta Kauffman and David Crane. Directed by Kevin S. Bright and Gary Halvorson. First aired 10 May 2001.

Fuller, D and R Kitchin (2004). Radical Theory/Critical Praxis: Academic Geography Beyond the Academy? Radical Theory/Critical Praxis: Making a Difference Beyond the Academy? Ed. by D Fuller and R Kitchin. Praxis e-Press. 1-20.

Gasher, M (2009). Mapping the Online News World: A News-flow Study of Three U.S. Dailies. Aether, the Journal of Media Geography, v 4: 102-116.

Gilley, J (2005). Writings of the Third Wave: Young Feminists in Conversation. The Alert Collector, v 44(3): 187-198.

Gorelick, S (1991). Contradictions of Feminist Methodology. Gender \& Society, v 5(4): 459-477.

Gossett, JL and S Byrne (2002). "Click here": A Content Analysis of Internet Rape Sites. Gender \& Society, v 16(5): 689-709.

Graham, E (1999). Cyborgs or Goddesses?: Becoming divine in a cyberfeminist age. Information, Communication \& Society, v 2(4): 419-438.

Graham, S (1998). The end of geography or the explosion of space? Conseptualising space, place, and information technology. Progress in Human Geography, v 22(2): 165185.

Grauerholz, L and L Baker-Sperry (2007). Feminist Research in the Public Domain: Risks and Recommendations. Gender \& Society, v 21(2): 272-294.

Green ER (2006). Debating Trans Inclusion in the Feminist Movement: A Trans-Positive Analysis. Journal of Lesbian Studies, v 10(1/2): 231-248.

Green, S (1999). A Plague on the Panopticon: Surveillance and power in the global information economy. Information, Communication \& Society, v 2(1): 26-44.

Grele, RJ (1998). Movement without aim: methodological and theoretical problems in oral history. The Oral History Reader. Ed. by R Perks and A Thomson. Routledge: London.

Grossman, AH and AR D'Augelli (2006). Transgender Youth: Invisible and Vulnerable. Journal of Homosexuality, v 51(1): 111-128.

Grundy, J and M Smith (2007). Activist knowledges in queer politics. Economy and Society, v 36(2): 294-317.

Halberstam, J (1998). Female Masculinity. Durham and London: Duke University Press.

-------- (2001). Telling Tales: Brandon Teena, Billy Tipton, and Transgender Biography. Passing: Identity and Interpretation in Sexuality, Race, and Religion. Ed. by MC Sánchez and L Schlossberg.. New York and London: New York University Press. 13-37. 
(2005). In a Queer Time and Place: Transgender Bodies, Subcultural Lives. New York and London: New York University Press.

Halley, J and A Parker (2007). Introduction. South Atlantic Quarterly, v106(3): 421-432.

Haraway, D (1991). Simians, Cyborgs, and Women: The Reinvention of Nature. New York and London: Routledge.

Harding, S (1987). Introduction: Is There a Feminist Method? Feminism and Methodology. Ed. by S Harding. Bloomington: Indiana University Press. 1-14.

Hegland, JE and NJ Nelson (2002). Cross-Dressers in Cyber-Space: Exploring the Internet as a Tool for Expressing Gendered Identity. International Journal of Sexuality and Gender Studies, v 7(2/3): 139-161.

Henry, MG and LD Lawrence (2006). Geographers Performing Nationalism and Heteromasculinity. Gender, Place and Culture, v 13(6): 629-645.

Herman-Jeglińska, A, A Grabowska, and S Dulko (2002). Masculinity, Femininity, and Transsexualism. Archives of Sexual Behavior, v 31(6): 527-534.

Hess, A (2009). Two Transgender Women Stabbed at 200 Q Street NW. Washington City Paper. Retrieved 10 September 2009, from

http://www.washingtoncitypaper.com/blogs/sexist/2009/08/26/two-transgender-menstabbed-at-200-q-street-nw.

Hill, DB and BLB Willoughby (2005). The Development and Validation of the Genderism and Transphobia Scale. Sex Roles, v 53(7/8): 531-544.

Hoad, N (2007). Queer Theory Addiction. South Atlantic Quarterly, v 106(3): 511-522.

Human Rights Commission (2007). To Be Who I Am: Report of the Inquiry into Discrimination Experienced by Transgender People. Retrieved 15 November 2008 from http://www.hrc.co.nz/hrc_new/hrc/cms/files/documents/15-Jan-2008_14-5648_HRC_Transgender_FINAL.pdf.

Jeffreys, S (2005). Beauty and Misogyny: Harmful Cultural Practices in the West. New York and London: Routledge.

Jolly, A (1999). Lucy's Legacy: Sex and Intelligence in Human Evolution. Cambridge: Harvard University Press.

Jones, A (1992). Writing Feminist Education Research: Am "I" in the Text? Women and Education in Aotearoa. Ed. by S Middleton and A Jones. Wellington: Bridget Williams Book Ltd. 1997 edition. 18-34.

Josefsson, U (2005). Coping With Illness Online: The Case of Patients' Online Communities. The Information Society, v 21: 143-153.

Kane, EW (2006). "No Way are My Boys Going to Be Like That!": Parents' Responses to Children's Gender Nonconformity. Gender \& Society, v 20(2): 149-176.

Karl, I (2007). On/Offline: Gender, Sexuality, and the Techno-Politics of Everyday Life. Queer Online: Media, Technology, \& Sexuality. Ed. By K O'Riordan and D J Phillips.

Peter Lang Publishing, Inc: New York. 45-64. 
Kavanaugh, AL, DD Reese, JM Carroll, and MB Rossom (2005). Weak Ties in Networked Communities. The Information Society, v 20: 119-131.

Knopp, L (2004). Ontologies of Place, Placelessness, and Movement: queer quests for identity and their impacts on contemporary geographic thought. Gender, Place and Culture, v 11(1): 121-134.

Koyama, E (2001). The Transfeminist Manifesto. Retrieved 13 August 2010 from http://intermargins.net/repression/deviant/transgender/trans_book/tf-collection.pdf.

von Krafft-Ebing (1882). Psychopathia Sexualis. London: Staples Press. 1965 edition.

Landén M, J Wålinder, and B Lundström (1996). Prevalence, Incidence, and Sex Ratio of Transsexualism. Acta Psychiatrica Scandinavica, v 93: 221-223.

Lane, R (2009). Trans as Boldily Becoming: Rethinking the Biological as Diversity, Not Dichotomy. Hypatia, v 25(3): 136-157.

Lee, A (2008). Trans Models in Prison: The Medicalization of Gender Identity and the Eighth Amendment Right to Sex Reassignment Therapy. Harvard Journal of Law \& Gender, v 31: 447-472.

Lawrence v Texas, 123 S. Ct. 2472, 2475 (2003).

Leydesdorff S, L Passerini, and P Thompson (1996). Introduction. Gender \& Memory. New Brunswick: Transaction Press. 2005 edition.

LiveJournal.com (2009a). Livejournal.com. Retrieved 14 September 2009, from http://www.livejournal.com/

(2009b). transgender - Community Profile. Retrieved 14 September 2009, from http://community.livejournal.com/transgender/profile.

(2009c). What Would You Do? Retrieved 14 September 2009, from http://community.livejournal.com/transgender/2101704.html.

(2009d). Job Advice? Retrieved 14 September 2009, from

http://community.livejournal.com/transgender/2101926.html.

(2009e). Do you have a hate crime or employment discrimination story? Be heard! Retrieved 14 September 2009, from http://community.livejournal.com/transgender/2102221.html.

(2009f). My mother got my coming out letter today. Retrieved 14 September 2009, from http://community.livejournal.com/transgender/2102307.html.

(2009g). no title. Retrieved 14 September 2009, from

http://community.livejournal.com/transgender/2102691.html.

(2009h). Callen-Lorde clinic in NYC Retrieved 14 September 2009, from http://community.livejournal.com/transgender/2102978.html.

(2009i). Need help getting my fiancee to understand. Retrieved 14 September 2009, from http://community.livejournal.com/transgender/2103249.html. 
(2009j). Pets as an emotional crutch? Retrieved 14 September 2009, from http://community.livejournal.com/transgender/2103622.html.

- (2009k). Depersonalization. Retrieved 14 September 2009, from http://community.livejournal.com/transgender/2103898.html.

(20091). Saw the endo... Retrieved 14 September 2009, from

http://community.livejournal.com/transgender/2104078.html.

--------- (2009m). Influence. Retrieved 14 September 2009, from

http://community.livejournal.com/transgender/2104431.html.

(2009n). Endo Appointment referenced earlier. Retrieved 14 September 2009, from http://community.livejournal.com/transgender/2104646.html.

(2009o). Controversial. Retrieved 14 September 2009, from

http://community.livejournal.com/transgender/2104865.html.

(2009p). FTM Testosterone Research Study. Retrieved 14 September 2009, from http://community.livejournal.com/transgender/2105173.html.

(2009q). ATTN: Folks in the DC Area. Retrieved 14 September 2009, from http://community.livejournal.com/transgender/2105410.html.

(2009r). Coming out to apartment managers???. Retrieved 14 September 2009, from http://community.livejournal.com/transgender/2105786.html.

(2009s). no title. Retrieved 14 September 2009, from

http://community.livejournal.com/transgender/2105949.html.

(2009t). Transgender anarchist 'Ariel Attack' suspected in Dem vandalism.

Retrieved 14 September 2009, from

http://community.livejournal.com/transgender/2106321.html.

(2009u). Having trust issues with cis people, considering a double life, can't

transition. Retrieved 14 September 2009, from

http://community.livejournal.com/transgender/2106494.html.

(2009v). Mental Health? Retrieved 14 September 2009, from

http://community.livejournal.com/transgender/2106858.html.

------- (2009w). no title. Retrieved 14 September 2009, from

http://community.livejournal.com/transgender/2106985.html.

(2009x). no title. Retrieved 14 September 2009, from

http://community.livejournal.com/transgender/2107160.html.

(2009y). Another fun-filled clinic query. Retrieved 14 September 2009, from http://community.livejournal.com/transgender/2107626.html.

(2009z). no title. Retrieved 14 September 2009, from

http://community.livejournal.com/transgender/2107861.html. 
(2009aa). Help. Retrieved 14 September 2009, from

http:/community.livejournal.com/transgender/2108133.html.

-------- (2009bb). Health Insurance Denial. Retrieved 14 September 2009, from http://community.livejournal.com/transgender/2108372.html.

Longhurst, R (2008). Maternities: Gender, Bodies and Space. New York and London: Routledge.

Malterud, K, L Candib, and L Code (2004). Responsible and responsive knowing in medical diagnosis: the medical gaze revisited. Nordic Journal of Feminist and Gender Research, v 12(1): 8-19.

Martin, F (2000). From Citizenship to Queer Counterpublic: Reading Taipei's New Park. Communal/Plural, v 8(1): 81-94.

McCarthy Brown, K (2001). Mimesis in the Face of Fear: Femme Queens, Butch Queens, and Gender Play in the Houses of Greater Newark. Passing: Identity and Interpretation in Sexuality, Race, and Religion. Ed. by M C Sánchez and L Schlossberg. New York and London: New York University Press. 208-227.

McLelland, M (2002). The Newhalf Net: Japan's “Intermediate Sex" On-Line. International Journal of Sexuality and Gender Studies, v 7(2/3): 163-175.

Medhurst, A (1991). Batman, Deviance and Camp. The Many Lives of Batman. Ed. by R Pearson and W Uricchio. New York: Routledge. 149-163.

Michel, A, M Ansseau, JJ Legros, W Pitchot, and C Mormont (2002). The Transsexual: What About the Future? European Psychiatry, v 17(6): 353-363.

Mills, C (2000) Efficacy and Vulnerability: Judith Butler on Reiteration and Resistance. Australian Feminist Studies, v 15(32): 265-279.

Mitchell, D (2004). Radical Scholarship: A Polemic on Makinga Difference Outside of the Academy. Radical Theory/Critical Praxis: Making a Difference Beyond the Academy? Ed. by D Fuller and R Kitchin. Praxis e-Press. 21-31.

Monro S and L Warren (2004). Transgendering Citizenship. Sexualities, v 7(3): 345-362.

Montenegro, M (2002). Ideology and Community Social Psychology: Theoretical Considerations and Practical Implications. American Journal of Community Psychology, v 30(4): 511-527.

Morland, I (2001). Is intersexuality real? Textual Practice, v 15(3): 527-547.

Morris III, CE (2005). Passing by Proxy: Collusive and Convulsive Silence in the Trial of Leopold and Loeb. Quarterly Journal of Speech, v 91(3): 264-290.

Nah, S, A Veenstra, and D Shah (2006). The Internet and Anti-War Activism: A Case Study of Information, Expression, and Action. Journal of Computer-Mediated Communication, v 12(1): 230-247.

Nash, C (1996). Reclaiming Vision: looking at landscape and the body. Gender, Place and Culture, v 3(2): 149-169. 
Nelson, L (1999). Bodies (and Spaces) do Matter: the limits of performativity. Gender, Place and Culture, v 6(4): 331-353.

Orgad, S (2005). The Transformative Potential of Online Communication: The Case of Breast Cancer Patients' Internet Spaces. Feminist Media Studies, v 5(2): 141-161.

O'Riordan, K (2007). Queer Theories and Cybersubjects: Intersecting Figures. Queer Online: Media, Technology, \& Sexuality. Ed. By K O’Riordan and D J Phillips. New York: Peter Lang Publishing, Inc.

O'Riordan, K and D J Phillips (2007). Introduction. Queer Online: Media, Technology, \& Sexuality. Ed. By K O’Riordan and D J Phillips. New York: Peter Lang Publishing, Inc.

Oswin, N (2005). Towards Radical Geographies of Complicit Queer Futures. ACME: An International E-Journal for Critical Geographies, v 3(2): 79-86.

Passerini, L (1998). Work ideology and concensus inder Italian facsism. The Oral History Reader. Ed. by R Perks and A Thomson. Routledge: London.

Peek, C (2004). Breaking Out of the Prison Hierarchy: Trangender Prisoners, Rape, and the Eighth Amendment. Santa Clara Law Review, v 44 :1211-1248.

Plummer, K (1995) Telling Sexual Stories: Power, Change and Social Worlds. London, New York: Routledge Publications.

Phillips, D (2002) Negotiating the Digital Closet: Online pseudonymity and the politics of sexual identity. Information, Communication \& Society, v 5(3): 406-424.

Pinterics, N (2001). Riding the Feminist Waves: In with the Third? Canadian Woman Studies, v 21(4): 15-21.

Portelli, A (1998). What makes oral history different. The Oral History Reader. Ed. by R Perks and A Thomson. Routledge: London.

Prosser, J (1998). Transexuals and the Transsexologists: Inversion and the Emergence of Transexual Subjectivity. Sexology in Culture. Ed. by L Bland and L Doan. Oxford:

Polity Press. 116-128.

Puar, J (2006). Mapping US Homonormativities. Gender, Place and Culture, v 13(1): $67-$ 88.

Raymond, J (1979). The Transsexual Empire: The Making of the She-Male. Boston: Beacon Press.

Reinharz, S (1992). Feminist Methods in Social Research. Oxford: Oxford University Press.

Roden, F (2001). Becoming Butlerian: On the Discursive Limits (and Potentials) of Gender Trouble at Ten Years of Age. International Journal of Sexuality and Gender Studies, v 6(1/2): 25-33.

Rollins, J and HN Hirsch (2003). Sexual Identities and Political Engagements: A Queer Survey. Social Politics, v 10(3): 290-311. 
Rose, G (1993). Feminism \& Geography: The Limits of Geographical Knowledge. Oxford: Polity Press.

----- (1997). Situating knowledges: positionality, reflexivities and other tactics. Progress in Human Geography, v 21(3): 305-320.

Rosenfeld, D (2009). Heteronormative and Homonormativity as Practical and Moral Resources: The Case of Lesbian and Gay Elders. Gender \& Society, v 23(5): 617-638.

Ruskola, T (2005). Gay Rights versus Queer Theory: What is left of sodomy after Lawrence v. Texas? Social Text, v 23(3-4): 235-248.

Said, E (1978). Orientalism. New York: Vintage Books.

Samuels, J (1999) Dangerous Liaisons: Queer subjectivity, liberalism, and race. Cultural Studies, v 13(1): 91-109.

Sangster, J (1998). Telling our stories: feminist debates and the use of oral history. The Oral History Reader. Ed. by R Perks and A Thomson. Routledge: London.

Schlossberg, L (2001). Introduction: Rites of Passing. Passing: Identity and Interpretation in Sexuality, Race, and Religion. Ed. by M C Sánchez and L Schlossberg. New York and London: New York University Press. 1-12.

Seidman, S (1993). Identity and Politics in a 'Postmodern' Gay Culture: Some Historical and Conceptual Notes. Fear of a Queer Planet: Queer Politics and Social Theory. Ed. by M Warner. Minneapolis: University of Minneapolis Press. 105-142.

Sharp, J (2005). Geography and gender: feminist methodologies in collaboration and in the field. Progress in Human Geography, v 29(3): 304-309.

Snyder, D (2002). “I Don't Go By Sean Patrick”: On-Line/Off-Line/Out Identity and SeanPatrickLive.com. International Journal of Sexuality and Gender Studies, v 7(2/3): 177-195.

Stanley, L (1992). The auto/biographical I: The theory and practice of feminist auto/biography. Manchester: Mancester University Press.

(1993). On auto/biography in sociology. Sociology, v 27(1): 41-52.

Sullivan, A (1995). Virtually Normal: An Argument about Homosexuality. London: Picador.

Sullivan, N (2003). A Critical Introduction to Queer Theory. Edinburgh: Edinburgh University Press Ltd.

Thompson, D (2004). Calling All Fag Hags: From Identity Politics to Identification Politics. Social Semiotics, v 14(1): 37-48.

Valentine, D (2003). 'The Calculus of Pain': Violence, Anthropological Ethics, and the Category Transgender. Ethnos, v 68(1): 27-48.

Valentine, D (2007). Imagining Transgender: An Ethnography of a Category. Durham and London: Duke University Press. 
Valentine, D and RA Wilchins (1997). One Percent on the Burn Chart: Gender, Genitals, and Hermaphrodites with Attitude. Social Text, v15(3 and 4): 215-222.

Vujovic, S, S Popovic, G Sbutega-Milosevic, M Djordjevic, and L Gooren (2009). Transsexualism in Serbia: A Twenty-Year Follow-Up Study. The Journal of Sexual Medicine, v 6(4): 1018-1023.

Wakefield, N (1997). Cyberqueer. The Cybercultures Reader. Ed. by D Bell and B M Kennedy. London: Routledge. 403-415.

Weedon, C (1987). Feminist Practice \& Poststructuralist Theory. Cambridge and Oxford: Blackwell Publishers.

Weird Universe (2009). News of the Weird / Pro Edition. Retrieved 29 September 2009, from http://www.weirduniverse.net/blog/comments/3246.

Weiss, MD (2008). Gay Shame and BDSM Pride: Neoliberalism, Privacy, and Sexual Politics. Radical History Review, v 100: 87-101.

Wiatt, G and A Gorman-Murray (2007). Homemaking and Mature Age Gay Men 'Down Under': Paradox, intimacy, subjectivities, spatialities, and scale. Gender, Place and Culture, v 14(5): 569-584.

Wiegman, R (2006). Heteronormativity and the desire for gender. Feminist Theory, $\mathrm{v}$ 7(1): 89-103.

Wichins, R (2004). Queer Theory, Gender Theory: An Instant Primer. Los Angeles: Alyson Books.

Wilson, SM and LC Peterson (2002). The Anthropology of Online Communities. Annual Review of Anthropology, v 31: 449-467.

Wyss, SE (2004). 'This was my hell': the violence experienced by gender non-conforming youth in US high schools. International Journal of Qualitative Studies in Education, v 17(5): 709-730. 